\title{
PROBLEM REPRESENTATION IN OCCUPATIONAL THERAPY
}

\author{
by
}

Linda J. Robertson

\author{
A thesis \\ submitted to the Victoria University of Wellington \\ in fulfilment of the \\ requirements for the degree of \\ Doctor of Philosophy
}

Victoria University of Wellington

1994 


\begin{abstract}
Clinical reasoning is a fundamental component of occupational therapy practice. Educators, researchers and clinicians are faced with the challenge of understanding and fostering the acquisition of clinical reasoning skills. The aim of this study was to examine the internal problem representations held by students and clinicians in respect of clients they had been treating for a period of time. Such representations form the basis on which treatment is formulated so are highly influential in the clinical reasoning process. The ultimate purpose of the study was to identify educational strategies that could be used to assist students to develop clinical reasoning skills.
\end{abstract}

Understandings gained from the literature and from observation, indicated that there would be differences between novices and experts and that the work setting would affect problem representation. Thus the influence of experience and location was the primary focus of the study. To place the study within the context of the occupational therapy literature, the beliefs underlying problem representation were also explored to determine whether or not these were consistent with the philosophical assumptions identified in the literature.

The method of investigation was an interview with pre-determined questions. The interview was consistent with the theory base of the study (ie. information processing), but the analysis also included the investigation of qualitative aspects. To ensure a developmental perspective was gained, respondents included students on two different levels of an occupational therapy course and clinicians who were currently practicing. The total number of respondents was 67 ie. 14 stage II students, 31 stage III students (ie. in their final year) and 22 clinicians. 
The study illustrated that the environmental context affects problem representation in respect of both the amount of data to be considered and the nature of that data. Differences between students' and clinicians' representation of the problem were related to qualitative aspects rather than identification of the elements relevant to treatment planning. In particular, clinicians were more able to elaborate on the data, justify their responses and provide a humanistic perspective beyond the more technical aspects of knowing the clients concerns. The beliefs governing thinking about treatment, demonstrated consistency with the occupational therapy literature (apart from one assumption).

A major finding of this study is that the development of schemata related to practice areas is the basis of sound reasoning and justification of treatment planning decisions. Both domain specific knowledge and an understanding of the environmental context are important to the forming of these schemata. The implication for teaching is that the wealth of experiential knowledge that is gained by students while on clinical practice should be tapped to enable them to make links with academic knowledge and thus develop a comprehensive problem representation. 


\section{ACKNOWLEDGMENTS}

My special thanks to the second and third year students at the CIT occupational therapy course during 1989/90 and to Wellington based Occupational Therapists who participated in this study. Without the willing co-operation of these colleagues, this study could never have taken place.

Also, the support of Katy Austin, Head of Department was invaluable in both encouraging me to embark on the project and being instrumental in ensuring that study time was available.

More recently, I have enjoyed the support of my colleagues in the Occupational Therapy Department at Otago Polytechnic and their input into various components of this study. I particularly acknowledge the assistance of Rosemary Caulton whose critical stance has been stimulating and forced some reluctant rethinking.

My thanks also go to my supervisor, Cedric Hall, who has helped me to understand the essentials of a PhD thesis and kept me focussed - not a mean feat! His willingness to comprehend the essentials of occupational therapy has been a key feature in his ability to help me to unravel my ideas.

Last, but certainly not least, my thanks to my long suffering husband who has hardly seen me without a pen in my hand for the last five years. 


\title{
TABLE OF CONTENTS
}

\author{
CHAPTER ONE

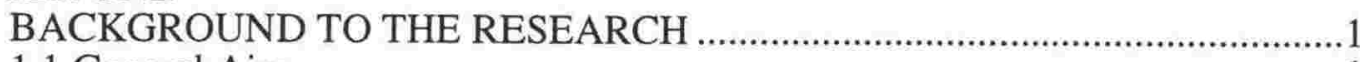

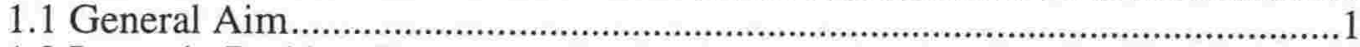

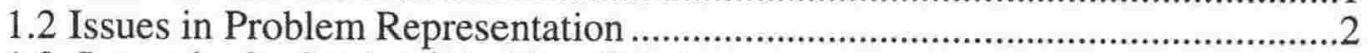 \\ 1.3 Issues in the Study of Problem Solving ......................................................

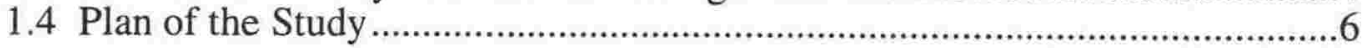

\section{CHAPTER TWO}

THE DEVELOPMENT OF THE PROFESSION OF

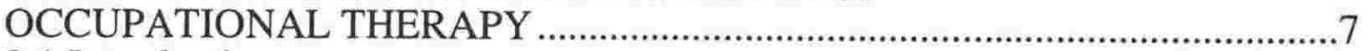

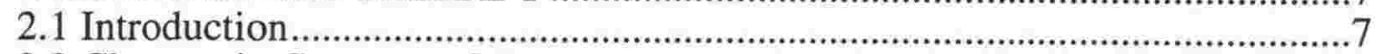

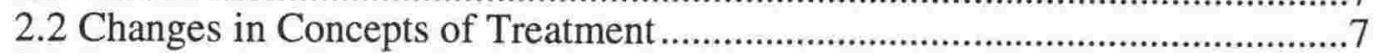

2.3 Re-asserting Occupational Therapy Traditions ..............................................10

2.4 Dissension in Occupational Therapy …………………………………...12

2.5 Philosophical Assumptions ....................................................................13

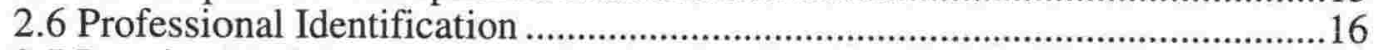

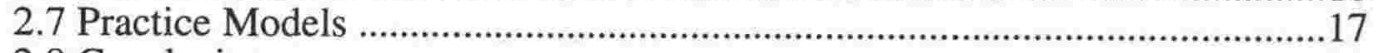

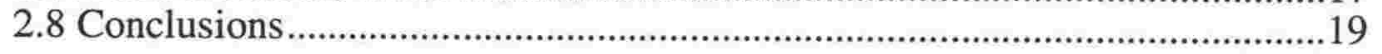

\section{CHAPTER THREE}

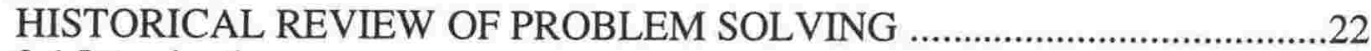

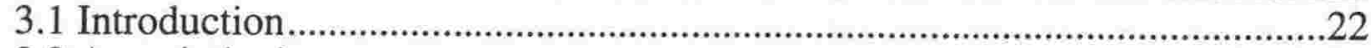

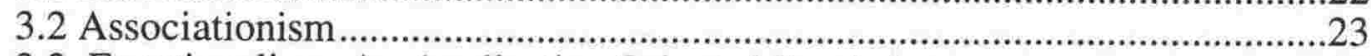

3.3. Functionalism: An Application Oriented Psychology ...................................25

3.4 Gestalt - Thinking as Restructuring of Problems ………………………......26

3.5 Thinking as Information Processing ............................................................32

3.6 Problem Solving as the Apex of a Hierarchy of Learning Tasks ....................37

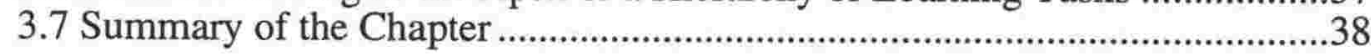

\section{CHAPTER FOUR}

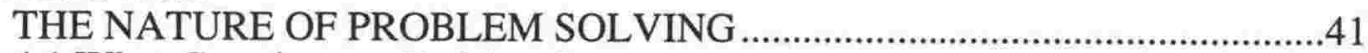

4.1 What Constitutes a Problem ?.......................................................................4

4.2 The Problem Solving Process .........................................................................42

4.3 Problem Representation and Problem Space ....................................................45

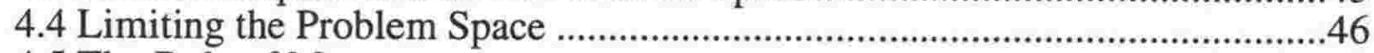

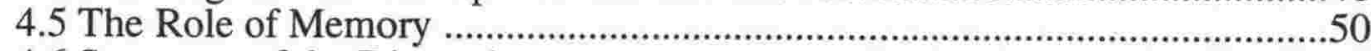

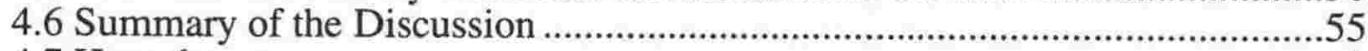

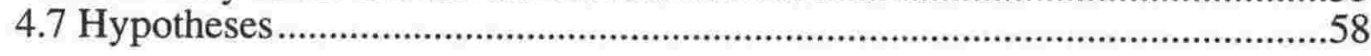

CHAPTER FIVE

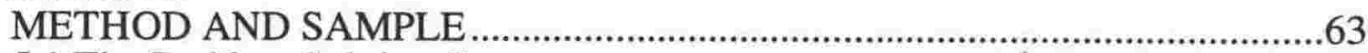

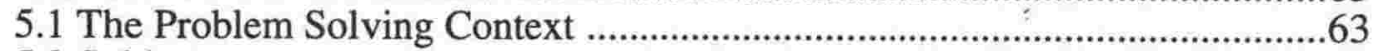

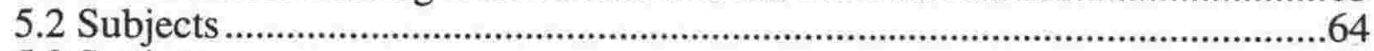

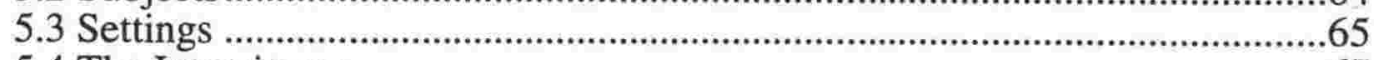

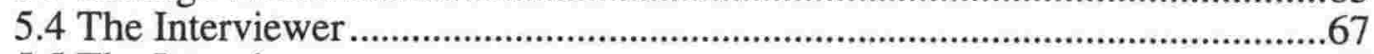

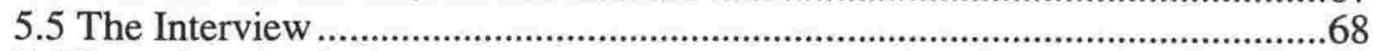

5.6 Interview Analysis ...................................................................................

5.7 Coding of Subjects ..............................................................................

5.8 Validity of Results .............................................................................

5.9 Establishing the Reliability of the Coding System ..........................................74

5.10 Statistical Analysis.................................................................................... 


\section{CHAPTER SIX}

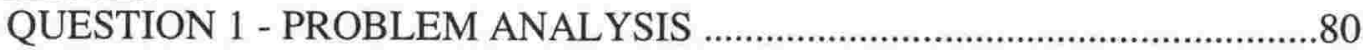

6.1 Introduction - Classification of Question Responses....................................80

6.2 Comparisons Between the Groups.............................................................8. 82

6.2.1 The Performance Component Skills ..............................................83

6.2.2 Occupational Performance Skills .....................................................86

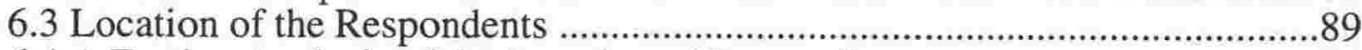

6.4 A Further Analysis of the Location of Respondents ........................................94

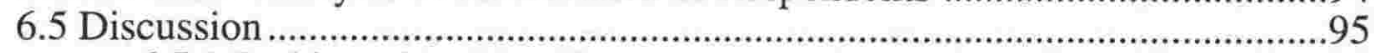

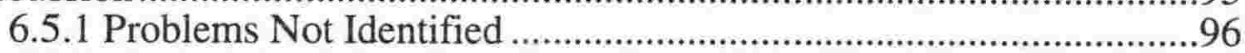

6.5.2 The Identification of a Large Range of Problems ..............................98

6.5.3 Location of Respondents................................................................104

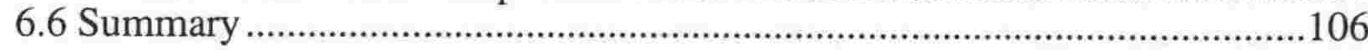

\section{CHAPTER SEVEN}

QUESTION 2 - TREATMENT PRIORITIES …..............................................107

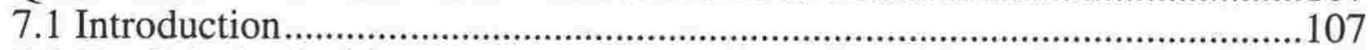

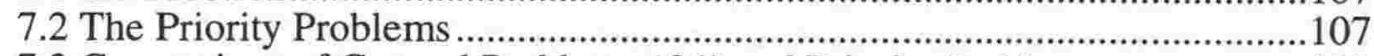

7.3 Comparison of General Problems (Q1) and Priority Problems ....................108

7.4 Treatment Principles - An Introduction .......................................................111

7.5 Comparison Between the Groups. .................................................................. 114

7.5.1 Principles Related to the Delivery of Treatment

Programmes .......................................................................................115

7.5.2 Principles Related to the Nature of Treatment

Programmes .....................................................................................118

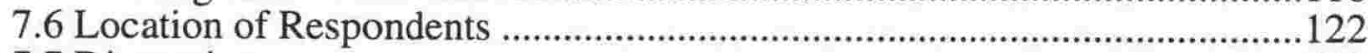

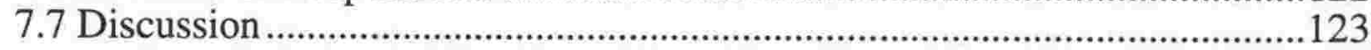

7.7.1 Relationship Between Treatment Priorties and Treatment

Principles.......................................................................................126

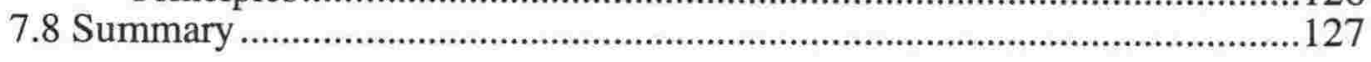

\section{CHAPTER EIGHT}

QUESTION 3 - TREATMENT OUTCOMES ................................................127

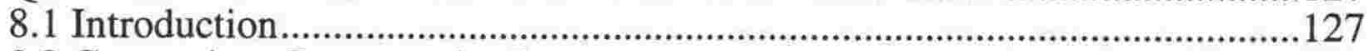

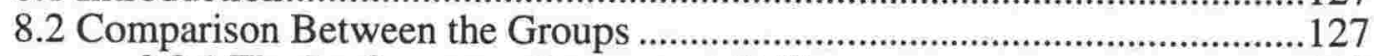

8.2.1 The Performance Component Skills ................................................128

8.2.2 The Occupational Performance Skills ...........................................131

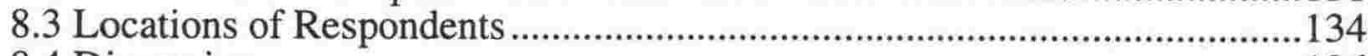

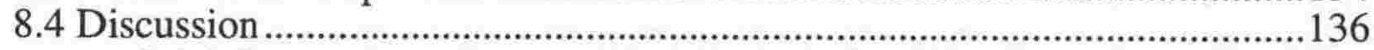

8.4.1 Comparisons Between the Problems Identified in
Questions One and Two and the Treatment Outcomes.........................138

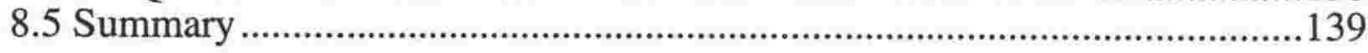

\section{CHAPTER NINE}

QUESTION 4 - BENEFIT TO THE CLIENT ...............................................140

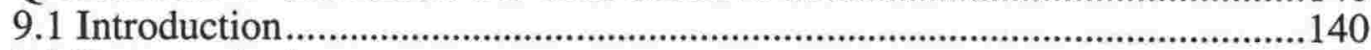

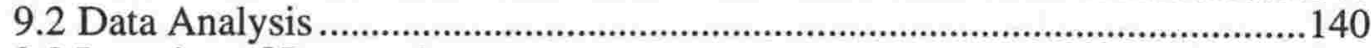

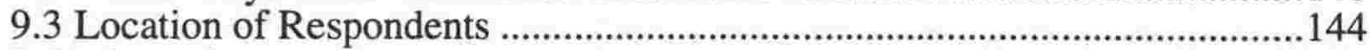

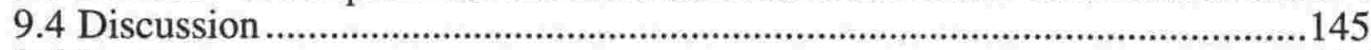

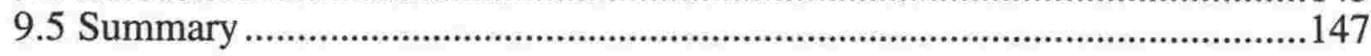


CHAPTER TEN

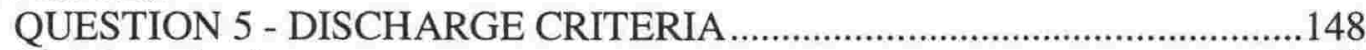

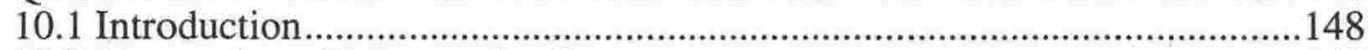

10.2 Comparisons Between the Groups ..........................................................149

10.2.1 The Performance Component Skills ....................................150

10.2.2 The Occupational Performance Skills........................................151

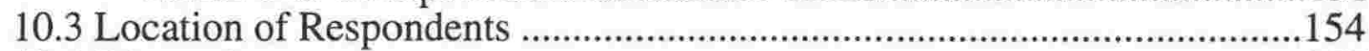

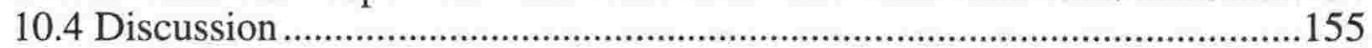

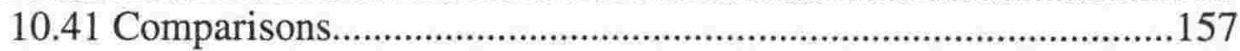

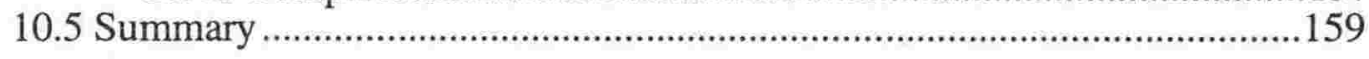

CHAPTER ELEVEN

QUESTION 6 - EFFECTIVENESS OF TREATMENT …................................160

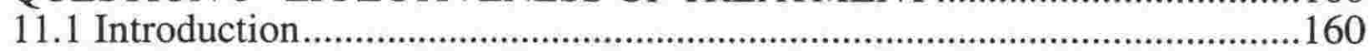

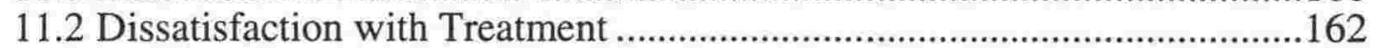

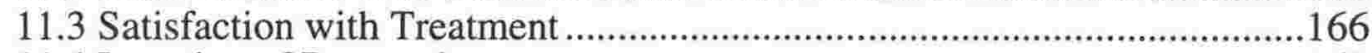

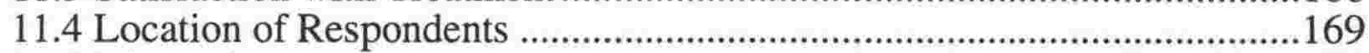

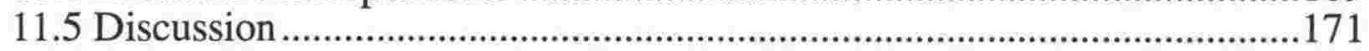

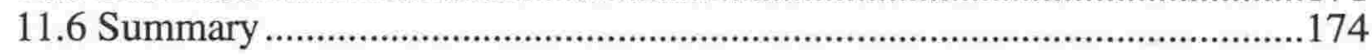

CHAPTER TWELVE

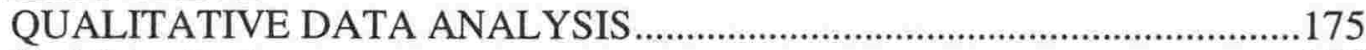

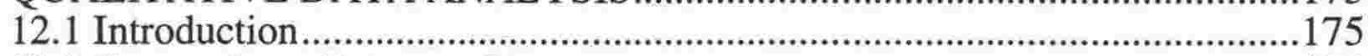

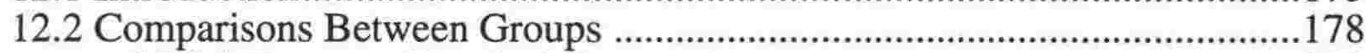

12.2.1 Focus and Logical Progression ...................................................180

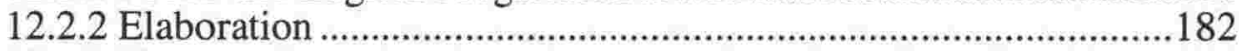

12.3.3 Human Dimension .................................................................184

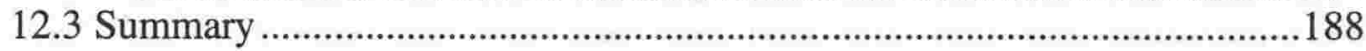

\section{CHAPTER THIRTEEN}

INTEGRATION AND ANALYSIS OF HYPOTHESES ...............................189

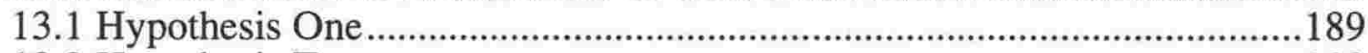

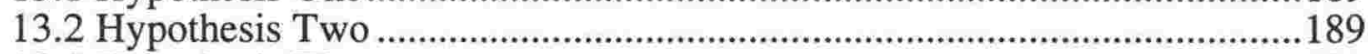

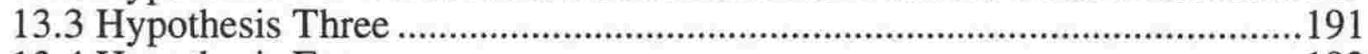

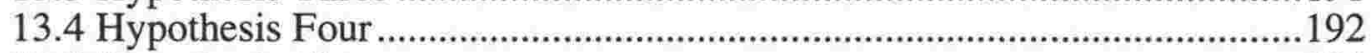

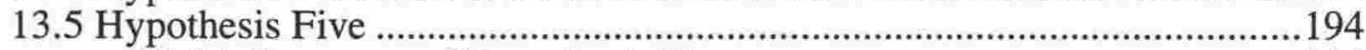

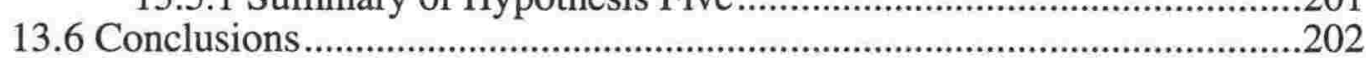

\section{CHAPTER FOURTEEN}

IMPLICATIONS FOR EDUCATION AND FURTHER RESEARCH ...........207

14.1 Implications for Education ......................................................................207

14.1.1 Development of Schema and the Ability to Elaborate................207

14.1.2 Understanding the Client's Perspective .......................................211

14.1.3 Location Differences .................................................................212

14.1.4 Beliefs of Occupational Therapists ............................................212

14.2 Implications for Further Research .........................................................212

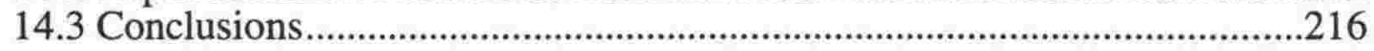

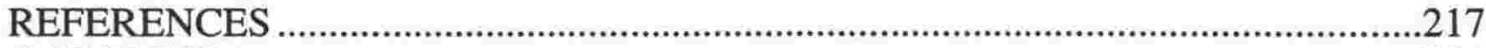

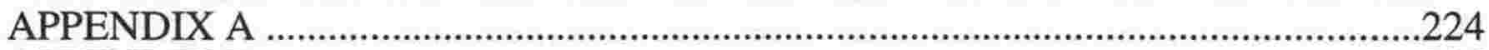

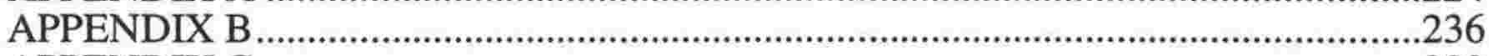

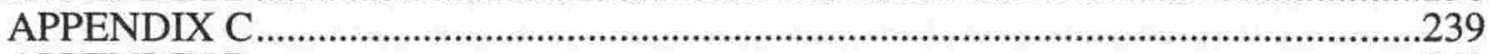

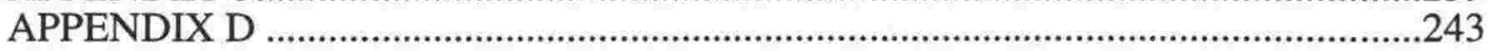




\section{TABLES}

Table 5.1 The number of Subjects Working in each Setting ............................66

Table 5.2 Interview questions ....................................................................... 70

Table 5.3 Link Between Model, the Hypothesis and the Interview Questions..71

Table 5.4 Agreement between raters: Initial Rating ….....................................76

Table 5.4 Agreement between raters: Second rating .........................................76

Table 6.1 Summary of the Responses given by the Three Respondent

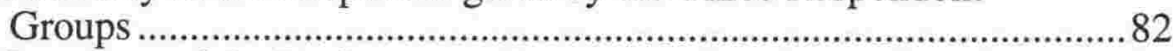

Table 6.2 Summary of the Performance Component Discharge Criteria .............84

Table 6.3 Summary of the Occupational Performance Problems .........................86

Table 6.4 Summary of Responses given in each Location ..................................90

Table 6.5 Location of the Respondents and the Performance Component

Problems ............................................................................................ 91

Table 6.6 Location of the Respondents and the Occupational Performance

Problems...................................................................................... 92

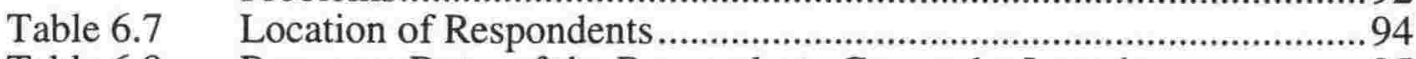

Table 6.8 Response Rates of the Respondents Groups by Location ......................95

Table 6.9 Respondents who did not Identify Problems in Response to Question One.

Table 7.1 Summary of the Responses given by the Three Respondent

Groups

Table 7.2 Beliefs Concerning the Delivery of Treatment Programmes .............. 116

Table 7.3 Beliefs Concerning the Nature of Treatment Programmes ................119

Table 7.4 Summary of Responses given in each Location ..............................122

Table 8.1 Summary of Responses .................................................................... 128

Table 8.2 Summary of the Performance Component Outcomes.........................129

Table 8.3 Summary of the Occupational Performance Outcomes .....................132

Table 8.4 Summary of Responses given in each Location .................................. 135

Table 9.1 Summary of Benefits to the Client.................................................. 141

Table 9.2 Location of the Respondents and the Perceived Benefits to the Client

Table 10.1 Summary of the Responses given by the Three Respondent

Groups ......................................................................................... 149

Table 10.2 Summary of the Performance Component Discharge Criteria ......... 150

Table 10.3 Summary of the Occupational Performance Discharge Criteria......152

Table 10.4 Location of the Respondents and the Summary of Responses ........ 154

Table 11.1 Summary of Reasons for Dissatisfaction and/or Satisfaction with Treatment ................................................................................. 161

Table 11.2 Summary of Reasons for Dissatisfaction with Treatment ................163

Table 11.3 Summary of Reasons for Satisfaction with Treatment .....................167

Table 11.4 Location of the Respondents and the Summary of Responses ......... 170 
Table 12.1 Mean and Standard Deviations for Focus (Problems and Outcomes),.. Elaboration and Human Dimension - Comparison Between

Groups ..................................................................................... 178

Table 12.2 Results of t-tests Between Groups for Scores on Focus (Problems and Outcomes), Elaboration and Human Dimension......................... 179

Table 13.1 Summary of the Assumptions Identified by the Three Respondent Groups.

Table A.1 Summary of the Responses given by the Three Respondent

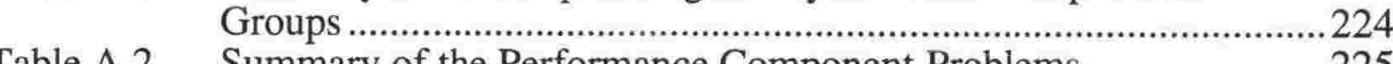

Table A.2 Summary of the Performance Component Problems ........................2225

Table A.3 Summary of the Occupational Performance Problems ........................2227

Table A.4 Summary of the Responses Given in each Location............................2228

Table A.5 Location of the Respondents and the Performance Component Priority Problems ................................................................................2229

Table A.6 Location of the Respondents and the Occupational Performance Priority Problems ........................................................................... 231

Table A.7 Location of the Respondents and the Beliefs Concerning the Delivery of Treatment Programmes...............................................233

Table A.8 Location of Respondents and the Beliefs Concerning the Nature of Treatment Programmes

Table B.1 Location of Respondents and the Performance Component Outcomes

Table B.2 Location of Respondents and the Occupational Performance Outcomes

Table C.1 Location of Respondents and the Performance Component Discharge Criteria

Table C.2 Location of Respondents and the Occupational Performance Discharge Criteria

Table C.3 A Comparison of the Performance Component and Occupational Performance Outcomes given in Response to Question Three and Five....

Table C.4 A Comparison of the Response Rates for Treatment Outcomes given in Questions Three and Five Table D.1 Location of the Respondents who Expressed some Dissatisfaction

Table D.2 Location of Respondents who were Satisfied with Treatment ..........244 


\section{FIGURES}

Fig. 1.1

Fig. 4.1

Fig. 13.1
Treatment Planning Process.

A model of Problem Solving in Occupational Therapy . .4 .58 Problem Representation in Occupational Therapy. A comparison between Student and Clinician 


\section{CHAPTER ONE}

\section{BACKGROUND TO THE RESEARCH}

\subsection{General Aim}

In preparing the occupational therapy student for a professional role, a major aim is to produce a competent practitioner. He or she is expected to acquire clinical knowledge by combining theoretical facts and clinical experience. Theoretical facts can be gained in a systematic way through academic studies but clinical experience is a more unpredictable element. In relation to nursing, it has been defined as:

"the transformation of preconceived notions and expectations by encounter with actual practical situations" (Benner \& Wrubel, 1982, p11).

This suggests that experience influences individuals in such a way as to modify their perception and understanding of all subsequent situations in a clinical setting. The general concern of this study is to determine how experience and knowledge alters clinical reasoning. The investigation will focus on both students' and clinicians' perceptions of the problems, goals and the beliefs that govern treatment planning - ie. students' and clinicians' internal representations of clinical problems will be the focus of the investigation. 


\subsection{Issues in Problem Identification}

For a four year period I was employed as a fieldwork tutor by the Occupational Therapy School in Wellington. This was a job that thrust me into the midst of a situation where students were having to apply their academic learning. The major difference between student contact in this situation and in an educational institution was the luxury of working with students on a one-to-one basis for up to three hours a week. During these periods of student contact I was able to observe students working with clients and then discuss with them their rationale for decisions regarding treatment procedures. Resulting from these experiences I became acutely aware of many students' lack of clarity in their understanding of what they were hoping to achieve in regards to treatment outcomes.

A particular difficulty for students was in formulating a treatment plan for clients who had been in hospital for long periods of time. They were able to carry on with the treatment program that the qualified therapist had established but had great difficulty identifying for themselves the problems that needed to be addressed by occupational therapy. It seemed as if there was too much data from the client's past records and too many treatment options that could be considered, with the result that students were unsure about what was an effective route to take.

A specific example to illustrate another difficulty was an instance when I discussed in depth with a student the treatment of a young man who had sustained a head injury. Throughout the discussion I had been careful to use facilitation techniques to ensure that the responses were given by the student and not spoon fed by myself. It surprised me that during a tutorial with other students later in the day, this same student was discussing the same client and 
listening to the suggestions given to her by her peer group as though she had never heard them before. The difficulty with the case in question was that there were no obvious problems for occupational therapy to address. The man was mobile, could carry out all his self-care skills independently, was living at home but as yet was unable to return to work. To treat this man effectively, one needed to be able to address issues that he identified such as a sense of worthlessness related to not being able to work and a need to see progress. Thus, because the problem to be dealt with was unclear in the mind of the student, her ability to identify appropriate treatment strategies was impaired. Furthermore, she needed to discuss this with those who were at her level of comprehension to clarify her thinking.

Clearly identifying the problem would seem to be crucial to determining appropriate treatment. One would expect that a qualified therapist who has had more experience than the student in the above example,would be able to determine the relevant problems more readily. However, there may be various circumstances that affect the way in which the occupational therapy process is applied in fieldwork settings, such as the influence of new theoretical developments in occupational therapy and constraints in the environment, for example, staffing levels and early discharge. Occupational therapy itself is a problem solving process; problem solving is commonly used in health care settings and is often referred to as the 'clinical reasoning process'. This process is depicted in Figure 1.1. 


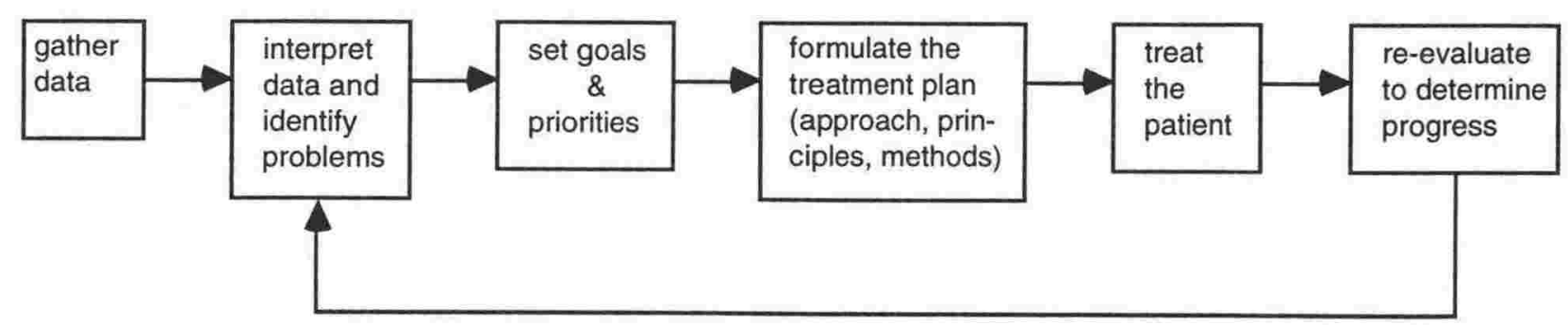

Figure 1.1 Treatment planning process (from Trombly, 1989, p 4).

Compounding the lack of clarity in identifying problems for occupational therapy intervention are two other factors. One is the complex nature of the problems of the client's with whom occupational therapists work. The medical diagnosis itself is never enough on which to establish treatment as both the social circumstances of clients and their own opinions about what is important to them influence the decisions regarding treatment planning. The other factor is the inability of the students and therapists to readily define occupational therapy. One often hears students allude to the fact that once someone discovers that they are doing occupational therapy, then there is an inevitable request for them to explain what occupational therapy is - seemingly this is a dreaded question as there is no easy answer.

\subsection{Issues in the Study of Problem Solving}

Studies that deal with problem solving in the clinical setting often use simulated patients or videos of clients in order to have a standard problem to which students and clinicians can respond (Corcoron, 1986; Elstein, Schulman \& Sprafka1978; Fetlovitch \& Barrows, 1984). While this is an effective method of obtaining consistency in the data, it does eliminate some of the 'real' variables which influence the reasoning process. Although the facts of a case 
and the patient's responses can be simulated or recorded, the environmental factors such as staff interactions, hospital ethos and community milieu,can never be totally replicated.

I would propose that these contextual factors have an important effect on reasoning especially in regards to perceptions of the problem and possible alternative solutions, i.e. treatment procedures. The notion of contextual factors having an influence on students' academic ability has been well documented (Marton \& Saljo, 1976b; Laurillard, 1979; Ramsden, 1984). Context dependent cognition has not been a focus in the clinical reasoning literature until recently. Elstein, Schulman \& Sprafka (1990) refer to the recent move in clinical reasoning which argues against the use of "novel problems stripped of context" (p.27) and for the view that the context should be considered. A recent study in the occupational therapy literature would support this change in focus by using ethnographic research methods to investigate clinical reasoning (Mattingly \& Gilette, 1991).

For this study, then, students and clinicians will be interviewed about their identification of treatment goals and priorities for a client whom they know well. In this way, each case will be considered in context and will be unique to each respondent. The analysis of the data, however, will consider global concepts common to all respondents and will also allow comparisons to be made between respondents in relation to issues such as level of expertise and environmental factors.

This study will draw upon two major sources of theoretical information - that outlining the development of the profession of occupational therapy and that dealing with problem solving. Both are considered to be equally important as 
the history of the profession explains the influence of factors which have led to various ways of conceptualising the work of the occupational therapist; and a problem solving analysis expresses current thinking about the nature of the work, which subsequently can be compared to the historical factors.

\subsection{Plan of the Study}

This chapter has focused briefly on the background and aims of the study. The next two chapters deal with the issues alluded to in the previous paragraph, i.e. the history of occupational therapy and the history of problem solving. Chapter Four deals specifically with the issue of the nature of problem solving with particular reference to the work on clinical reasoning. Chapter Five describes the method of data collection and chapters Six to Twelve each covers an aspect of the results of this study. Chapter 13 draws together the results, discusses the hypotheses and links the information to findings in the literature. The final chapter (14) considers the implications for education and identifies directions for further study. 


\title{
CHAPTER TWO \\ THE DEVELOPMENT OF THE PROFESSION OF OCCUPATIONAL THERAPY
}

\subsection{Introduction}

\begin{abstract}
Although the field of occupational therapy only came into existence threequarters of a century ago, the use of occupation as a form of treatment has a long and colourful history dating from the mid-eighteenth century. Some of the fundamental concepts that emerged at that time still constitute the core of its relevance for current practice.
\end{abstract}

\subsection{Changes in Concepts of Treatment}

The earliest form of occupational therapy was known as moral treatment and arose in the mid-eighteenth century as an alternative to the punitive and abusive methods of responding to the insane. The notion that the mentally ill needed to be imbued with fear arose from therapeutic intentions (Licht, 1948, cited by Kielhofner 1983). Moral treatment, in contrast, was a humanistic treatment that stressed compassion and the commonality of the human condition. Bockoven (1972) believed that effective results could be achieved through occupations ...

"which required the patient to invest interest in something outside himself in cooperation with others, namely manual work, intellectual work, recreation and religious worship" (pp 75-76). 
There was in this approach to treatment the view that the mind and brain were highly malleable and could be greatly influenced by physical and social surroundings.

The pioneers in occupational therapy embraced a view of mental illness articulated by Adolph Meyer (1922, cited by Kielfhofner 1992) in which habits, modes of adjustment and environments were major factors. The rationale and role of occupation as a remediative measure was that it maintained functional capacity and prevented depression and other problems that resulted from inactivity. Also, pathological thoughts were able to be substituted with healthy thoughts by orientating the patient to life tasks. By such involvement in life tasks, healthy patterns of living could be developed and normal patterns of work, rest, play and sleep established. Furthermore, it was believed that by involving patients in the community's everyday life tasks and events, their morale for living could be restored through providing a meaningful role in society.

A number of interrelated changes in science, society and medicine contributed to the decline of moral treatment. In the early 1930 s science was being pursued for its own sake and wasn't necessarily linked to humanistic goals as had been the case previously. Society moved from a view of all people being equal to a belief in the social Darwinism view of survival of the fittest. In this social climate, the notion of a moral obligation to care for the insane made less sense. The medical view of mental illness also changed from believing that environmental pressures caused such illnesses to ascribing the causes to discoverable neurological deficits (Bockoven, 1972; Magaro, Gripp \& McDowell, 1978). 
This philosophy of reductionism has resulted in the predominance of the medical model which viewed health as an absence of disease and emphasised pathology and symptom reduction. This deflected the focus from the occupational nature of humans to what Kielhofner (1983) refers to as the 'inner mechanisms' associated with kinesiological, neurologic and intra psychic function. Such beliefs lead to a precise and extensive technology for the treatment of a wide range of physical conditions and a psychoanalytic approach to mental disorders. This orientation resulted in a gradual erosion of the philosophical base underlying the profession. There was a shift in practice from a broad philosophical base to a practice based on techniques. In relation to the physically disabled, emphasis was placed on acquiring techniques such as progressive resistive exercises, activities of daily living and making orthotic devices (Forbes, 1951; Dunning, 1959; Shalik, 1954). In the psychosocial field, occupation became a vehicle through which patients could therapeutically fulfil needs and express feelings. Some therapists came to see occupations as only secondary to the process of establishing verbal relationships with clients and some abandoned it altogether in favour of purely verbal methods of treatment (Frank, 1958; Azima \& Azima, 1959). These techniques were practiced without integrating them into the concept of purposeful activity and without articulating a philosophical base.

The profession's search for a scientific rationale for its practice resulted in a replacement of its more substantive concern for health with the narrow perspective of the medical model based on the homeostatic principle of symptom reduction. Shannon (1977) viewed this attachment to the medical model as the beginning of the derailment process in occupational therapy. Other aspects of it were, he suggests, the alignment of the profession with the rehabilitation movement in the 1940's and the devaluation of the arts and 
crafts. Resulting from inadequate funding, the rehabilitation movement deteriorated into a management strategy for chronically disabled people rather than fulfilling its original holistic goal of total care. Meanwhile the use of arts and crafts was redirected by the reductionist approach, away from the idea of humans being creative and making their own choices, to the idea that they are ... "mechanistic creature(s) susceptible to manipulation and control via the application of techniques" (Shannon, 1977, p 233). In this way Mary Reilly's (1962) contention that the hypothesis on which the profession was built, that ..."man through the use of his hands as they are energised by mind and will, can influence the state of his own health" (p 8)... was being eroded.

\subsection{Re-asserting Occupational Therapy Traditions}

Once occupational therapists realised that this shift in practice had taken the profession away from its original purpose, efforts were made to articulate and shape theory in a manner consistent with the early occupational therapy traditions. These were organised on the existential premise that the client, through active practice and engagement with materials, tools and people, is involved in the healing process. In an attempt to re-establish activities as the core of occupational therapy, in 1979 the American Occupational Therapy Delegate Assembly adopted the following statement as the philosophical base of the profession:

"Man is an active being whose development is influenced by the use of purposeful activity. Using their capacity for intrinsic motivation, 
human beings are able to influence their physical and mental health and their social and physical environment through purposeful activity. Human life includes a process of continuous adaptation. Adaptation is a change in function that promotes survival and self-actualisation. Biological, psychological and environmental factors may interrupt the adaptation process at any time throughout the life cycle. Dysfunction may occur when adaptation is impaired. Purposeful activity facilitates the adaptive process.

Occupational therapy is based on the belief that purposeful activity (occupation), including its interpersonal and environmental components, may be used to prevent and mediate dysfunction, and to elicit maximum adaptation. Activity, as used by the Occupational Therapist, includes both an intrinsic and a therapeutic purpose" (Occupational Therapy Newspaper, 1979, p 1, cited by Mosey, 1981, p 58).

A particularly clear example of activity having both an intrinsic and therapeutic purpose can be found in Ayres (1979) thinking when she refers to the purposeful activity enabling the client to form adaptive responses which results in the improvement of the efficiency of the nervous system. In other words, the sensorimotor feedback associated with actions provides an incentive for the client to achieve a more mature level of neurological development. The goal of therapy is to improve the processing and organising of sensations in the nervous system so that the final outcome will be effectiveness in such tasks as educational performance and self-care activities. In this way the purpose of the activity is related to the therapist's understanding of the development of the nervous system rather than the goals 
and aspirations of the client. Thus the value of the activity lies in the process rather than the product.

\subsection{Dissension in Occupational Therapy}

It can be noted in the philosophical statement in the previous page, that the notion of purposeful activity is a key concept. There is evidence which suggests that Occupational therapists are using purposeful activity less frequently in favour of treatment approaches that are focused on pathology (Shannon, 1977). These therapists might deal directly with, for example, neurophysiological or sensorimotor deficits and would argue that many patients receiving occupational therapy are not at an appropriate level of motor activity to participate in purposeful activity. In such cases clinicians feel that the use of 'adjunctive' treatment techniques such as joint mobilisations and splinting to assist in the development of motor ability is needed to enable the patients to participate in purposeful activity (Pedretti, Smith \& McGuire 1992). Thus it is considered that the definition of purposeful activity needs to be expanded to incorporate contemporary treatment techniques that have proved to be effective.

Some therapists consider that purposeful activity is no longer the unifying core of the profession. Lyons (1983) states that although purposeful activity

"has been one of the unifying concepts of occupational therapy in the past... today the use of this term seems more divisive than unifying" (p 493). 
She also stated that the phrase 'purposeful activity' ... "has become an umbrella for a heterogeneous bag of human endeavours"... ( $p$ 493), where it has been interpreted in a variety of ways to suit individual therapists. She suggests that by allowing the term to be interpreted so freely, it is losing its power to direct and influence the profession.

\subsection{Philosophical Assumptions}

Because the philosophical statement adopted by the American Occupational Therapy Delegate Assembly does not define terms such as 'purposeful activity' or provide references, Mosey (1981) distilled from her own reading of the literature five philosophical assumptions for consideration. She states that these appear to be derived from the pragmatic, existentialist and humanistic schools of thought, which were prominent at the time of the profession's formal beginnings. They are as follows:

1. Each individual has the right to a meaningful existence; to an existence that allows one to be productive, to experience pleasure and joy, to love and be loved and to live in safe, supportive and comfortable surroundings.

The concept of a meaningful existence is interesting in comparison with the medical model where the right to life is of paramount importance. Once life is maintained, occupational therapy considers that the individual has the right to a meaningful existence and so to be treated as unique regardless of his/her current ability to be a productive member of the community. This has obvious 
implications for the role of occupational therapy with those who have chronic impairments and provides a basis for the idea of maintaining function in order that an individual's current abilities to engage in interpersonal relationships and to manipulate the non-human environment are preserved.

2. Each individual is influenced by stage-specific maturation of the species, the social nature of the species, and the cognitive structure of the species.

From this assumption, occupational therapy has derived an interest in the process of human growth and development, considering not only the reasonably predictable biological development, but also the less predictable sociological and psychological maturation which is heavily influenced by cultural and environmental factors. The individual's need for human interaction as having an influence on biological, sociological and psychological maturation, is reflected in the phrase 'the social nature of the species'.

The 'cognitive structure of the species' refers to the way in which information is used and processed. Human beings have an awareness of self and, because of cognitive sophistication, have more choices than other animals. Conversely, this results in psychological stress which can lead to creative endeavours or may lead to guilt, anxiety and depression. In addition, cognitive structures influence humans' shared ability to use language, to conceptualise and identify relationships among events and to contemplate their future. 
3. Each individual has the right to seek his or her potential through personal choice within the context of some social constraints.

Given a person's inherent capacities, 'potential' refers to the individual's ability regardless of various limitations. A disability need not be a limiting factor in being productive and finding satisfaction in life. 'Personal choice' refers to the right of individuals to decide to what degree, how, and in what way they will seek to reach their potential. It is the recognition of the right and privilege of clients to determine how they wish to live their lives.

The above assumption also recognises that a society has particular constraints which may influence an individual's behaviour. So although there is the matter of individual choice, the rights of the society must also be respected.

4. Each individual is able to reach his or her potential only through purposeful interaction with the human and non-human environment.

This emphasises the belief that learning is facilitated through doing, through interaction in concrete, immediate situations. Experiences that deal purely with the abstract or hypothetical are considered to be less conducive to integrated learning. Perhaps one of the clearest descriptions of 'purposeful interaction' is that given by Fidler \& Fidler (1978), who emphasise the role of experience in providing the opportunity for ...

\footnotetext{
"investigating, trying out and gaining evidence of one's capacity for experiencing, responding, managing, creating and controlling" (p305).
} 
In contrast, random activities are undirected and without a predetermined goal.

The need to consider both the human and non-human environments is important for recognising the wide range of contextual factors in people's lives. The knowledge, skills and attitudes acquired through purposeful interaction with the environment in its totality, are the essence of the occupational therapy process.

5. Each individual has inherent needs for work, play and rest which must be satisfied in a relatively equal balance.

This philosophical assumption seemingly became part of the occupational therapy model from its inception. Meyer (1922) and Slagle (1928), early contributors to the profession, both believed that an optimal balance between work, play and rest was a major factor in the restoration of function and the promotion of health. According to Mosey (1981),

"the philosophical assumptions of occupational therapy have been stated in a variety of ways throughout the profession's development. The differences, however, appear to be ones of semantics rather than substance. In actuality, there has been considerable consistency in the philosophical assumptions from the formal beginning of the profession" (p 63).

\subsection{Professional Identification}


Despite these reflections, there remains a dissatisfaction with the status of occupational therapy resulting in a search for a professional identity separate from that bestowed by the medical profession. The outcome sought is to obtain society's recognition of occupational therapists as independent practitioners not having to work under medical prescription. This has prompted a search for a comprehensive theory that will consolidate the profession's sense of self. The most well developed example of this is the Model of Human Occupation as proposed by Gary Kielhofner (1985). However, whether or not such a theory would resolve all the dilemmas facing the profession seems debateable, as it is unlikely that there would be loyalty by all members of the profession to one theoretical perspective. Mosey (1985) is one of the best known advocates of a pluralistic approach. Such theories that have been recently developed do at least provide a base which stimulates further thinking and results in various routes being explored from which an identity can be developed.

\subsection{Practice Models}

Over the years many models have been borrowed from other disciplines to be used as frames of reference from which to develop practice models and theories in occupational therapy. Reed (1984), refers to there being six "super" models which have provided a framework in which to develop the role of occupational therapy as a practice discipline. These are as follows:

1. Humanistic model: As discussed earlier in this chapter, this was the earliest model and gave rise to moral treatment. The focus was on the organisation of routines and being involved in the everyday life of the 
hospital unit. This engagement in useful activity was a means of improving health where the focus was on the integration of mind and body.

2. Reductionist model: In contrast to the humanistic model, this model viewed humans as machines where mind and body could be separated. This had a profound influence, and as already outlined, gave rise to a mechanistic, techniques-based approach to treatment which helped occupational therapy to achieve some recognition in the medical community because this was a more 'scientific' approach than humanism.

3. Development models: These are based on the view that an individual undergoes progressive and continuous change from birth to death and have been very popular in the practice of occupational therapy since about the 1940s. Intervention is considered to be necessary when any particular stage of development is not reached within a normal time frame.

4. Psychoanalytic model: This model had major influence and was based on the general assumption that behaviour is controlled by unconscious childhood anxieties and defence mechanisms. The orientation of intervention is to enable the individual to gain insight into inappropriate use of defence mechanisms.

5. Behaviouristic model: This views behaviour as being controllable not through understanding of past life experiences as in the previous model, but through reinforcement of desired behaviour. In contrast, it has a 
'here and now' focus and has given rise to programs such as 'behaviour modification'.

6. System model: This model grew out of a reaction against the reductionist model. The emphasis being on integration of parts into a cohesive whole where the focus is on the 'inputs' into the system as a way of influencing the 'outputs'. This model has had considerable influence on occupational therapists in recent years and Kielhofner's model of human occupation (1985) is a well known example of this.

Lastly, although not one of the "super" models, the holistic model has also had an effect on occupational therapy literature. This particular way of thinking results in the person taking responsibility for identifying any needs and collaborating with a therapist to bring about behaviour change.

\subsection{Conclusions}

Some of these models have developed more recently but all have had an influence on the practice of occupational therapy both in the past and in the present. Theories which guide treatment approaches will most certainly influence therapists' clinical reasoning. For instance, those who have strong humanistic ideals would be likely to think about their work in a very different way compared to the therapist who uses a reductionist approach such as the medical model.

These practice models have also strongly influenced teaching in the occupational therapy schools. For instance when the first occupational 
therapy school in New Zealand was established in 1940, the humanistic model was predominant, in the 1960 s reductionism was the preferred approach, while at the time of interviewing the students for this study, the systems model was in vogue.

History clearly demonstrates that society, technology and knowledge change over time. Occupational therapy has been responsive to these changes and reorganised its media, methods and rationales to be consistent with new information, values and technological trends. This process of change without a strong uniting philosophy has resulted in therapists using models which give them credibility in their particular setting but may not be specific to occupational therapy. As acknowledged by Francia de Beer in her summary of the Eleanor Clarke Slagle Lectures $(1987)^{1}$, there has been a hesitancy to pursue the issue of professional identification over the last 30 years. The lack of a strong professional identity begs the question of how clearly individuals are able to articulate their particular area of expertise in their day to day work.

The focus of this study will be on clinicians' and students' perceptions of their own experience of occupational therapy and will explore understandings of the nature of occupational therapy from the point of view of those working in a range of settings. Thus it will require the participants to clarify their day to day work.

The design of the study will draw, in part, on an information processing approach. The rationale for the use of this approach is that it is consistent with the reductionistic paradigm which has strongly influenced the profession and is responsible for much of current practice. Furthermore, this approach to studying

1 These lectures are the highest scholarly honour awarded by the American Association of Occupational Therapy and occur annually. 
clinical reasoning has been widely used in other health professions such as medicine and nursing so will enable comparisons to be made with the literature in these related disciplines. However, to take only one approach to such a complex phenomenon as clinical reasoning might result in valuable insights to problem representation being missed. Thus, this thesis will extend the analysis to include a humanistic dimension which will provide an opportunity to explore the extent to which the client's concerns are understood. 


\section{CHAPTER THREE \\ HISTORICAL REVIEW OF PROBLEM SOLVING}

\subsection{Introduction}

There are two major ways in which problem solving has been viewed over the years. It has been seen as an external, behavioural process or as an internal, cognitive process. Psychological definitions have been tied to behaviour as a manifestation of thinking processes, or alternatively tied to the thinking processes that underlie the behavioural manifestations.

There are a variety of approaches to the study of how people learn, think and solve problems. This includes the information processing approach to cognition, which may use computer simulation of human thinking (Newall \& Simon, 1972; Ernst \& Newall, 1969), new theories of semantic memory representation (eg. Greeno, 1973; Simon \& Gilmarton, 1973) and the new interest of American psychologists in cognitive development motivated largely by Piaget's work. Older roads which are still being developed include the Gestalt approach to problem solving based on the idea that thinking involves restructuring a problem, the study of concept learning (eg. Skemp, 1979) which suggests that the testing of hypotheses may be a part of thinking, and the associationist approach to thinking (eg. Thorndike, 1898) which is based on the principle of learning by reinforcement. This chapter will discuss a range of these approaches. 


\subsection{Associationism: Thinking by reinforcement}

According to this view, problem solving can be described as the trial and error application of pre-existing response tendencies known as habits. It is called associationism because it assumes that for any problem situation there are associations or links to many possible responses. Thus the three elements are: the stimulus (a particular problem solving situation), the responses (particular problem solving behaviours), and the associations between a particular stimulus and a particular response. The links are assumed to be in the problem solver's mind where they form a "family" of possible responses associated with any given problem situation. In addition, the responses may vary in strength with some associations being very weak and others being very strong. In this way, the responses for any given situation may be put into a hierarchy in order of their strength.

Thorndike (1898), one of the earliest learning theorists, conducted a now famous series of experiments involving cats in a puzzle box. He concluded that the cats solved the problem of escaping from the box by trial and error. Initially the correct response was achieved entirely by chance and eventually after repeated attempts to escape from the box the cat was more likely to repeat the response that did work rather than the ineffective response. The cat's actions led Thorndike to explain such problem solving as trial and error learning where the responses were seen to be in a random fashion with little evidence of thinking. Well practised responses were seen to increase the strength of the stimulus - response link (in the case of the cats, pushing a handle was the behaviour that released the cage door) while responses that did not help solve the problem were considered to lose their strength (eg. the cats eventually stopped performing actions such as extending their paws through the bars). 
Thus responses for any given situation were put into a hierarchy in order of their strength. In the problem solving situation, the problem solver (either overtly or covertly) tries the most dominant response in the hierarchy for that situation, if that fails tries the second strongest response, and so on until one works. This process is basic to the associationist's understanding of problem solving processes and is known as the application of the thinker's existing family hierarchy. Maltzman (1955) summarises this view by stating that thinking is an activity (not a response) that results in a change - a new combination of habit strengths - within a habit family hierarchy.

There is further evidence beyond the notion of cats in a puzzle box which lend support to the associationist theory. Some of this comes from studying how people solve anagrams. Much of this work has been carried out by Mayzner and Tresselt in a series of experiments using anagrams which were investigated for the subjects' use of the most familiar goal word $(1958,1966)$ and probable letter transition patterns $(1962,1963,1966)$. In summary, the experiments with anagrams offer four different lines of support for the idea that problem solving involves trial and error application of a subject's habit family hierarchy. With 120 possible ways to arrange a five letter anagram, it is clear that subjects do not try solutions at random but rather begin with the most dominant responses and go on to the weaker ones if those don't work. Thus, frequently used words, high probability transition words, words which require only minor rearrangement, or words which do not require breaking up a high transition probability letter combination, are solved more quickly than others.

In solving problems, the experience of the individual just prior to and during the problem solving situation are as important as his or her general past experience in determining the 'response hierarchy'. These combined experiences are 
known as the subject's problem solving set. It has been noted that subjects can be influenced in their choice of word solution when given ambiguous anagrams (Rees \& Israel, 1953; Maltzman \& Moorisett, 1953). In terms of the response hierarchy framework, these results indicate that several different habit family hierarchies may exist for a given problem situation.

The associationist approach offers a means of representing thinking and problem solving that allows for clear predictions. Some kinds of thinking can be explained by the response hierarchy model, however, it seems that such a model may not capture the complexities of human thought because it limits itself to trial and error application of past habits and does not include an analysis of thinking.

\subsection{Functionalism: An Application Oriented Psychology}

Functionalists were concerned with developing techniques in education and psychology that were applicable to real-world problems. From his observations, Dewey (1933) described a sequence of steps that effective problem solvers followed. These steps are still used in the development of programmes to teach people aspects of problem solving. They comprise:

- Presentation of the problem. The emphasis here is placed on all aspects of a problem being made explicit and ensuring that all information needed to solve a problem is available to students or has been previously mastered by them. 
- $\quad$ Problem definition. This stresses the ability of students' to define problems in as many ways as possible to provide the widest array of subsequent activities that will lead to problem solutions.

- Development of hypotheses. Once the problem is defined, the next step is to use as many hypotheses as possible for solving the problem. The more hypotheses generated, the greater the chances that a satisfactory solution will be found.

- Testing hypotheses. Choices need to be made between the various hypotheses that have been generated. Thus the process of testing and evaluating the hypotheses in terms of their potential benefits and drawbacks is emphasised.

- Selection of the best hypothesis. Once the evaluation process has been completed, the hypothesis that promises the greatest advantages should be selected.

\subsection{Gestalt: Thinking as Restructuring of Problems}

Gestalt psychology arose in the early part of the twentieth century in reaction to structuralism, functionalism and behaviourism. Gestalt theorists held that psychological experience could not be broken into elements or pieces that could be studied separately, instead they argued that people do not react to individual elements in their environments; rather they react to their total experiences. In his experiments with apes, Kohler (1925) concluded that they acted in ways that could be called insightful when they set about solving the problem of reaching 
fruit which was suspended from the cage. He argued that they solved the problems not through mere trial and error, but by perceiving the relationships essential to the solution. This hypothesis he extended to human beings.

According to Gestalt psychologists, the process of problem solving is a search to relate one aspect of a problem situation to another. This search results in structural understanding which is the ability to comprehend how all parts of a problem fit together to satisfy the requirements of the goal. This structural quality is wholeness. Such a process involves reorganising the elements of the problem situation in a new way so that the problem can be solved. An important concept is the idea that people get stuck solving problems because they cannot change their problem solving set - ie. they are unable to look at a situation in a new way so they cannot see new possibilities for fitting the problem elements together.

A typical problem that this approach considers is one where, for instance, the subject is given six match sticks and is asked to make four identical, equilateral triangles with them. In such a task many people have trouble changing their problem set from two dimensions to three. Giving such a hint is important to problem solving as it helps the person to break out of their old way of organising the situation. This resulting new way of looking at problems is called insight. A Gestalt problem will always involve a creative or novel situation. Essentially such an approach is dealing with the understanding of a very high level and creative type of mental process.

One of the basic concepts in the Gestalt approach is that there are two kinds of thinking: one is based on creating a new solution to a problem and is called productive thinking because a new organisation is produced; the other, based 
on applying past solutions to a problem, is called reproductive thinking because old habits or behaviours are simply reproduced. This distinction is described in the work of Wertheimer (1959), where students were taught how to find the area of a parallelogram by either a method that was based on rote learning or one that was based on understanding the concepts involved. Those that were taught by the "understanding" method were more able to transfer knowledge to finding the area of unusual parallelograms than were their counterparts.

The claim that learning by understanding structural relationships has improved not only the subject's ability to transfer learning but has also improved their ability to retain information over time has been investigated (Katona, 1940; Hilgard, Irvine \& Whipple, 1953). This has resulted in some evidence for the idea that giving problem solvers 'hints' so that they can discover the structure of the problem situation does aid in transfer, ie. productive problem solving. However, questions have been raised regarding the validity of some of this work. One area of concern is how meaningful the material was to the subjects the contention being that a meaningful principle can be learned in a mechanical way (Corman, 1957).

In more recent years, the distinction between these two kinds of learning to solve problems has taken the form of a separation between 'discovery' and 'expository' methods of instruction. Bruner (1968) has been a major proponent of the discovery method where the aim of developing productive thinking has been encouraged by assisting the learner to discover the structure of the problem situation.

Stages in problem solving have been redefined over the years. In his classic book, The Art of Thinking, Wallas (1926) suggests four phases: 
- Preparation: the gathering of information and preliminary attempts at a solution.

- Incubation: putting the problem aside to work on other activities or sleep.

- Illumination: the key to the solution appears - this is where the flash of insight occurs.

- Verification: checking out the solution to make sure it works.

This has been based on introspection rather than psychological experimentation, however, such an analysis can be applied to thinking processes in a descriptive way.

More recently, Polya $(1957,1965)$ has introduced a series of steps in problem solving based on observations he has made as a teacher of mathematics. Polya's four steps, as described in his classic book How to Solve It (1957) are:

Understanding the problem: data is gathered and questions such as what is unknown, what is the data and the conditions, are asked.

Devising a plan: past experience is used to find a solution method. This may involve restating the goal or the givens so that past experience can be useful.

Carrying out the plan: the solution plan is tried out and each step is checked. 
Looking back: results are checked by using another method or by seeing how it all fits together. The question ... "can I use this result or method for other problems?" ... is asked.

There are similarities between Polya's steps and those described by Wallas. As can be seen in the above steps there are many ideas that are consistent with Gestalt concepts. This can be noted in Polya's ideas of restating the goals and restating the givens, both of which are examples of the Gestalt idea of restructuring. Although Polya provides intuitive ideas about how the restructuring of events occurs and how to encourage it, the concept has still not been well studied experimentally.

Duncker (1945) attempted to study the stages in problem solving empirically. This resulted in a description of basic phenomena in problem solving. One such phenomena was the restructuring of problems into smaller problems or subgoals. Both Hayes (1966) and Thomas (1974) designed experiments to investigate this and demonstrated that their subjects did restructure problems into smaller ones and then tried to solve these sub problems.

Another major contribution of the Gestalt psychologists is their finding that prior experience can have negative effects in certain new problem solving situations. The idea that reproductive application of past habits inhibits productive problem solving has been called functional fixedness (Duncker, 1945), problem solving set (Luchins, 1942) and negative transfer (Bartlett, 1958). From the work of these psychologists it would seem evident that past experience can limit the type of solution that a subject devises in a new situation, ie. past habits become deeply engrained limiting the person's ability to conceive an alternative method of approach. 
There is complementary evidence that in some cases specific past experience may aid problem solving. Maier (1945) and Saugstad \& Raaheim (1960) demonstrated that in situations where similar functions are required, past experience is an aid. Their results seem to show that:

"problems which require productive solutions - reorganisation of the problem elements - are more easily solved by a mind that is prepared with appropriate general past experience. On the other hand, if those past experiences specifically tend to fix the function of an object in one way, creative problem solving can be hurt." (Mayer, 1977, p 85)

The above studies indicate that part of solving a problem is finding out how it related to past experience. Polya cited 'finding a related problem' as a main factor in devising a solution plan.

So how does a problem solver find the relationship between past experience and the reformulation of the problem? Earlier studies carried out by Maier (1930; $1931 ; 1933)$ lead him to believe that 'direction' is required, ie. subjects need some organising principle, a new way of looking at a situation. Such clues may be externally or internally generated and can be very subtle to the point where the subject does not realise how an idea has been generated.

In summary, the Gestaltists have attempted to understand some very complex mental processes - what they called 'productive thinking'. They have enriched the study of thinking by introducing ideas such as the distinction between productive and reproductive thinking, the notion that thinking occurs in stages, and the demonstration of rigidity due to the presence of a problem solving set. 
Their main tool for understanding such processes was the idea that problem solving involves reorganising or restructuring the problem situation.

There are a number of differences between the Gestalt approach to thinking and the associationist approach. They do not deal with the same kind of problems Gestalt is concerned with creative novel solutions to new situations, while the associationists are concerned with applying solution habits from past experience. Furthermore, Gestalt theory views thinking as re-arranging problem elements whereas the associationist view is that problem solving involves trying possible solutions until one works. In analysing thinking into its component parts, the Gestaltists rely on mental organisations as the unit of thought while the associationists describe thinking in terms of associations among stimuli and responses. And finally the Gestaltists deal with more complicated kinds of thinking than do the associationists, but their theory is more vague and thus more difficult to test scientifically. While critics of the Gestalt approach point out the lack of a sufficient scientific base for their theories, cognitive psychologists have more recently clarified some of the Gestalt ideas, as will be discussed in the next section on information processing.

\subsection{Thinking as Information Processing}

This approach considers that a human being is a processor of information. His or her mental state can therefore be represented as either ...

"a sequence of mental processes or operations performed on information in the subject's memory; or a sequence of internal states or changes in information that progress towards the goal." (Mayer, 1977, p 133) 
The goal of the information processing psychologist is therefore to define precisely these processes or states that a subject is using to solve a particular problem and so be able to list the exact sequence of operations used. The development of this idea has resulted, for example, in the construction of computer simulations to model mental processing.

Information-processing psychologists describe psychological events in terms of transformations of information from input to output. In the first instance information is received by receptors then at this stage either transferred into the working memory or lost from the processing system. This is referred to as selective perception. Working memory has a limited capacity, and information can be easily lost from here if not coded or rehearsed. Coded information goes through to long term memory, which by contrast, has a very large capacity. The coding is a transformational process in which new information is integrated with known information. Once stored in a long term memory, information is available for later use and is retrieved by the working memory to deal with current problems that have been identified via the receptors. This movement of information from input to output is an organised system.

As mentioned, computer simulations have been developed that display the same problem solving behaviour as humans. The experimental method used with computer simulation generally involves asking subjects to solve problems aloud while giving a running description of their thought processes and their behaviour. From careful analysis of the obtained protocols, the experimenter may derive a description of the mental processes a subject used to solve the problem. This then allows a comparison to be drawn between the subject's and the computer's protocols. 
This kind of approach is characterised by the work of Newell and Simon (1972) who developed a programme called the General Problem Solver. They derived a psychological theory of human problem solving from an analysis of protocols of people attempting to solve problems such as the following:

Given that each letter represents a number from 0 to 9 , and that

$\mathrm{D}$ is 5 , find the values of the other letters in the sum:

DONALD + GERALD $=$ ROBERT

The theory was based on the idea that human cognition is dominated by heuristic processes. The principal characteristics of this type of approach can be described in information processing terms such as means-end analysis, creation of sub-goals, working forwards from what is given, and working backwards from the intended goal. For the stated problem the means end analysis will require that in order to get to the given goal, the problem will need to be broken down into individual algebraic sums. Once this strategy is decided on, then use of knowledge of the rules of addition together with the given information must be used to deduce the various values. The creation of subgoals then follows in the form of considering individual columns. The solution may then proceed by working forwards from what is given (eg. $\mathrm{D}+\mathrm{D}=5+5=10$; therefore $\mathrm{T}=0$ ). On the other hand, a working backwards strategy may also be used where a particular letter is assigned a number (eg. suppose $\mathrm{R}=3$ : looking at the first column $(D+G), 5+$ something $=3$, which is impossible, therefore $R \neq 3$ ).

From protocols such as this, a series of heuristic's can be developed for the computer to work on: assemble known information; for each column generate the possible values for each letter; for each value deduced, check that it is not 
already occupied by another letter and so on. The programme developed from these steps will then represent the theory of how humans use these heuristic procedures to solve such a problem. In other words, the intention is to show that certain general problem solving techniques are involved in a wide spectrum of problems and that it is possible to state explicitly what these general procedures are in a computer programme that will be able to solve a wide variety of different types of problems.

General Problem Solver begins by translating a statement of the problem into an internal representation of the initial problem state (current situation when the problem is recognised), the goal state (outcome sought) and the set of operators (possible actions that could be taken when solving a problem). In addition it has stored in its memory a table of connections for each problem it will solve; the table of connections contains all possible problem states for that problem, with a listing of how far apart any two states are from one another. Problem solving involves breaking down a problem into subgoals, then achieving each of these by applying various problem solving techniques. The entire process is presided over by the problem solver executive which determines the order in which operators will be applied, attempts to achieve subgoals by using meansend analysis, and develops a new sub-goal structure if one does not work.

The computer simulation approach requires that the theories be stated precisely in a formal computer programme, and provides for the use of sophisticated laboratory equipment, ie. computers in testing theories. In this way it provides scientific evidence for thinking processes. However the information processing view of human beings as machine-like processors of information is limited. Although a programme may simulate human thinking behaviour it does not necessarily simulate the underlying cognitive processes. Also, because a 
simulation programme must contain lists of every possible problem state and a measurement of their distance from the goal, this would seem to represent reproductive thinking only, in Gestalt terms.

It is important to clarify the differences between computer and human information processing. As discussed at the outset, the parts of a computer system are functionally similar to the elements of the human information processing system. Both have ways of receiving information, working with information, then storing it, and both are able to output the information. Thus they have similar functional units within their systems, however they do differ in detail. For one thing, computers have a much larger working capacity than humans and their processing times are much faster. However, one of the features that gives humans an advantage over this confined system is that humans are context dependent. This feature ...

"allows for learning and adaptation and our tendency for partial memory allows us to think of novel situations to problems. In short, the human system has evolved to be adaptive." (Gagné , 1985)

Thus humans are able to consider problems and goal states that are poorly defined. The creativity engendered in considering this type of unstructured problem situation would be consistent with the Gestalt idea of productive thinking.

One of the greatest theoretical difficulties with the information processing approach is that of representing how the individual perceives the problem. Laurillard (1984) draws attention to Luger's (1975) work which indicates that characteristics of solution protocols differ according to the structure of the 
problem and how this is interpreted by the problem solver. It would seem that problem solving strategies adopted are in part determined by the form of the problem. Therefore it is essential to know how the individual represents the structure to him/herself. As E. Gagné (1985) indicates, problem representation is the most crucial aspect of problem solving because representation determines what knowledge will be activated in long term memory.

One of the greatest values of this theory lies in its descriptions of the heuristic procedures used in problem solving. Another contribution of the theory is the way in which it analyses the components of the problem representation. As indicated in the previous paragraph, it is vital to understand this aspect of problem solving because of the influence representation has on the solution paths sought.

\subsection{Problem solving as the apex of a hierarchy of learning tasks}

R. Gagné (1985) represents problem solving as the apex of a hierarchy of mental processes which range from simple response learning (associationism) to problem solving. The intermediate stages include: simple verbal learning (associating words with objects), concept learning (eg. understanding concepts such as colour, heat and "twoness"), and principle/rule learning (combining concepts to form rules such as 'don't drink and drive' or 'bend your knees when lifting'). Problem solving is the chaining or combining of rules in a new way to form a higher order rule, which then becomes part of the individual's repertoire and can be generalised to other new situations when problems of the same type are presented. Note that for Gagné, problem solving is more than simply the application of existing rules to achieve a goal; a restructuring takes place. In 
other words, something new is learned, that is, the individual's capability is changed so that when the person meets a similar situation again, it is no longer a 'problem' as it can be responded to by recalling previous knowledge gained through past experience.

Gagné also viewed problem solving as involving a range of competencies. The first of these was the understanding of the problem (ie. the problem schemata) which depends on both the internal state of the individual (eg. the person's readiness, motivation, experience, ) and the external information or 'givens'. The remaining competencies depend on internal conditions of the individual. These are the selection of intellectual skills from working memory, the arrangement of these in a proper order (ie. the development of a cognitive strategy), and the validation of the outcome(s) thus ensuring that any incorrect answers are eliminated.

One of the main values of this approach is in its ability to look beyond the application of rules in problem solving to consider the new learning that occurs in the process. Gagné stresses that the learning of higher-order rules is important because this enables the learner to develop cognitive strategies which can guide subsequent thinking behaviour.

\subsection{Summary of the Chapter}

Over the years, the study of problem solving has moved its focus from behavioural manifestations to underlying cognitive processes. The investigation of cognitive processes has varied from tightly structured analyses, such as an 
investigation of the heuristic's of problem solving, to a much looser approach which has enabled concepts such as 'illumination' and 'insight' to be explored. While the latter has not provided much in the way of empirical evidence for its conclusions, it has provided new ways of conceptualising problem solving.

All approaches seem to consider that previous experience plays an important role in problem solving in that a problem is never solved in a vacuum, rather the individual is able to recall previously learnt rules as well as domain specific knowledge. Some of the debates centre around the methods by which these rules can be successfully applied in new situations and how best knowledge should be organised to be effectively recalled. External influences at the time of problem solving are considered important as they have an influence on the ability of the individual to recall appropriate information and think creatively.

Another aspect that is common to all approaches is the need to sense a problem in the first instance and to define it. The earlier research considered problems that were well-defined and used these to understand the underlying processes, however later research has been able to deal with the more complex ill-defined problems which are the essence of real life situations. A theme that has evolved in the later research is the link between the quality of the problem representation and the quality of the problem solution.

Given that this link exists and that problem solutions are all important in the clinical field, this study will seek to investigate the quality of the problem representation in occupational therapy. In the chapter that dealt with the history of occupational therapy it was noted that one of the issues for the profession was the lack of a clear professional identity. Therefore one might expect that this would result in the parameters of occupational therapy practice being broad 
with subsequent difficulty in defining the problems that are appropriate for occupational therapy intervention. Consequently the major focus of this study will be on the problem representation in occupational therapy - that is, the information that is processed to build a mental picture of the problem. The information processing approach provides a clear framework for considering the elements that underlie the representation of a problem. These elements and the broader context of the information processing approach will be elaborated in the following chapter. 


\section{CHAPTER FOUR}

\section{THE NATURE OF PROBLEM SOLVING}

\subsection{What Constitutes a Problem?}

Essentially, a problem arises when someone wants to do something but either doesn't know how or is in some way blocked from implementing a known solution. Thus the problem is the gap which separates people from where they are now and where they want to be. This notion of a 'gap' is an essential feature of the views of most theorists on problem-solving (Hayes, 1978; R. Gagné, 1985).

In general, psychologists agree on certain elements or features that characterise a problem. These are the givens, the goals and the obstacles. The givens are the conditions, information etc. which are available at the onset of the work on the problem. The goals are the desired or final state of the problem; to reach such a position, thinking is required to transform the problem from the given state to the goal state. Obstacles are the blocks which prevent the individual from immediately identifying or implementing the changes that need to be made to reach the goal state. There might be one or several ways of accomplishing this, but no correct sequence of events is immediately obvious.

Problems come in a variety of forms, from deciding what to cook for dinner to planning a building that is earthquake proof and is ten stories high. They may be clearly defined or ill defined and require the problem solver to determine or clarify the nature of the problem; similarly, the outcome may be well defined 
3. The operators

4. The restrictions on the operators.

The initial situation is the one in which the person finds him/herself when a problem is recognised. In occupational therapy this involves an understanding of the functional abilities and problems of the client, the hospital procedures, knowledge of the causes of dysfunction and of occupational therapy theory and practice. It is therefore necessary to recall information from long term memory (see later in this chapter) as well as identify relevant data in the current situation. The other aspect important at this stage is an understanding of ones own strengths and weaknesses in relation to treatment skills. The more adequately the initial state is understood, the more effective the clinical problem solving will be.

The goal is simply the outcome a problem solver seeks. Clearly, understanding the goal is extremely important. In the clinical setting the goals are often not clearly defined and the problem solver must take an active role in determining what the problem and therefore the outcome will be. For instance in the case of a patient who has suffered a cerebral vascular accident (CVA/'stroke') the problem may be defined by an individual therapist in various ways:

i) The problem is a lack of control of movement, so the goal would be to improve neuromuscular functioning.

ii) The problem is the family's ability to manage the patient, therefore the goal is to help the family care for their disabled member. 
iii) The problem is the patient's loss of control over his/her own life, so the goal is to ensure the re-instatement of this control.

Often the goals are not clearly defined so it can be difficult to determine what actions to take. The clearer the goals are, the more explicit the paths taken to realise them become.

In addition to an understanding of the initial and goal states, a good problem representation includes an understanding of the operators, which, in information processing terminology, are the actions a person can take in solving a problem. In the above patient scenario a variety of operators can be chosen. The problem solver may involve the patient in a treatment program which focuses on preventing abnormal movements and encouraging normal symmetrical movement patterns. The problem solver may, however, choose to consider the home environment and compensatory measures which will ensure maximum independence; these may include the installation of rails, ramps and other aids and equipment along with the giving of advice on how to use them. The other alternative relevant to the cited problems is to involve the client in a time management program which emphasises the client's ability to plan daily activities based on the tasks he/she wants to accomplish, and taking into account his/her own value system and level of independence. Information processing psychologists suggest that the more that is understood about the actions that can be performed in solving problem - that is, the more that is known about the operators - the more effective the problem solving will be (Glover, 1987).

The last feature of problem solving is to understand the restrictions or limits on the operators. In regards to planning for treatment intervention, limits may 
come in the form of time constraints, financial limitations, hospital policies, therapists skills or knowledge and the priorities of the client and/or family.

\subsection{Problem Representation and Problem Space}

These two concepts, problem representation and problem space, are not used consistently in the literature. As indicated earlier, problem representation is the solver's internal model of the problem incorporating his/her interpretation of the initial situation (sometimes called the 'problem state'), the perceived goals or outcomes ('goal state'), the potential operators (possible treatments or 'solution paths'), and the restrictions on these operators.

The term problem space has often been used interchangeably with problem representation in the literature. For example, E. Gagné (1985) in citing Newell and Simon (1972), describes the information processing framework for viewing problems as including ...

"a goal state, a starting state, and all possible solution paths for reaching the goal. These three elements are called the problem space" (p 138).

On the other hand, other writers define the problem space as the total number of actions or solution paths (whether correct or incorrect) that the solver sees as possible (eg. Glover \& Bruning, 1987; Hayes, 1978). This definition in fact sees the problem space as a component of the problem representation, focusing on the range of possible solution paths or operators. However, this view still recognises that the problem space is influenced by the solver's interpretation of the initial situation or goal state; the range of potential solution paths will be 
affected by the amount and complexity of the information that the solver has to process.

For the present study, the definition used by Newall and Simon (1972) has been adopted: that is, problem space is used interchangeably with the term problem representation.

\subsection{Limiting the Problem Space}

A critical factor in solving problems is the ability of the solver to limit the problem space. As Simon (1978) reminds us ...

"an information processing system need not be concerned with the size of the haystack if a small part can be identified in which there is sure to be a needle" (p 277).

De Groot (1966), in his study on chess players, explored what makes master chess players different from less expert ones. He obtained protocols from former world champions and some skilful club players as they tried to make the best moves in a given situation. Surprisingly he found no strategy differences. All players tended to consider the same number of moves, and they also tended to look ahead to about the same distance in assessing the effects of a move (the initial problem space was the same). However, experts recognised more rapidly the best move, thereby reducing options and limiting the problem space (this example is discussed further in Section 4.5 on memory). 
The way in which problems are represented has considerable impact on the ease with which the solver is able to limit the problem space. Hayes (1978) suggests that there are two processes at work as people construct the problem representation:

1. The problem solver selectively attends to information presented ie. judgments are made about the relative importance of information in problems.

In the clinical setting it has been shown that novices in nursing tend to put equal emphasis on all information whereas experts emphasise certain aspects thereby showing an ability to selectively attend to information (Broderick, 1979; Benner \& Wrubel, 1982). Thus it would appear that experience results in clinicians being able to make judgements about the relative importance of information when deciding on a treatment plan.

2. The problem solver makes use of prior knowledge, including knowledge of solving problems.

In occupational therapy this might involve aspects such as knowledge of treatment procedures, knowledge of clinical conditions, and recall of previous clinical experience.

The ability to perceive the problem in a way that restricts the problem space has also been shown to occur in medical diagnosis research. Elstein, Schulman \& Sprafka (1978) concluded that the function of early hypothesis generation was to limit the size of the space that must be searched in order to obtain a solution. As in the chess player example, the expert clinicians did not generate more 
hypotheses, but they did interpret data more accurately to test their hypotheses, thus suggesting that they had more domain specific knowledge than those who had less expertise.

Hayes (1978) also identifies two different procedures which are used to search this space and so limit its size:

1. Random Search: Paths are chosen without any special knowledge. This method is usually not very effective when the problem space is large.

2. Heuristic Search: This uses information from the problem to find the correct or more probable search paths and is a systematic process. It is the method used by the experts in the examples quoted above.

Hayes further identifies different types of heuristic search strategies which can act as guides for defining and limiting the problem space:

i) Proximity Methods (or 'working forward')

This is the use of hints to reduce the search space and may involve the individual trying out one step towards the solution, evaluating whether or not it works then either rejecting it or attempting a further step towards the goal. This trial and error approach is typically used by the novice problem solver.

\section{ii) Pattern Matching}

This involves the recognition of relationships between elements of the data. In the clinical field this may involve remembering typical patterns of disease 
processes and treatment outcomes. Having this information from textbooks does not seem to be as effective for recall as being able to base information on experience with real patients, as in the case of the expert clinician. The patterns become strongly reinforced if typical cases are seen frequently.

A comparison may be drawn between the skills of a superior chess player (as discussed by Simon \& Chase, 1973; Simon \& Gilmarton, 1973) and the expert clinician. The chess player has a number of patterns stored in memory which allows him/her to look at a new scenario and foresee what the outcome of a certain move would be. The clinician would have a parallel ability in relation to new client scenarios. The patterns stored in memory would allow him/her to predict the outcome of a treatment procedure with far more ease than a novice who has not experienced similar situations and therefore does not have the relevant patterns stored. The concept underlying this method is very similar to 'chunking' which is discussed later in this chapter.

(iii) Planning Methods

The problem solver may make a mental model of the end product by picturing the consequences of a plan of action. Alternatively he/she may use a solution to a previous problem as an analogy to develop a plan of the steps that should be taken to solve the new problem. Abstraction is another planning method in which the original problem is simplified to obtain a related but easier one. If this simpler problem can be solved, its solution can be used by analogy as a plan for solving the original more complex problem. Much of the evidence for this explanation of problem solving as a searching process is based on mathematical examples (eg. Kohler, 1925; Greeno, 1974; Reed, Ernest \& Banerjii, 1974; Hayes \& Simon, 1976). Logically the same processes should 
apply to clinical settings, especially the planning by analogy where solutions to previous clinical dilemmas are used as a guideline for solving a present problem.

iv) Means-end Analysis (working backwards from the desired goal)

The steps involved are to first find the differences between the goal state and the current situation, find an operation that is relevant to that difference, then apply the operation in an attempt to reduce the difference. These steps are then repeated until the problem has been solved. This requires more knowledge than 'working forwards' as the problem solver has to have knowledge of operations that will effectively relate to the goal before success can be achieved. For example, if an occupational therapist is presented with a client who, although severely disabled, desperately wants to go home, the therapist would need to know what environmental modifications are possible and community support systems available, before the goal could even be considered.

\subsection{The Role of Memory}

As can be seen in the above discussion, memory plays an important role in problem solving as the solver relies heavily on past experience. Problem solutions require transformation of incoming data through interaction with information retrieved from memory.

Greeno (1974) proposed a memory model for problem solving based on the long established concepts of short term and long term memory. 
Short term memory (STM): This is a temporary storage device for holding information briefly (it may only be a few seconds) before it is either discarded or encoded in a way that enables it to be more permanently stored in long term memory (LTM). Before information can be transferred from STM to LTM, connections need to be made between the new information and information already stored in LTM. STM acts as a kind of filter for incoming information.

Long term memory: Unlike STM, LTM has an unlimited storage capacity which can hold information for very long periods - years or even decades. Hayes (1989) describes three processes in LTM: encoding, storage, and retrieval. The first of these is the process whereby information is transferred from STM to LTM (as above), storage refers to the systems that people have for structuring information in LTM, and retrieval is the means by which information is accessed and retrieved for use when needed.

In addition to STM and LTM, Greeno (1974) proposes a third facility which he calls working memory. This covers the processing that takes place when information from short and long term memories interact, for example, to generate and test a solution route to a problem. For a period of time, a mental representation exists which is undergoing development or transformation but which is not yet consolidated for long term storage. However, aspects of the mental representation may be retained in LTM thus enabling a person to pick up a problem from where they last left it off.

From the viewpoint of problem solving, the internal representation of the problem initially occurs in working memory, including the construction of links between the givens and the unknowns. Relevant past experience is used to modify the structure held in working memory. Eventually the mental 
representation moves into LTM as it becomes clarified and related to existing structures. In the process it will modify or expand what is held in LTM.

Greeno (1973) has also argued that the solution to a problem is often found through the retrieval of relational properties (connections between ideas in LTM), not just the retrieval of facts. In this way the unknowns in a problem are connected to the givens. He suggests that there are two stages in problem solving:

1. The first stage is the construction of a cognitive tree which represents the problem. This is carried out during the initial stages of identifying and understanding the problem and is a structure built into the subjects' working memory.

2. The second stage is the formation of a set of relationships between the problem state and the goal state. The solution plan is a relational network where transformations can change given features or variables into the desired ones. Thus what is required is a set of transformational relations stored in LTM which is then retrieved to construct a network among the problem elements contained in the working memory.

If this is an accurate representation of the memory strategies employed in the problem solving process, then those medical courses that approach their teaching curriculum as 'Problem Based Learning', (for examples see Barrows \& Tamblyn, 1980; Boud, 1985; Balla, Gibson \& Chang, 1989), would seem to put their students at an advantage when solving clinical problems. Such a scheme where students learn through the experience of solving medical dilemma, encourages the development of cognitive relationships between a range of data 
relevant to clinical problems. In this way the emphasis is on the transforming of data rather than the accumulation of data, as is stressed in the more traditional courses. Such an approach is supported by a study carried out by Norman (1988) who claims that clinical expertise is characterised not by superior general problem solving strategies, but the availability of an extensive organised body of specialised knowledge ie. 'experiential' knowledge.

This position is also supported by Fetlovitch (1981) who compared the problem solving skills of clinical experts with fourth year medical students. The expert's knowledge structure was found to be more interconnected and hierarchical than the novice's, thus enabling the expert to entertain more than one hypothesis at a time. In contrast, the novice tended to take a more piecemeal approach, considering only one hypothesis at a time. The novice also failed to demonstrate the ability to organise information hierarchically and to identify the relationships between certain diseases. In a problem solving situation, the novice typically reacted to the latest bit of information without keeping prior information in mind. In short, the novice's structure of knowledge did not allow for efficient management of memory.

The concept of chunking (Miller, 1956) has been used to describe another approach for organising knowledge so that it is able to be recalled easily. Simon and Chase (1973) in their investigation of chess players, showed that chess masters do not have superior visual memory compared to less skilful players, but that they are able to perceive groups of chess pieces, or chunks. The contents of these chunks are closely associated in memory so that once a chunk is accessed the recall of its component parts is rapid. While it was found that the less skilful players also used chunking, the size of the chunks were considerably smaller than that of the experts (1-2 pieces compared to 3-6 
pieces). In other words, the ability of experts to memorise bigger chunks of information enabled them to take account of more chess pieces at a time. Moreover, pieces were grouped in ways that were illustrative of chess knowledge, ie. they constituted common patterns on the chess board.

Differences in chunking between experts and non-experts have been observed in other domains. In electronics, Egan and Schwartz (1979) found that skilled technicians reconstructed symbolic drawings of circuit diagrams according to the functional nature of the elements in the circuits, such as amplifiers, rectifiers and filters. Novice technicians, however, produced chunks based on the spatial proximity of the elements. When Atkin (1980) asked architects to reconstruct building plans from memory, several levels of patterns were produced. First the architects recalled local patterns consisting of wall segments and doors, then rooms and other areas, then clusters of rooms or areas. In other words, the reconstruction process exhibited a hierarchical pattern of chunks within chunks.

The importance of this research is that when experts look at an apparently complicated situation, they are able to represent it in terms of a small number of patterns or chunks. If the situation is very intricate, as with architectural drawings, the experts knowledge is further organised into embedded sets within a hierarchical structure.

Also associated with storing of information is the concept of a schema. Isolated bits of information are vulnerable to being forgotten unless they are integrated with schemas or (as above) chunks. As Neisser (1984) has indicated, there is a tendency to forget loosely ordered bits of information, but information that is part of a well established knowledge system is seldom forgotten. Skemp (1979) postulated that the qualities of schemas are crucial determinants of success in 
problem solving. Such qualities might include the relevance of the content to the task in hand, the strength and quality of the connections, the extent of its domain and how well it represents the reality within this domain as well as how well it can assimilate new knowledge.

Skemp considers that a schema is a highly abstract concept which combines both knowledge and beliefs in such a way that they become a basis for planned action. Such plans can be intuitive or reflective, or a combination of the two. However, a good understanding of both the present state and goal state is considered a prerequisite for appropriate action.

For students to effectively use heuristic processes, they need to have built up patterns of knowledge about scenarios that they can readily recall and apply to new situations (see pattern matching, planning methods, chunking and schema). Furthermore they need to have adequate knowledge and skills that allow them to offer solutions for problems thus avoiding toying with trial-and-error type problem solving and enabling them to use more sophisticated procedures, such as means-end analysis. However, as already stated, this study will be concerned with the more basic issue of how students and clinicians represent problems; this requires consideration of the client, the goal of treatment, the actions that can be taken and the restrictions on such actions.

\subsection{Summary of the Discussion}

As the above discussion has highlighted, one of the critical issues in the process of problem solving is the initial representation of the problem. Elstein, 
Schulman \& Sprafka (1978) argued that in medical problem solving, hypothesis generation was a psychological necessity because of...

"the complexity of the clinical situation, the enormous amount of data that was potentially obtainable and the limited capacity of working memory" (p 9).

Elstein concluded that an efficient way to solve diagnostic problems was to transform them from an unstructured to a structured format by generating a small set of possible solutions - the hypotheses (or medical diagnosis).

Before the hypotheses can be generated however, there is a process whereby relevant information regarding the current situation is identified and prior knowledge and experience recalled. This data sorting process is characterised in the information processing paradigm as the interaction between the solver and the task environment. The result is an internal model of the problem. This problem representation is considered to incorporate the solver's interpretation of the initial situation, the perceived goals, the potential operators, and the restrictions on these operators (Hayes 1978). Another factor that influences this internal representation is the quality of the problem solver's schemata. These, according to Skemp (1979), contain both knowledge and beliefs.

The ability to recall information from memory is crucial to accurate representation of the problem. Use of previous knowledge is necessary in various aspects of the initial state and in conceptualising both the goals and the operators. A major issue that arises from the literature is the need for this knowledge to be organised in such a way that relationships between elements of information are developed, for example, into schemata or by chunking. 
Greeno (1973) suggests the existence of a working memory (in addition to STM and LTM) which processes information from short and long term memories so as to generate and test a solution route to a problem. From the viewpoint of problem solving, the internal representation of the problem initially occurs in working memory, including the construction of links between the givens and the unknowns. Relevant past experience is used to modify this representation. Eventually the representation moves into LTM as it becomes clarified and related to existing structures.

Figure 4.1 depicts a model of problem solving in occupational therapy. It illustrates the elements of both the problem representation (the understanding process) and the solving process, including the relationship between the two. In problem solving the understanding of the initial situation is of prime importance and this has been emphasised by allotting this aspect independent status. Both familiarity with the environment and knowledge base will influence the problem solver's understandings of the data in the first instance. (The data being referred to is considered to be that available prior to seeing the client.) From the understandings of this initial situation the problem solver develops potential goals and actions that can be taken to solve the problem (within the boundaries of the known restrictions in the scenario). This process takes place in the working memory initially where knowledge from the long-term memory is recalled and linked with the information in the current situation. 


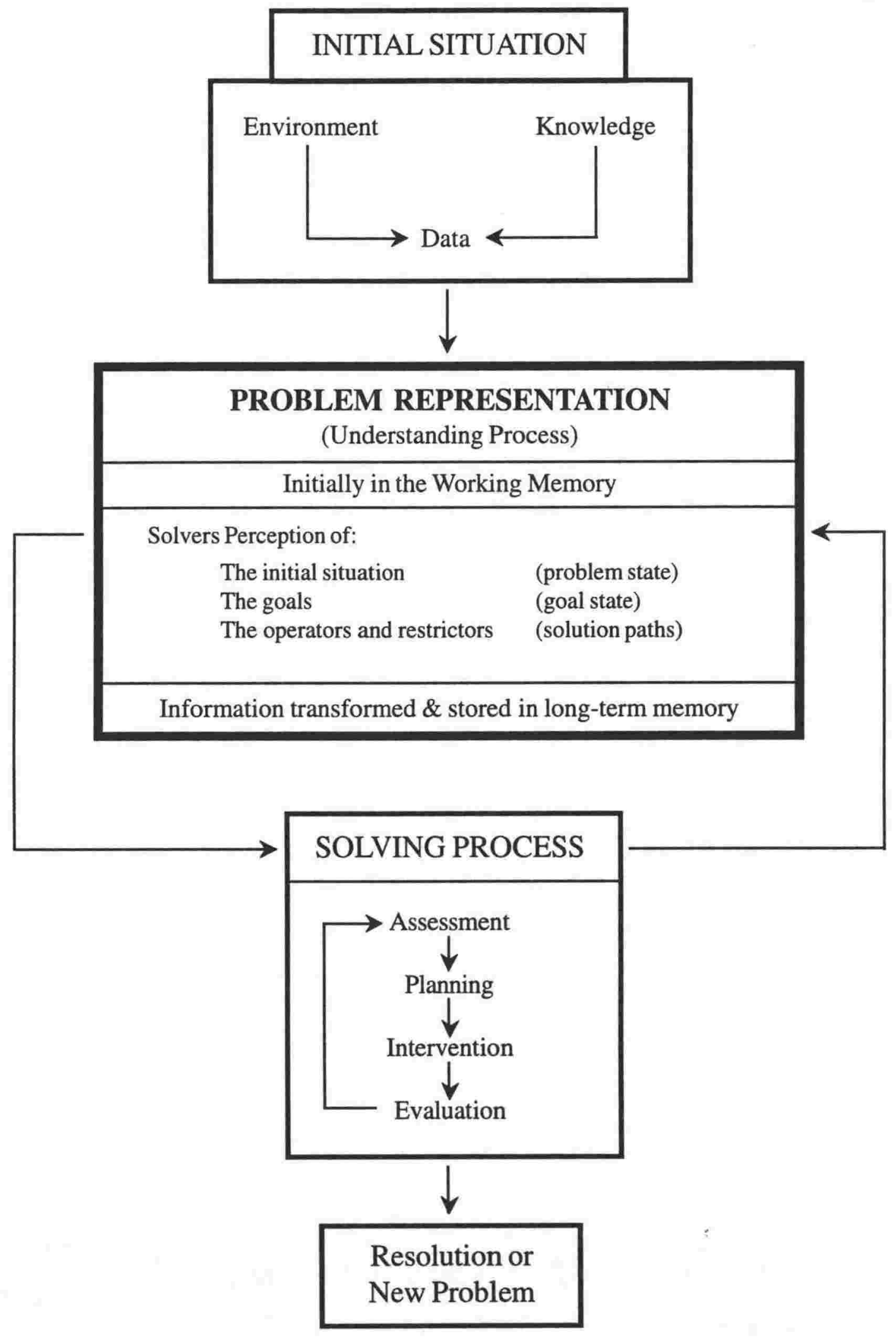

Figure 4.1 A model of problem solving in Occupational Therapy 
The solving process (in the clinical setting) involves carrying out assessments which will give a greater understanding of the elements of the data, planning and conducting intervention procedures, and evaluating the outcomes of these interventions. This process is illustrated as being linear but in reality it is an inter-related process where, for instance, all elements can be employed simultaneously during an intervention procedure. The problem representation is constantly being challenged and reformulated as new data from the solving process becomes available. Thus the mental representation undergoes transformation which in turn alters the information stored in long-term memory. In occupational therapy new data can arise from sources such as ongoing treatment sessions, assessments and the client's sharing of information as rapport develops. Finally, the problem solving process ends in either resolution or the emergence of a new problem which would lead to the development of a new mental representation.

The main purpose of this model is to focus on the key issues that will be investigated in the present study. One of the aims of the present research will be to develop a more comprehensive picture of problem representation in occupational therapy. The problem representation that is being investigated in this study is not the original formulation when first gathering data on a client, rather it is a representation that has been refined by time and experience with the client. 


\subsection{Hypotheses}

Three major themes being explored in this study that are pertinent to problem representation are (i) the environmental influences, (ii) the differences between novices and experienced clinicians, and (iii) the beliefs that govern the problem solver's internal representation of the problem situation. In keeping with these themes, two hypotheses have been developed that address issues relevant to the environmental influences, two relate to experiential differences and a final one relates to the beliefs that are held by the respondents.

H 1. That longer term settings will generate more data about the client compared to short term settings.

This seems obvious, yet there is no literature to support this hypothesis. This study will be able to make the relevant comparisons between these two types of settings (ie. long-term: rehabilitation and paediatrics; short-term: acute and community settings).

H 2. That the environmental context will influence the nature of the problems and treatment outcomes.

Subjects were in a variety of settings - hospital, community, schools enabling comparisons to be drawn between the different settings.

H 3. That direct connections between hypotheses and treatment outcomes will be more evident in the clinicians' thinking than in the students (ie. clinicians will have a more complete problem representation). 
The literature indicates that experts have a well organised body of knowledge, and in comparison to students, are better able to identify correct hypotheses in respect of clinical problem solving. This study can address this issue by comparing the extent to which clinicians and students are able to link problem to outcomes.

H 4. That compared to students, clinicians will be more likely to take a client centred focus.

This particular aspect is a current issue in the profession which is pertinent to the increasing demands for accountability and client satisfaction within the health service. It has also been identified as a significant aspect of the experienced clinician's perspective in recent studies in clinical reasoning in occupational therapy (Crepeau, 1991). The students' and clinicians' interviews can be analysed to identify if such differences exist.

One further hypothesis was developed that would enable the work to be embedded in the occupational therapy literature. This addressed the issue of the parameters within which occupational therapy was being viewed. As described in chapter Two, Mosey (1981) has developed five assumptions that she considers to represent the profession's orientation towards the provision of services. It was considered that the subject's understanding of his/her professional role, would have a bearing on how the problem representation was developed (ie. it is part of the knowledge base that the problem solver draws on). 
H 5. That the beliefs of the participants concerning occupational therapy treatment would be consistent with the assumptions identified by Mosey (1981).

The subjects in the present study represented a wide range of expertise and practice areas. This would enable the researcher to investigate the concepts held by a large group of subjects who were involved in the practice of occupational therapy and to consider any differences between the student and clinician groups. 


\section{CHAPTER FIVE}

\section{METHOD AND SAMPLE}

\subsection{Introduction: The Problem Solving Context}

To investigate the problem solving process in occupational therapy, students and clinicians were interviewed with a view to understanding how they thought through the dilemmas that confronted them in regards to the treatment of clients. Initially students only were to be interviewed, but after reviewing the literature it was decided to interview clinicians as well to highlight the developmental nature of the problem solving process.

Studies that deal with problem solving in the clinical setting often use simulated case studies or videos of clients in order to have a standard problem to which students and clinicians can respond. In this way the data is readily comparable from one interviewee to another. As mentioned in Chapter One, it was felt that the clinical environment itself was influential in the way in which problems are solved (especially in regards to restrictions on the operators). To eliminate environmental factors would make the study an academic exercise only, with limited application to student education. Therefore, with the objective to explore real clinical situations, the interviewees were each asked to focus their thoughts on one client whom they knew particularly well (in most instances they had worked with the client over a four week period at least) and the interviewer explored their thinking in relation to the management of this one client. 


\section{$5.2 \quad$ Subjects}

CLINICIANS: Permission to approach staff was obtained from charge occupational therapists in the larger hospitals in the Wellington area. This was followed up with a visit to staff meetings which allowed the purpose of the interviews to be explained and volunteers to be asked for. Times and dates for the interviews were established during these sessions. Further interviews were established with therapists working in smaller institutions and settings that were community based. A total of 22 occupational therapists were interviewed. This represents about two thirds of the number of therapists who attended the staff meetings; it is not possible to say whether those who volunteered were representative of the group overall.

STUDENTS: To give a balance between practice areas (physical and psychiatric dysfunction, community and hospital environments, etc.) all students in placement in the Wellington central area and at a large psychiatric institution (Porirua Hospital) were approached and asked to participate. This included both stage II and stage III students with the number of stage III students being greater as they were on placement on three occasions during the year compared to twice for the stage II students. It should be noted that there were no stage I students at the School of Occupational Therapy in Wellington at this time because the School was in the process of being closed and new schools being established in Dunedin and Auckland. This was not thought to be a problem because first year students would not have worked with a client over a sufficient length of time from which to draw valid conclusions.

All students agreed to participate, however, some interviews were missed due to illness, pressure of work and, on one occasion, a technical fault when the tape 
recorder did not function. A total of 45 students were interviewed: 14 stage II students and 31 stage III students.

Students placements last for a six week period. To enable students to become familiar with the nature of the work, interviews were not conducted until at least the fourth week of placement.

\section{$5.3 \quad$ Settings}

Table 5.1 provides a breakdown of the range of settings that students and clinicians were working in at the time of the interview. Each heading is explained in the following paragraphs.

PHYSICAL: These are settings where the primary area of dysfunction is physical in nature such as orthopaedics, neurology and general medicine.

PSYCHIATRIC: These settings deal primarily with psychosocial dysfunction such as psychiatric illness and mental retardation.

PAEDIATRIC: This is a setting in which children are the recipients of the service. In this study, the occupational therapy service was located in a school, a paediatric unit and in the child's own home.

For the purpose of this study it is necessary to identify the settings where clients are treated over a long period of time versus those where the work involves dealing with a client for a relatively short period (eg. over a one or two week period). 
Table 5.1

The Number of Subjects Working in Each Setting

\begin{tabular}{|c|c|c|c|c|}
\hline \multirow[b]{2}{*}{ SETTING } & \multicolumn{4}{|c|}{ RESPONDENTS } \\
\hline & $\begin{array}{c}\text { STAGE II } \\
N=14\end{array}$ & $\begin{array}{c}\text { STAGE III } \\
\qquad \mathrm{N}=31\end{array}$ & $\begin{array}{l}\text { CLINICIANS } \\
\mathrm{N}=22\end{array}$ & $\begin{array}{c}\text { TOTAL } \\
\mathrm{N}=67\end{array}$ \\
\hline \multicolumn{5}{|l|}{ PHYSICAL } \\
\hline ACUTE & $2(14 \%)$ & $3(10 \%)$ & $4(18 \%)$ & $9(13 \%)$ \\
\hline REHABILITATION & $3(21 \%)$ & $9(29 \%)$ & $9(41 \%)$ & $21(31 \%)$ \\
\hline COMMUNITY & - & $4(13 \%)$ & $1(5 \%)$ & $5(7 \%)$ \\
\hline SUBTOTAL & $5(36 \%)$ & $16(52 \%)$ & $14(64 \%)$ & $35(52 \%)$ \\
\hline \multicolumn{5}{|l|}{ PSYCHIATRIC } \\
\hline ACUTE & $3(21 \%)$ & $3(10 \%)$ & - & $6(9 \%)$ \\
\hline REHABILITATION & $5(36 \%)$ & $8(26 \%)$ & $7(32 \%)$ & $20(30 \%)$ \\
\hline SUBTOTAL & $8(57 \%)$ & $11(36 \%)$ & $7(32 \%)$ & $26(39 \%)$ \\
\hline \multicolumn{5}{|l|}{ PAEDIATRIC } \\
\hline & $1(7 \%)$ & $4(13 \%)$ & $1(5 \%)$ & $6(9 \%)$ \\
\hline SUBTOTAL & $1(7 \%)$ & $4(13 \%)$ & $1(5 \%)$ & $6(9 \%)$ \\
\hline
\end{tabular}

$\mathrm{N}=$ number of respondents, eg. 14 stage II students. The unbracketed number is the number of respondents in a particular category eg. 2 respondents from the stage II group were located in physical acute settings.. The bracketed number is the perceentage of the total respondents group eg. 2 respondents is equivalent to $14 \%$ of the stage II group

Both the physical and psychiatric settings can be further subdivided into acute care and rehabilitation. In acute care, clients are seen for a short period of time and may either be discharged or referred on to rehabilitation or community based settings. In rehabilitation settings clients will be seen for longer periods of time, this may include outpatient involvement. The paediatric sevice is also long-term in nature with children often being treated over a period of years. 
Community based work in physical settings is frequently relatively short term where the work consists of assessment visits only, with treatment being preventative in nature and ensuring safety in the home environment. On the other hand, there may be involvement with a client over a very long period of time, especially if he/she has a progressive disorder. Even in this situation, the work stops and starts as new problems arise and are dealt with, rather than it being a continual ongoing process as in the settings that have been designated, 'rehabilitation'. Therefore 'community' is considered to be a short-term setting in this study.

\subsection{The Interviewer}

All interviews were conducted by the author of this study. At the time of the study, the author was employed as a fieldwork tutor by the School of Occupational Therapy in Wellington. This job entailed supervision of students while they were on fieldwork practice in the Wellington area. It was emphasised that the interview had no bearing on the outcome of the students clinical placement, that is, their responses would not affect their final evaluation in the placement. 


\subsection{The Interview}

The main concern was that the interview should yield data that could be analysed in relation to the information processing model given in Chapter Four (see Figure 4.1). To this end, a pilot study was undertaken in July 1989 with 18 subjects to test the effectiveness of interview questions in eliciting information on how subjects represented and analysed the client's problem(s). These interviews were taped and transcribed for analysis. Following these trials the interview questions were modified in order to ensure that the information given was consistent with the information processing model of problem representation.

In the pilot study some questions required recipients to discuss treatment procedures and in this way were delving into the solving process which was not the primary focus of this study. For instance, one question was "How did you go about deciding which treatment procedures would be appropriate?" followed by a second question, "Was any part of this difficult? Why?" Typical responses described the treatment procedures and often gave quite simple answers such as "I looked back at what she had done previously.......and asked her what she was interested in." Many respondents did not consider the process of deciding on treatment procedures to be difficult. For example, one student said that her strategy was to look back on the files and "seeing what had worked before and reenforcing those procedures rather than coming in and changing completely what she (the client) had done previously." Neither of these questions tended to give more information on how the respondents perceived the issues, rather they lead to a more pragmatic discussion about what actions were taken. Furthermore the reasons for the choice of actions often seemed to be based on what was an 
accepted course of treatment rather than on a conscious decision making process based on an understanding of the problem being addressed. Because these particular questions did not prompt answers which gave an indication of how students viewed the problem situation they were not considered appropriate for this study.

A further question was modified for inclusion in the final study. Originally it reas "How satisfactory do you think these treatment procedures will be?" This question encouraged a discussion on how the goals were being reached rather than identifying what the actual goals were. As the individual's perception of the goal is a crucial aspect of problem representation, the question was modified to explore this issue more directly (Table 5.2, question 3 ).

From the pilot study five questions were developed to tease out each subject's representation and analysis of the problem situation. After a small number of interviews with stage II students, a sixth question was added to investigate the subject's understanding of any restrictions that might influence treatment. Only six of the stage II students answered this question.

The final interview schedule is given in Table 5.2; it should be noted that additional probing questions were asked when necessary to clarify a subject's response. 
Table 5.2.

Interview Questions

Q1: What problems did you identify as important for occupational therapy intervention?

Q2: Which problem area(s) took priority in your planning? Why?

Q3: In your evaluation, what would be a satisfactory treatment outcome? That is, what should be achieved?

Q4: What are the main benefits to the client/patient? What will he/she get out of your intervention?

Q5: What criteria do you think should be met before he/she is discharged?

Q6: How effective do you think the treatment procedures are for this client? Given an ideal world, is there anything you would like to change? (If so what and why, if not, why not ie. why are the present procedures effective?)

Questions one, two, three, five and six all asked for information that clarified how the interviewee represented the problem, that is, how the subject viewed the initial situation, the goal, the operators and the restrictions on these. Question 2 provided information on the beliefs governing treatment decisions by asking the subject to explain why one (or more) of the client's problems was considered to be a priority for treatment. Question four was included to get further information on how well the subject looked at the problem from the client's perspective (ie. the goal state from the client's perspective).

Table 5.3 lists the questions used in the interview and indicates beside each question, the issues that were addressed in respect of the internal representation of the subject's problem thus showing the link with the model given in chapter four 
(Figure 4.1) Furthermore, the relationship between the hypotheses and each of the questions is also indicated.

Table 5.3.

Link Between the Model, the Hypothesis and the Interview Questions

\begin{tabular}{|lll|}
\hline \multicolumn{2}{|c|}{ PROBLEM REPRESENTATION } & \\
\hline SURVEY QUESTIONS & FOCUS & $\begin{array}{l}\text { HYPOTHESES } \\
\text { ADDRESSED }\end{array}$ \\
\hline Q1 (Problems for OT Intervention) & Problem state & $\mathrm{H} 1, \mathrm{H} 2, \mathrm{H} 3$ \\
Q2 (Priority and Why ) & Problem state & $\mathrm{H} 1, \mathrm{H} 2, \mathrm{H} 3$, \\
Q3 (Treatment Outcomes) & Beliefs & $\mathrm{H} 4, \mathrm{H} 5$ \\
Q4 (Benefit to Client) & Goal state & $\mathrm{H} 2, \mathrm{H} 3, \mathrm{H} 4$ \\
Q5 (Discharge Criteria) & Goal state & $\mathrm{H} 3, \mathrm{H} 4$, \\
Q6 (Effectiveness of Treatment) & Goal state & $\mathrm{H} 2, \mathrm{H} 3, \mathrm{H} 4$ \\
\hline
\end{tabular}

In 1990, students were interviewed and recorded while they were on six week clinical placement blocks. Approximately nine students were interviewed during each six week placement.

Prior to the interview, the subject was asked to identify a client with whom they were familiar. For students this would be someone they had been allocated to work with, whereas clinicians were asked, where possible, to identify not only someone they knew well, but also someone who was typical of their case load. All interviewees were given the option of having the case notes with them. The first questions was always preceded by the statement ... "Now in relation to the client you have in mind. . ". 
Prior to the interview taking place, all questions were reviewed with the interviewee to check the relevance of the questions; for instance, question five, dealing with discharge, was not always an option for the client. This procedure enabled subjects to feel confident that they would not be asked awkward or inappropriate questions. Basic data such as the interviewee's age, years of experience of clinicians, and the setting in which subjects worked, were noted prior to the interview.

\subsection{Interview Analysis}

The method of dealing with the data was to search for common themes within each question and then look for relationships between questions. In the process, any differences in orientation between the three respondent groups or arising from the settings in which individuals worked, were examined. The data was analysed in relation to the five hypotheses identified in Chapter Four.

In addition, question two was analysed using Voss's (1983) modification of Toulmin's (1958) information processing analysis of arguments. The aim of this analysis was to identify the underlying beliefs or principles, often implicit, held by subjects in relation to the interventions they implement. This method of analysis focuses on three elements: the data which the subject uses to support an argument, the claim that is made from the argument, and the warrant $(s)$ or rationale which are applied to the data to produce the claim. The critical feature for this study are the warrants held by subjects to justify their choice of problem priority; this reveals the kinds of principles - implicit as well as explicit - that 
subjects call upon to justify their treatment decisions. More information is given in Chapter Seven with the presentation of results.

To throw further light on hypotheses three and four, the interviews were further analysed using a qualitative approach. The following issues were explored - the logic between the problems, outcomes and beliefs, the extent to which rationales were provided to explain the responses and the ability of the respondents to show an understanding of the human dimension of the problem.

\subsection{Coding of Subjects}

Subjects are classified in the results chapters of this thesis on the following basis:

$$
\begin{aligned}
& \mathrm{A}=\text { Stage III students } \\
& \mathrm{B}=\text { Stage II students } \\
& \mathrm{C}=\text { Clinicians } .
\end{aligned}
$$

Thus the code A/4 refers to student four of the stage III group; similarly, C/10 is the tenth clinician in the study.

\subsection{Validity of Results}

Any research needs to address the two questions of reliability and validity. Reliability is dealt with in the next section.

In general terms, validity focuses on the notion of 'fitness for purpose', that is, that the methods used to achieve the results are appropriate and give information that is 
a true commentary on the way people think, act or behave. For this research, two features of validity need to be considered:

- Validity of the interview schedule;

- Validity of the model (see Figure 4.1) and processes used to analyse data.

The first of these has been dealt with through the pilot study. This study provided a basis by which questions could be refined or replaced in relation to their capacity to yield information of relevance to the model and hypotheses under analysis.

The validity of the model and processes used to analyse the data is harder to assess. One test to be used is whether the information provided enables useful conclusions to be drawn, that is, information which expands both our theoretical and practical understanding of how students solve problems in an occupational therapy setting. It is important therefore that the model under analysis is derived from a sound evaluation of the literature and is able to be used or adapted to the present context. Chapter Four deals with this aspect of validity. In addition, the model and processes used should be able to distinguish between different groups in a way that reflects their level of development in the subject. The data should also meaningfully address the hypotheses under consideration and indicate the way in which teaching practice can be developed to improve student learning. The final chapter re-assesses the validity of the model under analysis.

\subsection{Establishing the Reliability of the Coding System}

The reliability for the coding of responses to each question was established in two steps. The first stage was a clarification of the classification of the data and the 
second was a procedure to enhance agreement between the researcher and an independent rater.

\section{Stage One:}

The rater was given:

i) Definitions for the four 'performance components'.

ii) The responses from the clinicians $(\mathrm{N}=22)$.

The rater was asked to categorise all the 'performance component' problems from question one into the four given categories.

Results: For the four categories, the following rate of agreement with the researcher was reached:

$\begin{array}{ll}\text { Sensorimotor: } & 59 \% \\ \text { Interpersonal } & 40 \% \\ \text { Cognitive } & 67 \% \\ \text { Intrapersonal } & 71 \% \\ \text { Overall } & 56 \%\end{array}$

Some of the difficulties were caused by a misunderstanding of technical words eg. dysphagia. However, most of the inconsistencies were due to definitions lacking clarity.

\section{Stage two:}

All definitions were rewritten and expanded to ensure that the content of the categories were clear and the boundaries well defined. To overcome the issue of technical words posing difficulties in establishing the correct categories, a rater who was an occupational therapist was chosen for this second phase. The rater was given:

i) A definition of all categories of the data. 
ii) Six complete interviews which were selected on the basis of representing the three respondent groups and the three major settings (physical, psychiatric and paediatric).

Results:

There were a number of discrepancies following the rater's initial analysis of the data (see Table 5.4). Following discussion it became apparent that the rater had a tendency to interpret the respondents intentions rather than work with the data that was actually given ie. assumptions were made based on the rater's knowledge of occupational therapy. A second reason for the discrepancies was a computer error in which two categories of the data from question six were combined, making it appear as one category only. A third reason for differences were due to mistakes ie. in some instances data was unintentionally recorded in the wrong category. These problems were then rectified and the entire procedure repeated. The results of the re-classification are given in Table 5.5.

Table 5.4

Agreement Between Raters: Initial Rating

\begin{tabular}{|llllllll|}
\hline QUESTION & Q1 & Q2a & Q2b & Q3 & Q4 & Q5 & Q6 \\
AGREEMENT & $63 \%$ & $100 \%$ & $30 \%$ & $56 \%$ & $67 \%$ & $67 \%$ & $63 \%$ \\
\hline
\end{tabular}

Table 5.5

Agreement Between Raters: Second Rating

$\begin{array}{llllllll}\text { QUESTION } & \text { Q1 } & \text { Q2a } & \text { Q2b } & \text { Q3 } & \text { Q4 } & \text { Q5 } & \text { Q6 } \\ \text { AGREEMENT } & 88 \% & 100 \% & 100 \% & 100 \% & 67 \% & 100 \% & 100 \%\end{array}$


In all, four discrepancies, one from each of four of the six interviews, were found (see Table 5.5). The ensuing discussion of the intention of the respondents resulted in the researcher changing the categorisation of three of these items to eliminate the potential ambiguity. However on the fourth item it became apparent that the interpretation of both researcher and rater were valid and that the response needed to be classified into two categories.

Based on this exercise, the classification of responses for other interviews was modified to improve the reliability of the coding.

In relation to the qualitative analysis of interview data, the coding of responses was initially done by the researcher. The classification of fourty seven of the sixty seven interviews were given to a rater with a psychology background who, in consultation with the researcher, suggested modifications to some of the coding. The modifications eliminated minor sources of ambiguity between researcher and rater. The researcher then recoded the data for the remaining twenty interviews.

\subsection{Statistical Analysis}

Chapters 6-11 analyse each of the research questions in turn, classifying responses according to particular categories (eg. cognitive, interpersonal). Statistical analyses have been undertaken using chi-square because the data is in the form of nominal categories and the purpose of the analysis is to indicate whether differences exist between groups in such features as the response rates and the number of problem categories. 
To assist statistical significance the conventional 0.05 level $(\mathrm{p} \leq 0.05)$ has been chosen. For the interest of the reader 0.01 and 0.001 have also been indicated where chi-square values reach this level. In some instances, chi-square analysis were not undertaken simply because the expected cell frequencies were less than five.

In chapter twelve, a different kind of statistical analysis was undertaken in which respondents' responses overall ie. across questions, was categorised according to the following four codes (see chapter 12 for further explanation).

\section{Focus on the problem:}

3 Problems identified in questions one and two are complete, clearly stated and related to outcomes.

2 Some problems are stated but are not complete as more information is given later.

1 No problems identified in response to question one but are identified later in the interview.

$0 \quad$ Problems never identified.

\section{Focus on the Outcomes:}

3 Clearly focussed, logical progression from problems to outcomes and the beliefs are consistent with this progression.

2 Outcomes are stated but are not all related to the initial problems.

1 Outcomes appear unrelated to the initial problems.

$0 \quad$ No outcomes mentioned. 


\section{Elaboration:}

3 Provides justification for claims, descriptive responses to questions.

2 Attempts some justification for claims, may need to be prompted to do this.

1 Does not attempt any justification, answers questions in a matter-offact way without explanations.

$0 \quad$ Not applicable.

\section{Human Dimension:}

3 Provides a clear sense of the personal identity of the client as an individual

2 Gives some sense of the individual as apposed to a general description.

1 Very general. Could have applied to any individual with the given problem.

$0 \quad$ Not applicable.

The groups were then compared using a T test analysis. Again the 0.05 level of significance was chosen as the criteria for significance with 0.01 and 0.001 levels also included for the interest of the reader.

The following chapters ( 6 to 11 ), will analyse the data from the six questions. Each question has been taken in turn and observations made in respect of the information that was provided by the respondents. By contrast, chapter 12 analyses the interviews from a "horizontal" perspective and considers the overview of each of the interviews. 


\section{CHAPTER SIX \\ QUESTION 1: PROBLEM ANALYSIS}

\subsection{Introduction: Classification of Question Responses}

Chapter six is the beginning of the data analysis chapters and includes considerable material in quantitative form. This is to indicate the range of analysis that has been undertaken in these chapters and should not be taken to indicate that qualitative data is considered less important. In subsequent chapters less quantitative material will be presented with the balance located in the appendix.

The response to question one will be discussed in this section, ie. "What problems did you identify as important for Occupational Therapy intervention?"

The problems identified by the respondents were divided into two major categories i) performance components and ii) occupational performance skills. This division is consistent with the occupational therapy literature.

1. Performance Components: these are the elements of human functioning (eg. intrapersonal, sensory motor, interpersonal and cognitive skills) that affect an individual's ability to perform daily living tasks. In occupational therapy, their significance is evaluated in relation to their impact on occupational performance (Kielhofner, 1983). In her description of the domain of concern for occupational therapy, Mosey (1981) considers that the performance components are the core and so should be the primary or first area of consideration in the evaluation and intervention process. 
2. Occupational Performance: as stated by Christiansen \& Baum (1991), this is a reference to...

"the day to day engagement in occupation that organise our lives and meet our needs to maintain ourselves, to be productive, and to derive enjoyment and satisfaction within our environments" (p 27).

In this study, occupational performance skills have been divided into the following major areas: activities of daily living, family interactions, school, work, leisure, social life and time management. This final area refers to the ability to organise time in order that the individual is able to carry out the other activities. In this way he/she can gain a sense of pleasure from being able to participate in normal social roles.

This chapter will initially review the types of problems identified by the respondent groups and then carry out a more detailed analysis of the response categories where differences between the three groups will be identified. The next section will analyse the data in respect of the location that the respondents were in and identify any apparent differences. Finally, the issues that were raised in the data will be further discussed using examples from the interviews to illustrate the earlier findings. 


\subsection{Comparisons Between the Groups}

Table 6.1 is a summary of the types of problems (ie. performance component and occupational performance) that were identified by each of the respondent groups.

Table 6.1

Summary of the Responses given by the Three Respondent Groups

\begin{tabular}{|c|c|c|c|c|}
\hline \multirow[b]{2}{*}{ PROBLEM TYPE: } & \multicolumn{4}{|c|}{ RESPONDENTS } \\
\hline & $\begin{array}{l}\text { STAGE II } \\
\qquad \mathrm{N}=14\end{array}$ & $\begin{array}{l}\text { STAGE III } \\
\qquad \mathrm{N}=31\end{array}$ & $\begin{array}{l}\text { CLINICIANS } \\
\qquad \mathrm{N}=22\end{array}$ & $\begin{array}{l}\text { TOTAL } \\
\mathrm{N}=67\end{array}$ \\
\hline $\begin{array}{l}\text { PERFORMANCE } \\
\text { COMPONENT }\end{array}$ & $18(1.29)$ & $33(1.06)$ & $32(1.45)$ & $83(1.24)$ \\
\hline $\begin{array}{l}\text { OCCUPATIONAL } \\
\text { PERFORMANCE }\end{array}$ & $14(1.00)$ & $44(1.42)$ & $28(1.27)$ & $86(1.28)$ \\
\hline TOTALS & $32(2.29)$ & $77(2.48)$ & $60(2.73)$ & $169(2.52)$ \\
\hline
\end{tabular}

$\mathrm{N}=$ number of respondents, eg. 14 stage II students. Unbracketed number $=$ number of responses made in this category eg. 18 responses were made by stage II students in the performance component category. Bracketed number (with decimal points) $=$ mean response rate, eg. the response rate for the performance components was 1.29 for the stage II students (18 $\div 14)$.

Table 6.1 indicates that:

1. The number of problem categories identified per respondent, increases with experience $(2.29<2.48<2.73)$, however, the result is not statistically significant (chi-square $=0.56$, d.f. $=2$, n.s.).

2. The response rates for the two major categories (performance components and occupational performance) varied between the 
respondent groups. The clinicians and stage II students emphasised the performance components ( $1.45 \mathrm{cf} .1 .27 ; 1.29 \mathrm{cf} .1 .00)$ and that stage III students emphasised the occupational performance category (1.42 cf. 1.06). However, a chi-square analysis indicates that the variation between groups is not significant (chi-square $=2.29$, d.f. $=2$, n.s.).

A more detailed analysis of the above responses has been summarised in Tables $6.2 \& 6.3$ below. The responses have been ranked from most to least frequently mentioned. An explanation of the sub-categories used in the tables will occur in the ensuing discussion.

\subsubsection{The Performance Component Skills}

Table 6.2 summarises the responses of the three respondent groups in respect of each of the performance component areas. In this table the figure ' $6(.43 / 33)$ ', for example, means that 6 of the 14 stage II students identified problems that were 'sensory motor' in origin; the response rate for 'sensory motor' is therefore $0.43(6 \div 14)$; given that a total of 18 classifications were made by stage II students for the performance components, $33 \%$ of the classifications made $(6 \div$ $18 \times 100$ ) were for sensory motor problems.

The highest proportion of respondents worked in settings where physical dysfunction was predominant and this is reflected by the highest number of responses being in the sensory motor domain. The problems identified in this category were those that involved motor dysfunction such as restricted range of movement, decreased strength and endurance. In addition, difficulties in the area of sensory integration were also included ie. the individual's ability to co- 
ordinate sensory input with motor functioning in order to produce controlled movement. Reference was made by the subjects to problems such as restricted mobility, weakness or paralysis of an arm/hand and unco-ordinated upper limb movements. A relatively high percentage of the clinician group (50\%) referred to this problem area.

Table 6.2

Summary of the Performance Component Problems

\begin{tabular}{|c|c|c|c|c|}
\hline \multirow[b]{2}{*}{ PROBLEMS } & \multicolumn{4}{|c|}{$\underline{\text { RESPONDENTS }}$} \\
\hline & $\begin{array}{l}\text { STAGE II } \\
\qquad N=14\end{array}$ & $\begin{array}{l}\text { STAGE III } \\
\qquad \mathrm{N}=31\end{array}$ & $\begin{array}{l}\text { CLINICIANS } \\
\qquad \mathrm{N}=22\end{array}$ & $\begin{array}{l}\text { TOTAL } \\
\mathrm{N}=67\end{array}$ \\
\hline SENSORY MOTOR & $6(.43 / 33)$ & $10(.33 / 32)$ & $11(.50 / 34)$ & $27(.40 / 33)$ \\
\hline INTRAPERSONAL & $6(.43 / 33)$ & $7(.21 / 23)$ & $6(.27 / 19)$ & $19(.28 / 23)$ \\
\hline COGNITIVE & $3(.21 / 17)$ & $8(.24 / 26)$ & $8(.36 / 25)$ & $19(.28 / 23)$ \\
\hline INTERPERSONAL & $3(.21 / 17)$ & $6(.18 / 19)$ & $7(.32 / 22)$ & $16(.24 / 19)$ \\
\hline CONTROL & - & $2(.06 / 6)$ & - & $2(.03 / 2)$ \\
\hline TOTAL RESPONSES & $18(1.29)$ & $33(1.06)$ & $32(1.45)$ & $83(1.24)$ \\
\hline $\begin{array}{l}\text { *NUMBER OF } \\
\text { SUBJECTS: }\end{array}$ & $12(86 \%)$ & $22(71 \%)$ & $17(77 \%)$ & $51(76 \%)$ \\
\hline
\end{tabular}

* Note: This figure refers to the number of subjects who identified performance component problems. A subject may have given responses that were recorded in more than one category.

The next most frequently mentioned identified group of problems were the intrapersonal ones. This category deals with a person's ability to process information in such a way as to view themselves, others and their own life situation realistically. Subjects made reference to poor self-esteem, poor self- 
awareness and lack of motivation. In comparison to the other two groups, the second year students put more emphasis on this aspect ( $0.43 \mathrm{cf} 0.21 \& 0.27$ ). This may reflect the fact that the majority of this group were located in psychiatric settings.

The cognitive problems dealt with decision making, concentration and processing of information. The clinician group had the highest response rate (0.36, cf. $0.24 \& 0.21)$, which might be explained by the possibility that they (the clinicians) could be dealing with more complex cases where cognitive problems are common.

Difficulties in interpersonal skills included inability to communicate because of poor social skills, such as controlling angry outbursts, poor non-verbal skills, or an inability to speak resulting from damage to speech centres in the brain, or the muscles that control speech.

The amount of control that the individual has in his/her life was noted by two students. One student referred to the client as perceiving herself as having an "external locus of control" (A/17). The other student described the client as having "no control over his environment" (A/21); this was due to his inability to physically control his movements.

Table 6.2 indicates that:

1. The breakdown within performance components (sensory motor, intrapersonal, cognitive and interpersonal) differs little across the three groups; the only possible difference is between the stage II students and clinicians on the intrapersonal category (33\% versus $19 \%$ ), but the 
numbers involved are too small to draw a firm conclusion or warrant a more detailed statistical analysis.

2. Overall, clinicians made substantially more responses (1.45) than either group of students (1.29 and 1.06) respectively, but the differences are not statistically significant (chi-square $=1.59$, d.f. $=2$, n.s.).

\subsubsection{Occupational Performance Skills}

As previously stated, these are the daily tasks that individuals are involved in.

The summary of the responses can be seen in Table 6.3.

Table 6.3

Summary of the Occupational Performance Problems

\begin{tabular}{|lcccc|}
\hline & & \multicolumn{2}{c|}{ RESPONDENTS } & \\
PROBLEMS & STAGE II & STAGE III & CLINICIANS & TOTAL \\
\hline & $\mathrm{N}=14$ & $\mathrm{~N}=31$ & $\mathrm{~N}=22$ & $\mathrm{~N}=67$ \\
\hline A.D.L. & $7(.50 / 50)$ & $22(.71 / 50)$ & $13(.59 / 46)$ & $42(.62 / 49)$ \\
LEISURE & $3(.21 / 21)$ & $11(.35 / 25)$ & $2(.09 / 7)$ & $16(.23 / 19)$ \\
SOCIAL & $1(.07 / 7)$ & $4(.13 / 9)$ & $3(.14 / 11)$ & $8(.12 / 9)$ \\
FAMILY & - & $1(.03 / 2)$ & $6(.27 / 21)$ & $7(.10 / 8)$ \\
EMPLOYMENT & - & $4(.13 / 9)$ & $1(.05 / 4)$ & $5(.07 / 6)$ \\
TIME & $2(.14 / 14)$ & $1(.03 / 2)$ & $3(.14 / 11)$ & $6(.09 / 7)$ \\
EDUCATION & $1(.07 / 7)$ & $1(.03 / 2)$ & - & $2(.03 / 3)$ \\
\hline TOTAL RESPONSES & $14(1.00)$ & $44(1.41)$ & $28(1.27)$ & $86(1.28)$ \\
*NUMBER OF & $12(86 \%)$ & $30(97 \%)$ & $17(77 \%)$ & $60(90 \%)$ \\
SUBJECTS & & & & \\
\hline
\end{tabular}

*Note: This figure refers to the number of subjects who identified occupational performance problems. A subject may have given responses that were recorded in more than one category. 
The major area within the label 'occupational performance skills' is classified as 'Activities of Daily Living'. The abbreviation 'ADL' is frequently used by occupational therapists and occurred several times in the interviews. This is an area of work which involves dealing with a broad spectrum of activities considered to be necessary prior to the individual being able to take part in other facets of life, such as work and recreation. ADL includes:

Personal self care - $\quad$ eg. bathing, dressing, feeding and hygiene.

Home making - $\quad$ eg. cleaning, cooking and laundry.

Money management - $\quad$ eg. budgeting, banking and shopping.

Communication - $\quad$ eg. dealing with agencies, shopkeepers, basic reading / writing skills related to self care, home making and money management.

Mobility - $\quad$ eg. negotiating steps, transferring from bed to chair and managing a wheelchair.

Health care - $\quad$ eg. managing pain, stress, medication and diet.

Problems in ADL were the most frequently raised issue by all groups of respondents (response rates of $0.50,0.71$ and 0.59 respectively), accounting for about half (49\%) of the classifications.

Leisure activities were the next most frequently raised issue. This referred to the ability of the individual to engage in activities for the sake of amusement, relaxation or stimulation. Reference was made to aspects such as limited leisure interests, unable to continue previous interests, lack of productive meaningful activity, and lack of leisure skills. It is interesting to note that for some 
respondents, leisure was tied to the need to be productive, ie. as a substitute for work. Quite clearly some respondents saw the extrinsic nature of the activity, such as being productive, to be as important as the intrinsic one which might be for the purpose of relaxation and enjoyment.

Social isolation was the next most frequently mentioned area of concern and dealt with the need for people to have social contacts. Some indicated that a major source of social stimulation lay in the person's leisure pursuits. Social isolation was connected to such factors as: limited social skills, mobility restrictions, high stress levels and poor hygiene.

Family roles and responsibilities raised issues such as the ability of the client to fulfil their roles eg. as a wife, husband or mother. Also mentioned was the carer role ie. the amount of support that family members were able to provide. In some instances the family were seen to need assistance to care for the disabled member.

Time management included issues such as lack of structure in the day, and a need for a change in daily routine because someone was not able to return to work.

Employment refers to the ability to hold down remunerative employment - this may be in either open or sheltered work situations. It encompassed the idea of the work role being important to the individual as well as work skills needing to be practiced. Reference was made to inability to continue in paid employment, the need to identify work interests, the lack of identity caused by not having a job, and sporadic work habits. 
Education refers to the activities of a client relevant to school work. In both instances in this study, the concern was in respect of the client having adequate writing skills. This was only raised by members of the student group which can be readily explained as there were no clinicians interviewed in education settings.

Table 6.3 indicates that:

1. Overall, substantially more responses were made by clinicians and stage III students than stage II, but the results are not statistically significant (chi-square $=1.51$, d.f. $=2$, n.s. $)$.

2. All three groups gave greatest weight to ADL (50\%; $50 \%$ \& $46 \%$ respectively).

3. Some differences exist within occupational performance categories eg. clinicians had a low response rate for "'leisure' and a high rate for "family". However the numbers in the various 'cells' of the table are too small to justify a more detailed statistical analysis.

\subsection{Location of the Respondents}

Table 6.4 is a summary of the two main categories of problems that were generated by respondents with respect to the location in which they were working at the time of the interview. These locations have been grouped in such a way that the long-term and short-term areas of work can be easily identified. In this study, the rehabilitation and paediatric settings are considered to be long-term with the community and acute settings considered as short-term. 
Table 6.4

Summary of the Responses given in each Location

\begin{tabular}{|lcccccc|}
\hline \multicolumn{7}{c}{ LOCATIONS } \\
& \multicolumn{7}{c}{ PHYSICAL } & PSYCHIATRIC & PAEDIATRIC \\
PROBLEMS & Acute & Rehab. & Com. & Acute & Rehab. & \\
& $\mathrm{N}=8$ & $\mathrm{~N}=22$ & $\mathrm{~N}=5$ & $\mathrm{~N}=6$ & $\mathrm{~N}=25$ & $\mathrm{~N}=6$ \\
\hline $\begin{array}{l}\text { PERFORMANCE } \\
\text { COMPONENTS }\end{array}$ & $4(0.57)$ & $28(1.27)$ & $2(0.40)$ & $5(0.83)$ & $33(1.65)$ & $11(1.83)$ \\
OCCUPATIONAL & $10(1.25)$ & $32(1.52)$ & $5(1.0)$ & $7(1.16)$ & $27(1.35)$ & $5(0.83)$ \\
\hline PERFORMANCE & $14(2.00)$ & $60(2.61)$ & $7(1.40)$ & $12(2.00)$ & $60(3.00)$ & $16(2.67)$ \\
\hline SUBTOTALS & & $81(2.31)$ & & $72(2.77)$ & & $16(2.67)$ \\
TOTALS & & & & & \\
\hline
\end{tabular}

The following abbreviations have been used in the table above: Rehab = rehabilitation; Com = community.

Table 6.4 indicates that :

1. The response rates for the three broad categories of location (physical, psychiatric and paediatrics) are much the same $(2.31,2.77$ and 2.67 respectively). However, they differ in respect of their distribution between performance components and occupational performance. The results indicate that physical locations are more associated with occupational performance, paediatrics with performance components while the balance is more even for psychiatric. These results are not statistically significant (chi-square $=3.9$, d.f. $=2$, n.s.).

2. If the 'locations' data is re-organised into long-term (rehabilitation and paediatric) and shorter-term (acute and community) settings, a significant difference in the response rates is observed ( 2.81 for long 
term and 1.74 for shorter-term; chi-square $=6.6$, d.f. $=1, \mathrm{p}<.01$ ). A significant difference is also observable in these two settings in respect of the distribution of performance component and occupational performance skills (chi-square $=3.9$, d.f. $=1, \mathrm{p}<.05$ ). Occupational performance is associated with short-term settings and performance component with the long-term settings.

A more detailed analysis of the responses can be found in Tables 6.5 and 6.6.

The responses have been listed in the same sequences as in Tables 6.2 and 6.3.

Table 6.5

Location of the Respondents and the Performance Component Problems

\begin{tabular}{|lcccccc|}
\hline \multicolumn{7}{c}{ LOCATIONS } \\
& \multicolumn{7}{c}{ PHYSICAL } & PSYCHIATRIC & PAEDIATRIC \\
PROBLEMS & Acute & Rehab. & Com. & Acute & Rehab. & \\
& $\mathrm{N}=8$ & $\mathrm{~N}=22$ & $\mathrm{~N}=5$ & $\mathrm{~N}=6$ & $\mathrm{~N}=20$ & $\mathrm{~N}=6$ \\
\hline SENSORY MOTOR & $4(.5 / 100)$ & $15(.68 / 54)$ & $2(.4 / 100)$ & - & $2(.1 / 6)$ & $4(.67 / 36)$ \\
INTRAPERSONAL & - & $1(.05 / 4)$ & - & $3(.5 / 60)$ & $13(.65 / 39)$ & $1(.17 / 9)$ \\
COGNITIVE & - & $7(.32 / 25)$ & - & $1(.17 / 20)$ & $9(.45 / 27)$ & $2(.33 / 18)$ \\
INTERPERSONAL & - & $4(.18 / 14)$ & - & $1(.17 / 20)$ & $9(.45 / 27)$ & $3(.5 / 27)$ \\
CONTROL & - & $1(.05 / 4)$ & - & - & - & $1(.17 / 9)$ \\
\hline TOTAL & $4(.57)$ & $28(1.27)$ & $2(.4)$ & $5(.84)$ & $33(1.65)$ & $11(1.83)$ \\
*NUMBER OF & & & & & & \\
SUBJECTS & $4(50 \%)$ & $18(82 \%)$ & $2(40 \%)$ & $4(67 \%)$ & $17(85 \%)$ & $6(100 \%)$ \\
\hline
\end{tabular}

*Note: This figure refers to the number of subjects who identified performance component problems. A subject may have given responses that were recorded in more than one category. 
Table 6.5 illustrates that:

1. Not surprisingly, sensory motor problems were most evident in the physical and paediatric settings whereas the intrapersonal difficulties were more apparent in the psychiatric settings.

2. The reorganisation of the data by long-term and shorter-term settings, indicates a significant difference in the response rates, in line with the earlier finding for performance component overall (1.48 for long term and 0.58 for shorter-term; chi-square $=8.70$, d.f. $=1, p<.01$ ).

Table 6.6

Location of the Respondents and the Occupational Performance Problems

\begin{tabular}{|c|c|c|c|c|c|c|}
\hline \multirow{4}{*}{ PROBLEMS } & \multicolumn{5}{|c|}{ LOCATIONS } & \multirow{4}{*}{ PAEDIATRIC } \\
\hline & \multicolumn{3}{|c|}{ PHYSICAL } & \multicolumn{2}{|c|}{ PSYCHIATRIC } & \\
\hline & Acute & Rehab. & Com. & Acute & Rehab. & \\
\hline & $\mathrm{N}=8$ & $\mathrm{~N}=22$ & $\mathrm{~N}=5$ & $\mathrm{~N}=6$ & $\mathrm{~N}=20$ & \\
\hline A.D.L. & $8(1.0 / 80)$ & $15(.68 / \underline{47})$ & $5(1.0 / 100)$ & $3(.50 / 43)$ & $9(.45 / \underline{33})$ & $2(.33 / 40)$ \\
\hline LEISURE & - & $8(.36 / 25)$ & - & $1(.17 / 14)$ & $6(.30 / \underline{22})$ & $1(.17 / 20)$ \\
\hline SOCIAL & - & $2(.09 / \underline{6})$ & - & $2(.33 / 29)$ & $4(.20 / \underline{15})$ & - \\
\hline FAMILY & $2(.25 / 20)$ & $3(.14 / 2)$ & - & - & $2(.10 / 7)$ & - \\
\hline EMPLOYMENT & - & $2(.09 / \underline{6})$ & - & - & $3(.15 / 11)$ & - \\
\hline TIME & - & $2(.09 / \underline{6})$ & - & $1(.17 / 14)$ & $3(.15 / 11)$ & - \\
\hline EDUCATION & - & - & - & - & - & $2(.33 / 40)$ \\
\hline TOTAL & $10(1.25)$ & $32(1.45)$ & $5(1.00)$ & $7(1.16)$ & $27(1.35)$ & $5(.83)$ \\
\hline RESPONSES & & & & & & \\
\hline $\begin{array}{l}\text { *NUMBER OF } \\
\text { SUBJECTS }\end{array}$ & $8(100 \%)$ & $19(86 \%)$ & $5(100 \%)$ & $4(67 \%)$ & $18(90 \%)$ & $5(83 \%)$ \\
\hline
\end{tabular}

*Note: This figure refers to the number of subjects who identified occupational performance problems. A subject may have given responses that were recorded in more than one category. 
Table 6.6 suggests that:

1. ADL problems occur in all locations and contexts (acute, rehabilitation and community). The response rates indicate that $\mathrm{ADL}$ accounts for the majority of problems in the 'acute' and 'community' contexts of the physical locations.

2. The two rehabilitation areas give rise to the greatest range of problems (ie. each covers six categories) and the highest response rates overall (1.45 \& 1.35). Of interest are the percentages for the two rehabilitation columns (underlined for convenience); these show a similar pattern of identified problems across the sub-classes.

3. The re-organisation of the data by long-term and shorter-term settings, indicates that the response rate is higher for long-term than short-term settings, in line with the earlier finding for performance component overall, however this finding is not statistically significant (1.33 for long term and 1.16 for shorter-term; chi-square $=0.23$, d.f. $=1$, n.s.).

4. There is a high degree of agreement on what the problems are in the community setting. All respondents identified only one sub-class, ie. ADL.

5. Paediatric settings are the only ones to identify 'education' issues, however, little can be drawn from this column because of insufficient numbers. 


\subsection{A Further Analysis of the Location of Respondents}

As noted in Table 6.1, clinicians identified more problems than the other two groups, although the difference was not found to be significant. However, given the finding that a significantly greater number of problems was identified in long-term settings, it was decided to look at the response rates of the three respondent groups in terms of long and short-term location. The relevant Tables are 6.7 and 6.8 .

Table 6.7 shows the location of each of the three groups. The distribution is similar for all three groups - all were located more often in long-term settings (chi-square $=0.85$, d.f. $=2$, n.s. $)$.

Table 6.7

Location of Respondents

\begin{tabular}{|lccc|}
\hline & \multicolumn{3}{c|}{ RESPONDENTS } \\
LOCATION & STAGE II & STAGE III & CLINICIANS \\
& $\mathrm{N}=14$ & $\mathrm{~N}=31$ & $\mathrm{~N}=22$ \\
\hline SHORT-TERM & $5(36 \%)$ & $10(32 \%)$ & $5(23 \%)$ \\
LONG-TERM & $9(64 \%)$ & $21(68 \%)$ & $17(77 \%)$ \\
\hline
\end{tabular}

Table 6.8 looks at the response rates for each of the classifications. These show little variation across the three groups in respect of short-term settings $(0.57$ to 0.41 ), however a bigger variation is present in the long-term settings (1.79 to 2.36). Overall, the results in Table 6.8 show no significant relationship between respondent classification and location (chi-square $=1.47$, d.f. $=2$, n.s.). 
Table 6.8

Response Rates of the Respondent Groups by Location.

\begin{tabular}{|lccc|}
\hline & & \multicolumn{3}{c|}{ RESPONDENTS } \\
STAGE II & STAGE III & CLINICIANS \\
LOCATION & $\mathrm{N}=14$ & $\mathrm{~N}=31$ & $\mathrm{~N}=22$ \\
\hline SHORT-TERM & $8(0.57)$ & $16(0.52)$ & $9(0.41)$ \\
LONG-TERM & $24(1.79)$ & $61(1.97)$ & $51(2.32)$ \\
\hline
\end{tabular}

\subsection{Discussion}

The initial question of the interview "What problems did you identify as important for occupational therapy intervention ?" was designed to elicit the 'initial situation' aspect of problem representation. Because respondents were asked to discuss a client whom they had known for a period of time, it was assumed that the basic data would have been sorted and the hypotheses which formed the basis for treatment planning, established. Two indications of difficulties in establishing a clear problem representation would be where there was no obvious problem identified at all, or where there were a great number of problems identified. Both these scenarios could result in the generation of a large number of treatment options. and are evident in this study. They will be discussed in the following pages. Finally, there will be a focus on the major differences highlighted in the statistical analysis of the first question; that of the relationship between the data and the location of the respondents. 


\subsubsection{Problems Not Identified}

In some instances, the problem(s) being dealt with were not identified in response to question one (see Table 6.9 below). Generally this information emerged later in the interview, especially in response to the question asking for the treatment priority. All of the respondents who did not clearly identify problems were located in long term settings (six in psychiatric rehabilitation and two in physical rehabilitation) where there is a great deal of historical data available on the clients and less certainty about outcomes.

Table 6.9

Respondents who did not Identify Problems in Response to Question One

\section{RESPONDENTS}

\begin{tabular}{|cccc|} 
STAGE II & STAGE III & CLINICIANS & TOTAL \\
$\mathrm{N}=14$ & $\mathrm{~N}=31$ & $\mathrm{~N}=22$ & $\mathrm{~N}=67$ \\
\hline $4(29 \%)$ & $1(3 \%)$ & $3(14 \%)$ & $8(12 \%)$ \\
\hline
\end{tabular}

Of the respondents in Table 6.9, most identified outcomes that were important to the client, rather than the problems that prevented the person attaining the particular outcome. For example...

"This person was wanting to go into the community and wanting to get some kind of job ... to find a programme for her to attend would be as high as I could aim for" (C/4: psychiatric rehabilitation). 
"Initially the reason for OT intervention was looking for employment and identifying what she would have to do in terms of getting a job; also to identify what she was interested in doing..." (A/26: physical rehabilitation).

"... what was important to her ... she said she wanted to work in creative arts ... and she enjoys crafts so we looked at that sort of thing ..." (B/4: psychiatric rehabilitation).

One student discussed how she went about collecting the data.

"Well first of all I got the information from the initial interview ... she expressed quite a few things that were pretty important to her, so I sort of worked on that and then thought I'd do an interest check-list and I found out heaps more information after doing that " (B/3: psychiatric rehabilitation).

The fact that some stage II students (29\%) did not clearly identify problems is consistent with the findings in medicine (Elstein, Schulman \& Sprafka, 1978) and elsewhere (see Chapter 4) where it has been shown that novices have difficulty in restricting the problem space. In contrast, it has been reported that experts are able to start with a more accurate hypothesis. However this has not been entirely supported by the data in this study as three clinicians (14\%), also had difficulty in clearly identifying the problems for occupational therapy intervention. The stage III students were able to verbalise most clearly the problem areas with which they were dealing. 


\subsubsection{The Identification of a Large Range of Problems}

This study has identified that the greatest range of problem categories were generated by:

i) Clinicians (see Table 6.1), although the response rates between the three groups were not statistically significant.

ii) Those working in long term settings. The response rates were significant (see Table 6.4).

The identification of a large number of problems raises the issue of how this is represented. The two main methods evident in this study will be discussed disjointed pieces of data or as data where links are made between cause and effect. Such linking can be made at various levels as the following discussion will explain.

Responses where a range of problems are identified can be illustrated by the following quotes from clinicians who were working in the three long term settings.

INTERVIEW QUESTION: WHAT PROBLEMS DID YOU IDENTIFY AS IMPORTANT FOR OCCUPATIONAL THERAPY INTERVENTION?

"The patient was dyspraxic ... had quite a significant receptive dysphasia ... and some neglect on the right side and right homonymous hemianopia ... marked proprioceptive loss on the right side and difficulty releasing objects" (C/18: physical rehabilitation). 
" .... he was really confused and disorientated and didn't know where he was 'cos he'd been moved around a lot in the community ... at the present time he didn't have a major role or function and he's lost ties with his family ... he is also losing his eye-sight and has poor understanding of English ... and (has) low mood ..." (C/5: psychiatric rehabilitation).

"... he was unable to lift his head when he was on the floor ... he was unable to sit alone ... he wasn't developing any exploration of his environment ... his cognitive skills were delayed ... socially he wasn't developing language or social skills with peers ... " (C/14: paediatrics).

In the above examples, the respondents have presented the problems as a series, where they are isolated from one another. As indicated previously some respondents made links between the various bits of information when describing quite complex cases. For example:

"The client had a limited range of movement due to a Colles fracture which she had sustained about a year ago and her main problem for OT was bathing (because) she can't put any weight on her right hand which was affected by the fracture" (A/28 community).

"She's had a CVA so a limited co-ordination between her left and right sides and the complications it results in, just functional ability" (B/11 psychiatric rehabilitation).

"The client had a severe stroke and had all the problems of hemiplegia; hemianopia, left side neglect, apraxias which involved not only dressing, but her mobility and ability to do activities" (C/13 physical rehabilitation). 
In all three examples, links are made between the medical diagnosis (Colles fracture, CVA and 'stroke'), the resulting performance components (can't put weight through right hand, limited co-ordination between left and right sides; hemianopia, left sided neglect and apraxia) and subsequent ability to carry out occupational performance tasks (bathing, functional ability and doing activities).

This method of defining a problem is consistent with Rogers and Holm's (1991) description of an Occupational Therapy diagnosis. They state that such a diagnosis will generally consist of four elements: descriptive, explanatory, cue and pathology. The first component describes the deficit in the occupational performance skills. The second component is an explanation of why this might occur and frequently relates to the performance component deficits. The third component is not apparent in this study and is the evidence that supports the explanation, and the final element is the pathological agent (eg. medical condition) which has had an effect on the skill deficit. The sequence here is interesting as it is given in reverse order by the respondents quoted above, ie. they have begun with the pathological agent, then followed this by the explanatory and descriptive components. As activity is the focus for occupational therapy intervention, it is surprising that a description of this is not mentioned in the first instance.

Some respondents made links between two of the elements only. Of these, some did not include the occupational performance skill. For example:

"He had poor prone extension so that's quite an important factor in his visual tracking and perception" (A/29 paediatric). 
"Lack of belief in their skills and ability to do anything which sort of lead them to having really low self esteem" (B/6 acute psychiatric).

"She has chronic schizophrenia ... and showed very chronic symptoms and lack of motivation and concentration and lack of affect" (C/12 psychiatric rehabilitation).

Other respondents did not make a link back to the origin of dysfunction such as the medical diagnosis but did make links between the performance component and occupational performance skills. For example:

"His main problem was that he had decreased hand function and that meant he wasn't able to hold his cutlery" (A/18 community).

"Unable to grip small objects, like she can but she's having problems with writing, peeling potatoes, even her grip on a pot" (A/16 community).

"His lack of concentration affects his participation in the programme and his organisation of his own day, not only in the programme, but effective use of this own time outside the programme..." (A/10 psychiatric rehabilitation).

Making links between elements of the presenting problems would result in a more restricted problem space compared with not making such links.

Potentially a lack of linking could result in each problem being viewed as a possible basis for treatment and therefore a less restricted problem space. This linking process would be comparable to 'chunking' as described by Miller (1956). He suggests that experience enables people to 'chunk' and so 
deal with more information. This study does not seem to support this idea of chunking being used more by those with experience. On reviewing the data, linking is evident in all three respondent groups as follows:

$\begin{array}{lll}\text { Stage II students } & =5 & (36 \%) \\ \text { Stage III students } & =7 & (26 \%) \\ \text { Clinicians } & =7 & (32 \%)\end{array}$

Another way of presenting the problems was for respondents to present the occupational performance deficits in the first instance. Those who took this approach gave quite concise responses. The following quotes taken from each of the respondent groups illustrate three different approaches to the initial identification of the occupational performance problem.

" Being unable to get in and out of the shower, unable to get on and off the toilet, not having a suitable chair at home to sit in and not having a bed of suitable height to get in and out of" (C/20: physical acute).

In this instance, only the occupational performance problems were mentioned.

"The fact that she has few social interests, she's got a very limited concentration span and that's mainly because she is anxious ... especially with new or pressured situations and she's generally insecure about how people are feeling about her ..." (B/7: psychiatric rehabilitation).

The above is an example of an instance when the occupational performance problem (few social interests) has been related to the performance component deficits (anxiety and limited concentration). 
" The first one (problem) was the ADL, the dressing and the showering and that sort of thing ... we then started working on the balance and using the flaccid arm for more activities, but that was only done because I had the time, whereas a normal therapist wouldn't " (A/1: physical acute).

This respondent identifies the occupational performance problem (ADL) and although the performance component deficits are also identified (poor balance and a flaccid arm), no links are made between these. The latter part of the above statement regarding problems being dealt with, gives an interesting perspective on legitimate treatment from the point of view of a student.

As indicated previously in the chapter, the assumption was made that the basic data would be well sorted as the respondents had been working with the client for a period of time. It was therefore thought that question one would result in a clear statement of the hypotheses on which treatment was based. However, as discussed, a concise reply was not the usual way of responding and, generally, respondents gave more elaborated versions of the problems faced by the client. Such an approach is consistent with Mattingly's (1991) description of narrative reasoning where she considers that occupational therapists are concerned with how the illness experience affects the client's life. The examples given previously in this chapter where respondents identified the client's goals and aspirations rather than stating the 'problems' at the outset, illustrate this type of thinking.

Making judgements about the relevant importance of information is an important concept when endeavouring to represent a problem (Hayes, 1978). Table 6.1 would seem to indicate that the students are more successful at this 
process of eliminating irrelevant information because they identified the smaller numbers of problems. Another explanation might be that they simply failed to respond to all the cues and so their limited number of problems stemmed from an inability to recognise cues rather than to sort the data. Whether or not this is true will become evident when the responses to question three (treatment outcomes) are compared to the initial problems given in question one.

Possibly students are not able to easily take account of all the aspects of a client's situation consequently providing responses that are more focussed than those who are able to take into account a wider range of information. If this is the case, then question two (ie."Which problem area took priority in your planning?") should indicate that students identified a similar number of problems to that given in question one.

\subsubsection{Location of Respondents}

The statistical analysis of the data indicates that differences do exist between those in short-term and long-term settings in respect of problem identification. One such difference is in the range of categories - those in long-term settings identify more than those in short-term locations (Table 6.4).

The other major difference was in the identification of the two major types of problems - occupational performance and performance components. The short term locations were more associated with the occupational performance deficits while those in long term settings were more likely to also consider the underlying performance component problems (Tables $6.4 \& 6.5$ ). As stated above, this could be explained by the fact that those in long term care are more likely to have a greater range of underlying problems, on the other hand the 
explanation may lie in the fact that there is time to consider all deficit areas and not just those that have significance for imminent discharge.

Differences between locations were noted in the distribution between the performance component and the occupational performance categories (see Table 6.4). Those working in physical settings were more likely to identify the occupational performance category, by contrast those in paediatric settings were more attuned to the performance component issues.

An explanation for this difference may be that children are still developing so the focus of treatment is on improving the underlying performance components such as head control. Adults, on the other hand, are less likely to make such great gains in the performance component areas so the focus moves quickly to the aspects that enable the individual to maintain independence. Another explanation might be that the therapist is less skilled in treating performance component deficits. Finally, the demands of the system might be such that there is pressure to discharge clients early so the immediate concern of being able to return the client to their own home takes priority over aspects such as improving control of movement.

In psychiatric settings there was more of a balance between the two categories. In this type of setting the nature of the performance component difficulties is such that they affect cognitive, interpersonal and psychological domains such as self respect. These areas do not readily respond to treatment and are more difficult to compensate for in contrast to the motor defects. Thus a more equal balance between the person's ability to get on with life and the recognition of the underlying difficulties which they might have to constantly live with would seem to be logical. 


\subsection{Summary}

Differences between short-term and long-term locations are evident in the data and confirmed by statistical analysis. There was a significant difference between these settings in both the response rate (higher for long-term compared with short-term) and the category of problems identified. Occupational performance was associated with short-term settings and performance components with the long-term settings.

This initial question, taken in isolation, has not identified major differences between students and clinicians although a possible trend of the number of problem categories increasing with experience has been noted. 


\section{CHAPTER SEVEN \\ QUESTION TWO: TREATMENT PRIORITIES}

\subsection{Introduction}

The responses to the second question will be explored in this chapter. The question was in two parts:

"Which problem area took priority in your planning ? and Why ?"

This chapter will first identify the priority problems and then consider the beliefs that respondents conveyed in response to the question of why they selected a particular problem as a priority.

As in the previous chapter, a range of analyses were carried out and a set of tables prepared which parallel those in chapter six. However, rather than present all of these here and risk burying the essential results in the detail of the tabulated data, only the key information is shown. Appendix A sets out all the relevant tables ie. Tables A.1 to A.6. These correspond to Tables 6.1 to 6.6 in the previous chapter.

\subsection{The Priority Problems}

Despite that fact that some respondents had identified a range of problems in response to the first question, it seemed easy for them to quickly identify the priority issues for the client. Although the majority presented one problem as a priority, a few presented two and even as many as three, as priority problems. Apart from one student who was located in an acute psychiatric area, those 
presenting multiple concerns for the priority were located in long-term care settings, ie. psychiatric and physical rehabilitation and paediatric treatment areas.

As with the results in chapter six, no significant differences were identified between the respondent groups. However significant differences were evident in the distribution of performance components and occupational performances for the three locations of physical, psychiatric and paediatrics and for the long and short-term outcomes (see Table A.4). The physical and short-term settings were associated with occupational performance outcomes, paediatric with performance components while the balance between the two types of outcomes was more even in the psychiatric and long-term locations. There was also a significant difference in the response rates between those in long-term and short-term settings where a higher rate for performance component outcomes was associated with long-term settings (Table A.5).

\subsection{Comparison of General Problems (Q1) and Priority Problems (Q2)}

An assumption made in this study is that question one would identify all the issues that were appropriate for occupational therapy intervention and question two would identify the problem(s) that was used as the basis for treatment planning. Such an assumption would be consistent with information processing theory, ie. treatment plans are the 'solution paths' which are based on a 'hypothesis' (ie. priority problem) which arises from the data in the given situation.

The following observations can be noted in respect of the three respondent groups: 
1. As would be expected, a comparison of Tables 6.1 and A.1 indicates that the three respondent groups show an overall decrease in response rates in the second question.

2. The response rates are lower for stage II students compared with the stage III and clinician groups in both questions (see Tables 6.1 \& A.1). It was proposed in chapter six, that stage II students might be more focussed and if this were the case the response rate should have been similar for both questions. This, however, is not the case ie. the response rate moved from 2.29 for question one to 1.06 for question two. Another explanation might lie in the notion that stage II students are less able to elaborate on their responses and in general give less information.

3. The stage III students put an emphasis on the occupational performance categories in both questions (see Tables 6.1 \& A.1). The orientation of the stage III group towards the occupational performance category might indicate that current educational trends have influenced their thinking. For example, recent trends in education have favoured the use of the Model of Human Occupation (Kielhofner, 1985) as an approach to treatment planning. Many clinicians would be more familiar with a medical model approach which would influence their identification of problem areas in favour of performance component issues. However, this trend in students is not evident in the stage II group - perhaps they take cues from the clinicians and as yet are unable to think independently or are less able to make use of theoretical notions of treatment.

The location data indicates that there is a difference in the distribution of the performance component and occupational performance categories ie. physical was 
associated with occupational performance problems, paediatrics with performance components and psychiatric settings had a more even balance between the two categories. This was a trend in Table 6.4 but became significant in Table A.4.

When divided into short and long-term locations, the response rate was higher for the long-term locations. This finding was significant in Table 6.4 but when focussed on the priorities it lost significance but the trend was still noticeable (see Table A.4). An aspect that remained significant over both questions was the association of the short-term settings with the occupational performance category. The long-term settings were associated with performance components in Table 6.4 but in Table A.4 demonstrated more of an even balance between the two categories.

Comparisons can be made between the reported performance component problems in Tables 6.5 \& A.5. In the long-term settings, both tables indicate that the responses are more varied and the response rates higher when compared to the short-term settings. The focussing of the responses to a smaller range of categories for priorities is particularly noticeable in the community where performance components are not identified at all. In some instances there were large drops in the responses for the sub-categories. For instance, the sensory motor area attracted 15 responses in question one for those in physical rehabilitation areas, but moved to six responses only in question two (response rates of $0.68 \& 0.27)$. On the other hand, in one instance the response rate remained constant, ie. those in the field of paediatrics referred to sensory motor problems at the rate of 0.67 in both questions.

In the occupational performance category, the sub-category 'ADL' retained the greatest weighting for both questions suggesting that in all settings, this is a 
particularly important problem area for occupational therapists to deal with. The fact that family issues were raised as a general problem area but then not identified as a priority, suggests that it is a contextual factor rather than one that is dealt with directly in treatment planning. For some of the sub-categories there were large drops in the response rates - this is evident in the psychiatric rehabilitation settings in respect of 'ADL' (the response rate decreased from 0.45 to 0.10 ). In some instances the response rate remained constant, ie. in the physical rehabilitation settings 'social' retained a response rate 0.09 , in acute psychiatry, leisure retained a response rate of 0.17 and in the community the response rate remained at 1.0 for $\mathrm{ADL}$.

Having now considered the problems that respondents indicated were the major concerns for occupational therapy intervention, the remainder of this chapter will investigate why these particular issues were important to the respondents.

\subsection{Treatment Principles: An Introduction}

Asking respondents to explain their priority in treatment was a method of eliciting the beliefs that they held in relation to treatment. It provided a link between the problems that they identified and the treatment procedures they were using. As stated in Chapter Five, the method of analysis used to discover the underlying beliefs was a modification of Toulman's analysis. Essentially this consisted of data being given and a claim arising from this with the belief being the linking element between the two. In this interview, the data was a client problem that had been identified - usually in response to question one - the claim was a statement concerning the treatment and generally arose from the response to question two. 
On some occasions, these claims were made in response to other questions especially question one where some respondents gave elaborated versions of their client's problems and also included their treatment strategies. Treatment beliefs also arose in response to other questions, eg. when discussing outcomes often a reply would include the justification for the outcome so in this way underlying beliefs were also explained. Usually the beliefs were implicit rather than explicit, ie. in stating the argument, the beliefs were not specifically stated but could be deduced from the data, the claim and other background information. In the following examples of the data (D), claims, (C) and beliefs (B) the quotation marks indicate actual statements made by the subjects, but the underlying beliefs were drawn from these statements rather than clearly defined by the subject.

A/7:

D. "Physical limitations ... resulted in frustration and boredom."

C. "Activity would provide a base from which she would be able to concentrate on other things."

B. Involvement in one activity can lead to participation in other activities.

A/16:

D. "She was having problems like peeling potatoes.."

C. "That was the one I worked on first because she identified that as being her first problem."

B. It is important to deal with problems that the client identifies.

$\mathrm{B} / 11$

D. "She had limited co-ordination between her left and right sides."

C. "The co-ordination and bilateral activities took priority because .. it was going to have more effect on how she coped at home." 
B. Emphasis should be on those aspects of function that prevent her managing at home.

$\mathrm{C} / 13$ :

D. " "She was mentally alert and desperately wanting to be kept busy."

C. "She becomes down and more difficult to manage on the ward and unhappy if she's not kept occupied."

B. Engagement in activity can maintain a sense of wellbeing.

$\mathrm{C} / 19$ :

D. "I've started with the simplest (treatment) which was transferring and dressing."

C. "They were the less hazardous and .. we're using the skills that he had at the time to develop them further so he can go on to the next stage."

B. Gaining competence in the simplest task provides a basis for more complex (hazardous) tasks.

Once the beliefs had been extracted using the above method, these were then categorised according to the treatment principle that they were illustrating. The principles fell into two main categories - those that reflected the characteristics of treatment programmes (process), and those that dealt with the nature of the treatment itself (content). The results have therefore been divided into these two major categories.

The characteristics of treatment programmes focussed on the way in which treatment was delivered. These issues dealt with the process of delivery and would not be unique to occupational therapy in that they dealt with general issues such as the safety of clients and success of treatment. The nature of treatment 
programmes dealt with the specifics or the content of the occupational therapy service such as the teaching of particular skills and the use of activity as a medium of treatment (see Tables 7.2 and 7.3).

The beliefs that were reflected often had more than one element, ie. they often conveyed an understanding of both process and content issues. For example, one respondent said that difficulties in motor functioning in upper limbs affects involvement in all daily living skills (A/3). This was a reflection of both the sequential nature of treatment and the fact that daily living skills was something that an occupational therapy programme dealt with. Others reflected more than one type of process issue or more than one type of content issue. For instance, one second year student $(\mathrm{B} / 8)$ referred to the learning of self care tasks being important for someone who was to live on their own thus reflecting the content issues of learning skills and coping in the home environment.

\subsection{Comparison Between the Groups}

Table 7.1 is a summary of the two types of beliefs (content and process) that were identified by each of the respondent groups.

Table 7.1 indicates that:

1. The response rates for the two major categories (process and content) indicates that clinicians put greater emphasis on process whereas the student groups put more emphasis on content. However the result is not statistically significant (chi-square $=2.59$, d.f. $=2, p=$ n.s. . 
Table 7.1

Summary of the Responses Given by the Three Respondent Groups

\begin{tabular}{|c|c|c|c|c|}
\hline \multicolumn{5}{|c|}{ RESPONDENTS } \\
\hline & STAGE II & STAGE III & CLINICIANS & TOTALS \\
\hline BELIEF: & $\mathrm{N}=14$ & $\mathrm{~N}=31$ & $\mathrm{~N}=22$ & $\mathrm{~N}=67$ \\
\hline PROCESS & $11(0.79)$ & $20(0.65)$ & $21(0.95)$ & $52(.78)$ \\
\hline CONTENT & $15(1.07)$ & $32(1.03)$ & $17(0.77)$ & $63(.94)$ \\
\hline TOTALS & $26(1.86)$ & $52(1.68)$ & $38(1.73)$ & $115(1.72)$ \\
\hline
\end{tabular}

A more detailed analysis of the above responses has been summarised in Tables

7.2 and 7.3. The sub-categories are sequenced in order of rate of response and will be explained in the discussion following the tables.

\subsubsection{Principles Related to the Delivery of Treatment Programmes}

The notion of treatment being sequential was evident in a number of the responses. The common theme was that one aspect of functioning can have an impact on other facets of function. Some responses illustrated beliefs about how the individual's ability to be competent in specific skills resulted in benefits such as being able to go home or develop friendships, while others focussed on how skill acquisition was important to the individual's self-esteem. For example, one respondent made reference to the learning of self-care skills as being important for the individual's self-esteem $(\mathrm{C} / 7)$, while another said that skill in self-care activities could determine whether or not a patient needs to be in hospital (C/9). 
Table 7.2

Beliefs Concerning the Delivery of Treatment Programmes

\begin{tabular}{|lcccc|}
\hline & \multicolumn{2}{c|}{ RESPONDENTS } & \\
PROCESS & STAGE II & STAGE III & CLINICIANS & TOTAL \\
\hline BELIEFS: & $\mathrm{N}=14$ & $\mathrm{~N}=31$ & $\mathrm{~N}=22$ & $\mathrm{~N}=67$ \\
\hline $\begin{array}{l}\text { SEQUENTIAL } \\
\text { IMPORTANT TO }\end{array}$ & $6(.43 / 55)$ & $9(.24 / 45)$ & $11(.50 / 52)$ & $26(.39 / 50)$ \\
CLIENT & $2(.14 / 18)$ & $5(.16 / 25)$ & $6(.27 / 29)$ & $13(.19 / 25)$ \\
SAFE & $2(.14 / 18)$ & $4(.13 / 20)$ & $4(.18 / 19)$ & $10(.12 / 19)$ \\
SUCCESSFUL & $1(.07 / 9)$ & $2(.06 / 10)$ & - & $3(.04 / 6)$ \\
\hline TOTAL RESPONSES & $11(.79)$ & $20(.65)$ & $21(.95)$ & $52(.78)$ \\
*NUMBER OF & $9(64 \%)$ & $18(58 \%)$ & $17(77 \%)$ & $44(66 \%)$ \\
\hline RESPONDENTS & & & & \\
\hline
\end{tabular}

*Note: This figure refers to the number of subjects who identified process beliefs. A subject may have given responses that were recorded in more than one category.

Others reflected on more basic issues that would affect the individual carrying out skills such as belief in self, self-awareness, pain and motor functioning. For instance, one respondent referred to the issue of difficulties in motor functioning in upper limbs affecting involvement in all daily living tasks (A/3) while another suggested that lack of belief in your own ability pervades all aspects of life (B/6).

Yet others considered that involvement in activities could result in benefits beyond the activity itself. Such benefits were said to be improvement in self esteem and motivation ( $\mathrm{A} / 12)$, the overcoming of feelings of uselessness resulting in concentration on other tasks $(\mathrm{C} / 7)$, and the development of social contacts $(\mathrm{A} / 15)$. 
The idea that treatment should deal with issues that are important for the client was expressed in different ways; the concerns expressed included the clients' priorities, their particular anxieties, their specific interests and their goals. Some respondents gave reasons as to why this client driven focus was important, eg. it will help to maintain a sense of self-worth $(\mathrm{C} / 17)$, help to reduce anxiety $(\mathrm{C} / 21)$ and help the client to make decisions about his/her own life (A/26).

This notion is supported by the literature. For instance, Kielhofner (1985) suggests that the client-therapist interaction should reflect the valuing of "mutual co-operation" (p 52). It reflects a pragmatic view of treatment where intervention is determined by the client's perceived needs. To what extent the client is able to influence his/her own treatment is not clear. The orientation seems to be that the therapist plans the treatment then accommodates the client's goals within this, rather than being directed solely by the client's goals.

Safety was usually associated with the home environment and the need to ensure safety prior to discharging a patient to live at home (eg. A/14, C/9, B/3). It was also related to precautions following surgical intervention (eg. C/8, C/20) and personal safety in respect of someone having a potential for self harm (B/1). One student was concerned that the client should have access to a communication system in case of emergencies (A/18).

The need for treatment to be immediately successful was noted by three students. Generally this was seen to be important because the client would have immediate results which related to their comfort, skills or involvement in activity. In one case, such a result was desirable because it provided credibility and enabled the therapist to develop rapport which was useful as a basis for further assessments 
$(\mathrm{B} / 3)$. This was not an issue for clinicians - possibly because they assume that treatment will be successful so would not see a need to make this explicit.

Table 7.2 indicates that:

1. Treatment being sequential in nature was an important belief for all three respondent groups with $45 \%$ or more of the responses being in this category.

2. Treatment being important to the client, assumes greater significance with experience as indicated by the percentages of the responses of the three respondent groups $(18 \%<25 \%<29 \%)$.

3. Overall, clinicians had a higher response rate than the students $(0.95 \mathrm{cf}$. $0.79 \& 0.65)$. A chi-square analysis indicates that this variation is not significant (chi-square $=1.6$, d.f. $=2$, n.s.).

\subsubsection{Principles Related to the Nature of Treatment Programmes}

The focus in this section is on the content of the treatment offered by Occupational Therapists.

The highest response was in relation to clients ability to cope with life beyond the confines of a treatment programme either within their own home or more generally, in the community. This was most frequently related to the fact that individuals were discharged to live in their own homes and were often perceived as needing to be independent in self care tasks, especially if they lived alone $(\mathrm{B} / 11, \mathrm{~A} / 8, \mathrm{C} / 2)$. Some respondents referred to clients needing to manage money $(B / 15, A / 31)$, or more generally manage the home $(A / 5, A / 27)$. One third year 
student stated categorically that the main aim of the occupational therapy programme was "to keep her (the client) as independent as possible" (A/28).

Table 7.3

Beliefs Concerning the Nature of Treatment Programmes

\begin{tabular}{|lcccc|}
\hline & \multicolumn{3}{c}{ RESPONDENTS } & \\
& STAGE II & STAGE III & CLINICIANS & TOTAL \\
\hline CONTENT & $\mathrm{N}=14$ & $\mathrm{~N}=31$ & $\mathrm{~N}=22$ & $\mathrm{~N}=67$ \\
\hline COPIEFS $:$ & $5(.36 / 33)$ & $11(.35 / 34)$ & $3(.14(18)$ & $19(.28 / 30)$ \\
DEVELOPING SKILLS & $6(.43 / 40)$ & $6(.29 / 28)$ & $4(.18 / 24)$ & $18(.27 / 29)$ \\
USE OF ACTIVITY & $2(.14 / 13)$ & $8(.26 / 25)$ & $4(.18 / 24)$ & $14(.21 / 22)$ \\
$\begin{array}{l}\text { ENVIRONMENTAL } \\
\text { ADAPTATION }\end{array}$ & $2(.14 / 13)$ & $4(.13 / 13)$ & $6(.27 / 35)$ & $12(.18 / 19)$ \\
\hline $\begin{array}{l}\text { TOTAL RESPONSES } \\
\text { *NUMBER OF } \\
\text { RESPONDENTS }\end{array}$ & $15(1.07)$ & $32(1.03)$ & $17(0.77)$ & $63(.94)$ \\
& $9(64 \%)$ & $27(87 \%)$ & $14(64 \%)$ & $50(75 \%)$ \\
\hline
\end{tabular}

*Note: This figure refers to the number of subjects who identified content beliefs. A subject may have given responses that were recorded in more than one category.

Skill acquisition referred to the learning of a range of skills such as managing self-care tasks (such as showering and dressing; $\mathrm{C} / 19, \mathrm{~A} / 3$ ), home making tasks $(B / 18)$, writing $(B / 14)$, leisure skills $(A / 11)$, communication and social skills $(B / 2$, $\mathrm{A} / 11, \mathrm{~A} / 25)$. Quite clearly those who mentioned skill acquisition were in the business of teaching skills in order that clients would be able to cope with living in the community, as discussed above, or for the purpose of improving their confidence and self-esteem. 
The use of activity within treatment was mentioned by all respondent groups. Such involvement was considered to have a range of benefits for the client such as preventing boredom or unhappiness (A/24, C/13), cognitive stimulation $\mathrm{C} / 10$ ), improved concentration $(\mathrm{A} / 7)$, motivation and self esteem $(\mathrm{A} / 12, \mathrm{C} / 22)$. Other benefits were perceived to be the rapport that was established between client and therapist $(\mathrm{B} / 13$. $\mathrm{C} / 16)$ and the fact that the outcome is a tangible product $(\mathrm{A} / 22)$. The range of activities mentioned were leisure or recreational, work programmes and self-care activities. In some cases references were made to 'structured' activity programmes where the type of activity was not specified.

Two students $(\mathrm{B} / 2, \mathrm{~A} / 10)$ indicated that clients needed to actively participate in a structured programme before they could expect to gain any benefits. Both students were in psychiatric settings where clients are often poorly motivated to participate and frequently don't. It is possible that this is more of a source of frustration for students than for clinicians who would better understand why some clients were reluctant to get involved in activity programmes.

Finally the environment - both human and non-human - was an issue for a number of respondents. There was reference to the need to consider the people that the individual lived with, for instance, it was noted that treatment should ensure a satisfactory outcome for both client and spouse $(\mathrm{C} / 1)$ and that the presence of someone in the home environment would influence the level of independence required $(\mathrm{C} / 20, \mathrm{C} / 18)$. One clinician indicated that treatment should compensate for a social background that did not provide support for the client $(\mathrm{C} / 3)$. Conversely, another respondent noted the need to compensate for a social background that provided too much support in the sense of the client being unable to make any decisions due to dependence on nursing care (A/17). One response had elements of both the human and non-human environments when it 
was considered that people should be able to feel comfortable with a new environment (non-human) before demands (human) are made on them (C/5).

The manipulation of the non-human environment was also raised. For example, a change of environment was considered to be able to facilitate the maintenance or learning of skills (C/12) and to influence mental well-being (A/23). Also, modifying the home environment was thought to make it easier for the patient once discharged (B/8) and could enable someone to carry out their roles for a bit longer (A/16). Finally one respondent referred to the need to modify a wheelchair (an aspect of the non-human environment) in order that the client was comfortable (A/18).

Table 7.3 indicates that:

1. Overall, the students had a higher response rate compared to the clinician group ( $1.07 \& 1.00 \mathrm{cf}$. 0.77$)$. However, this result is not statistically significant (chi-square $=1.4$, d.f. $=2$, n.s.).

2. Some differences exist within the content categories. For instance students put greater emphasis on developing skills and coping strategies when compared to the clinicians $(0.36 \& 0.35 \mathrm{cf} .0 .14)$, whereas clinicians put more emphasis on environmental adaptations. However, the numbers in each of the 'cells' of the table are too small to justify a statistical analysis. 


\subsection{Location of Respondents}

Table 7.4 is a summary of the two main categories of beliefs that were generated by the respondents with respect to the locations in which they worked at the time of the interview.

Table 7.4

Summary of the Responses Given in each Location

\begin{tabular}{|lccccccc|}
\hline \multicolumn{7}{c}{ LOCATIONS } \\
& \multicolumn{9}{c}{ PHYSICAL } & PSYCHIATRIC & PAEDIATRIC \\
BELIEF: & Acute & Rehab. & Com. & Acute & Rehab. & \\
& $\mathrm{N}=8$ & $\mathrm{~N}=22$ & $\mathrm{~N}=5$ & $\mathrm{~N}=6$ & $\mathrm{~N}=20$ & $\mathrm{~N}=6$ \\
\hline PROCESS & $5(0.63)$ & $15(0.68)$ & $7(1.40)$ & $4(0 . .67)$ & $16(0.80)$ & $5(0.83)$ \\
CONTENT & $10(1.25)$ & $22(1.00)$ & $3(0.60)$ & $6(1.00)$ & $16(0.80)$ & $6(1.00)$ \\
\hline SUBTOTALS & $15(1.86)$ & $37(1.68)$ & $10(2.00)$ & $10(1.67)$ & $32(1.60)$ & $11(1.83)$ \\
TOTALS & $62(1.77)$ & & & $42(1.62)$ & $11(1.83)$ \\
\hline
\end{tabular}

Table 7.4 indicates that:

1. The response rates for the three broad categories of location (physical, psychiatric and paediatric) are much the same $(1.77,1.62$ and 1.83 respectively). They differ a little with respect to their distribution between process and content beliefs, but this is not a statistically significant finding (chi-square $=0.17$, d.f. $=1$, n.s., with paediatrics eliminated due to the small cells). 
2. Apart from the community setting which has a response rate of 2.00 , the overall response rates are similar in all the settings varying only from 1.60 to 1.86 .

3. If the location data is re-organised into long-term (rehabilitation and paediatric) and shorter-term settings (acute and community), a difference in the response rates is observed (short-term 1.84 and long-term 1.65). However this result is not significant (chi-square $=0.23$, d.f. $=1$, n.s.). No real difference is observed in the distribution of the process and content responses between these settings (chi-square $=0.02$, d.f. $=1$, n.s.).

A more detailed analysis of the responses can be found in Tables A.7 and A.8. These may be found in Appendix A.

\subsection{Discussion}

The philosophical base of Occupational Therapy as defined by the American Occupational Therapy Delegate Assembly (see Chapter 2), stated that there was both an intrinsic and therapeutic value in activity. This has been reflected in many of the beliefs regarding treatment in that the value of learning to do tasks and being involved in activities was often related to the person's sense of self-esteem as well as to the benefits such as being able to live in their own home, and meeting other people. 
The content issues fall into three major concerns - those related to:

a) the individual (ie. their coping strategies and skill acquisition related to this or more generally to improved self-esteem and confidence). This aspect was given the most emphasis by all respondents;

b) the environment and how this can be managed to assist the individual to cope, and finally;

c) activity as it is used in treatment.

The above categorisation is consistent with the three basic elements of the Occupational Adaptation framework (Schlade \& Schlutz 1992). The 'person' element of this framework is concerned with a desire for mastery in occupational situations which is similiar to the above concepts under the 'individual' where 'coping strategies' and 'developing skills' can be viewed as the individual's need to gain mastery in their daily lives. The occupational environments of the framework include physical, social and cultural sub systems - the study has identified only physical and social elements. Finally occupation is viewed as...

"activities that are characterised by three properties - active participation, meaning to the person and a product that is the output of a process". (p 831)

All these aspects have been identified under the 'activity' component of this study.

Overall, clinicians put a greater emphasis on the process issues, whereas both groups of students were more highly represented in the content categories. This observation would be consistent with what is known about learning in the clinical field; ie. the novice learner tends to focus initially on specific tasks and once comfortable with these, is able to consider the broader issues such as how the end 
is achieved. One such process issue that was given notably more importance by the clinician group was the need to take into account the clients' concerns and priorities.

There were differences arising from the various work environments. Those in community work mentioned process skills more frequently than content, and in particular the assumption that treatment should take into account those issues that are important to the client. This finding would be compatible with the community work environment where dealing with people in their own homes tends to place the client in a controlling position. The content beliefs were focused on two subcategories only ie. coping strategies and the environment. This again is consistant with the nature of the service in that the time frame would not allow for teaching skills and involvement in activity.

The respondents in the acute physical settings, rated the content issues more highly than the process ones. This service is hospital based and meets the needs of clients in order that they can be discharged to their own homes or into rehabilitation services. Hence, as the data indicates, the focus is on the content issues of 'coping strategies' and 'skill acquisition'.

The two rehabilitation settings put most emphasis on the use of activity as a treatment principle whereas this was not rated at all by those working in acute settings. Possibly time constraints were a factor in the short-term settings where the coping strategies were favoured, presumeably to prepare clients for early discharge.

The physical settings put more emphasis on safety compared to other areas and less on treatment being sequential. Both the psychiatric and paediatric settings 
had high response rates (all at 0.50 ) for the sequential nature of treatment. The reason for this is not obvious - possibly the clients in physical areas have problems that can be dealt with more immediately, rather than having to work through a sequential process.

\subsubsection{Relationship Between Treatment Priorities and Treatment Principles}

ADL problems have been identified as a major priority area for occupational therapy intervention. This is strongly connected to the major content issue of 'coping strategies' as well as 'skill acquisition' and 'environmental adaptation'. Clients having difficulties in daily activities quite clearly have a need to overcome these to enable them to cope with the basics of daily life; and in some instances their environment may need to be modified to accommodate their change in health status.

The use of activity in treatment was clearly related by the respondents to three of the performance components, ie. intrapersonal, interpersonal and cognitive aspects as well as having connections with the occupational performance sub-categories of leisure, work and ADL. Activity seems to be quite a pervasive concept in occupational therapy - in some instances it is used as a specific treatment medium for the improvement of various performance components and in other instances it is regarded as the outcome of treatment, as can be noted in the employment, ADL and leisure tasks.

Sensory motor problems was the major performance component category identified, but is not clearly linked to any of the content issues. However, reference to the need to deal with underlying sensory motor problems is noted as 
an issue by some respondents when considering the need for a client to relearn or acquire skills.

\subsection{Summary}

Statistical significance was established for the priority problems in respect of the differences between the locations. This included variation between long and short-term settings in both the distribution of the type of priority problem and in the response rate. Also there was a difference in the distribution of the type of priority problem between the physical, psychiatric and paediatric locations.

No significant differences between the three respondent groups were found.

In the beliefs section, no significant differences were noted, however clinicians put greater emphasis on process issues whereas students emphasised the content ones. Of the process issues, clinicians put greater emphasis on treatment being important to the client when compared to the students.

Another finding was that the community setting was notably different to other settings in that there was a particularly high response rate, a focus on process issues and, in particular, a need for treatment to be important to the client. 


\section{CHAPTER EIGHT}

\section{QUESTION 3: TREATMENT OUTCOMES}

\subsection{Introduction}

This chapter will address the third question of the interview: "In your evaluation, what would be a satisfactory treatment outcome?" To be consistent with the analysis of the problems, the two major categories "Performance Components" and "Occupational Performance" have been used as well as the same sub-categories found in chapter six although there have been minor adjustments made to these as necessary.

\subsection{Comparison Between the Groups}

Table 8.1 is a summary of the types of treatment outcomes that were identified by each of the respondent groups.

Table 8.1 indicates that:

1. The response rate for the treatment outcomes increases with experience $(1.22<1.55<1.64)$. However the result is just short of statistical significance at the 0.05 level (chi-square $=5.0$, d.f. $=2, p=0.08$ ).

2. The response rates for the two major categories indicates that all the three groups put more emphasis on the occupational performance compared to the performance component skills. 
Table 8.1

Summary of Responses

\begin{tabular}{|lcccc|}
\hline \multicolumn{5}{c}{ RESPONDENTS } \\
OUTCOMES: & STAGE II & STAGE III & CLINICIANS & TOTAL \\
& $\mathrm{N}=14$ & $\mathrm{~N}=31$ & $\mathrm{~N}=22$ & $\mathrm{~N}=67$ \\
\hline $\begin{array}{l}\text { PERFORMANCE } \\
\text { COMPONENTS } \\
\text { OCCUPATIONAL } \\
\text { PERFORMANCE }\end{array}$ & $6(0.43)$ & $18(0.58)$ & $16(0.73)$ & $40(.60)$ \\
\hline TOTAL RESPONSES & $11(0.79)$ & $30(0.97)$ & $20(0.91)$ & $61(.91)$ \\
\hline
\end{tabular}

A more detailed analysis of the responses has been summarised in Tables 8.2 and 8.3. The responses have been ranked from most to least frequently mentioned. Descriptions of the sub-categories have been given in the discussion following each of the tables.

\subsubsection{The Performance Component Skills}

A group of treatment outcomes was related to sensory motor improvements. Control of movement, strength and co-ordination was one aspect, the other was the issue of general physical fitness and avoiding fatigue resulting from carrying out daily tasks. One respondent who identified the very specific outcome of having full tendon excursion, was dealing with a client who had a hand injury, but in other instances the motor outcomes were related to the ability of the individual to carry out daily tasks such as writing, and in this way were not seen as an end in themselves. However, not all respondents identified 
these more functional outcomes. All respondents in this group were located in either physical or paediatric settings.

Table 8.2

Summary of the Performance Component Outcomes

\begin{tabular}{|lcccc|}
\hline & \multicolumn{3}{c}{ RESPONDENTS } & \\
OUTCOME: & $\begin{array}{c}\text { STAGE II } \\
\mathrm{N}=14\end{array}$ & $\begin{array}{c}\text { STAGE III } \\
\mathrm{N}=31\end{array}$ & $\begin{array}{c}\text { CLINICIANS } \\
\mathrm{N}=22\end{array}$ & $\begin{array}{c}\text { TOTAL } \\
\mathrm{N}=67\end{array}$ \\
\hline SENSORY MOTOR & $3(.21 / 50)$ & $4(.13 / 22)$ & $5(.23 / 31)$ & $12(.18 / 30)$ \\
INTERPERSONAL & - & $4(.13 / 22)$ & $6(.27 / 38)$ & $10(.15 / 25)$ \\
SELF RESPONSIBILITY & $1(.07 / 17)$ & $5(.16 / 28)$ & $1(.05 / 6)$ & $7(.10 / 18)$ \\
COGNITION & - & $3(.10 / 17)$ & $2(.09 / 13)$ & $5(.07 / 13)$ \\
INTRAPERSONAL & $2(.14 / 33)$ & $2(.06 / 11)$ & $2(.09 / 13)$ & $6(.09 / 5)$ \\
\hline $\begin{array}{l}\text { TOTAL RESPONSES } \\
\text { *NUMBER OF }\end{array}$ & $6(0.43)$ & $18(0.58)$ & $16(0.73)$ & $40(0.60)$ \\
RESPONDENTS: & $8(57 \%)$ & $14(45 \%)$ & $10(45 \%)$ & $31(46 \%)$ \\
\hline
\end{tabular}

*Note: This figure refers to the number of subjects who identified performance component outcomes. A subject may have given responses that were recorded in more than one category.

The interpersonal skills outcome was raised by all respondent groups. This was expressed in various ways. One of the concerns being that the individual could listen effectively and initiate conversation with others. Another concern was that of the individual needing to deal with behaviour problems that resulted in alienating people - this aspect was only mentioned by clinicians. The above examples are drawn from respondents who worked in psychiatric settings. One respondent working with physically disabled who mentioned this, did so in a different manner where the issue was in relation to word loss 
and the client being able to compensate for this by writing down messages in a notebook.

Self-responsibility refers to the individual's recognition of him/herself as accountable for his/her own actions in respect of setting personal goals and accepting the limitations that disability imposes. All respondent groups raised this issue. The second year students and the clinicians concerned were working in psychiatric rehabilitation settings, but the third year students were in a wider range of settings ie. physical, psychiatric and paediatric. In general there was a theme that people should learn to accept the limitations of their disability and take responsibility for their own actions/health. The outcomes ranged from clients simply making their own decisions to seeking assistance when necessary. Implicit in this is the need for the individual to recognise that he/she is capable of being able to take action in response to situational demands.

An outcome mentioned by six respondents concerned the individual's intrapersonal development. This was expressed in words such as 'self-worth', 'expectations of success' and 'self-esteem'. In one instance this was linked to a client's ability to cope with daily living tasks, otherwise it was an end in itself. All respondents who referred to this aspect were in psychiatric settings.

Improvements in cognitive functioning was raised by the stage III students and clinician groups. Reference was made to mental stimulation, improved concentration span and the need for a client to "sort out his thought processes" $(\mathrm{A} / 10)$. 
Table 8.2 indicates that:

1. Overall, the number of performance component outcome categories increases with experience $(0.43<0.58<0.73)$. However, this is not statistically significant (chi-square $=1.3$, d.f. $=2$, n.s. $)$.

2. The breakdown within the performance component category (sensory motor, interpersonal, self-responsibility, cognition and intrapersonal) shows some variation between the three groups. However the small number of responses overall do not allow any conclusions to be drawn.

\subsubsection{The Occupational Performance Skills}

The issue most frequently mentioned, was that of the client's ability to carry out daily living activities and so be as independent as possible and safe in their home. This included self-care tasks such as dressing, eating and bathing, home making skills such as cleaning, cooking and washing clothes, and the ability to manage money in order that appropriate food and clothing can be purchased. The tendency was for the respondents to mention several of these issues at one time, eg.

"That he be safe and independent at home managing with all areas like self care and cooking and all that kind of thing" A/13.

Alternatively, this range of concerns was fused together into one global statement, eg. "For the person to be able to go home safely and independently" $\mathrm{A} / 30$. 
Table 8.3

Summary of the Occupational Performance Outcomes

\begin{tabular}{|c|c|c|c|c|}
\hline \multirow[b]{2}{*}{ OUTCOMES: } & \multicolumn{3}{|c|}{ RESPONDENTS } & \multirow[b]{2}{*}{$\begin{array}{l}\text { TOTAL } \\
\mathrm{N}=67\end{array}$} \\
\hline & $\begin{array}{l}\text { STAGE II } \\
\mathrm{N}=14\end{array}$ & $\begin{array}{c}\text { STAGE III } \\
\mathrm{N}=31\end{array}$ & $\begin{array}{l}\text { CLINICIANS } \\
\qquad \mathrm{N}=22\end{array}$ & \\
\hline A.D.L. & $6(.43 / 55)$ & $19(.61 / 63)$ & $13(.59 / 65)$ & $38(.56 / 62)$ \\
\hline ACTIVITY & $2(.14 / 18)$ & $6(.19 / 20)$ & $3(14 / 15)$ & $11(.16 / 18)$ \\
\hline SOCIAL & $1(.07 / 9)$ & $1(.03 / 3)$ & $2(.9 / 10)$ & $4(.07 / 7)$ \\
\hline EDUCATION & $1(.07 / 9)$ & $2(.06 / 7)$ & - & $3(.05 / 5)$ \\
\hline $\begin{array}{l}\text { FAMILY } \\
\text { RESPONSIBILITY }\end{array}$ & - & - & $2(.09 / 10)$ & $2(.03 / 3)$ \\
\hline TIME & $1(.07 / 9)$ & $1(.03 / 3)$ & - & $2(.03 / 3)$ \\
\hline EMPLOYMENT & - & $1(3 / 3)$ & - & $1(.02 / 2)$ \\
\hline TOTAL RESPONSES & $11(.79)$ & $30(.97)$ & $20(.91)$ & $61(.91)$ \\
\hline $\begin{array}{l}\text { *NUMBER OF } \\
\text { RESPONDENTS }\end{array}$ & $8(57 \%)$ & $26(84 \%)$ & $18(88 \%)$ & $52(78 \%)$ \\
\hline
\end{tabular}

*Note: This figure refers to the number of subjects who identified occupational performance outcomes. A subject may have given responses that were recorded in more than one category.

The client's ability to carry out these life tasks was referred to in different ways. Some respondents simply stated that the client should be able to return home and be safe and independent. Others qualified this by mentioning the necessity of outside help (eg. district nurses, meals on wheels) or the use of aids and equipment. For clients already living at home or in the community, the issues were related to specific aspects of independence such as getting out of a chair, eating, getting shoes on - by implication these were the only concerns that the client had. Some referred to both self-care and home making skills together. The respondents were in a wide range of settings. 
The need for the individual to be involved in activities was identified by all respondent groups. The purpose of this was stated by one respondent as providing something the person finds enjoyable, another respondent felt the purpose was to provide physical and mental stimulation. All respondents were working in long-term settings. The actual location varied from hospitals dealing with psychiatric and physical dysfunction to community based work such as day care centres.

The issue of developing social networks was also raised by all respondent groups. The idea encompassed in this was that an important aspect of maintaining a satisfactory life in the community was to have friends and feel comfortable meeting new people.

Education referred to the need for children to function adequately in the classroom eg. being able to write, paint, cut and play games. This was raised by the three respondents who were in educational settings.

Family responsibility as an outcome was only raised by the clinicians. Two aspects of this were mentioned, one being to establish a mother role in respect of a young family, the other was the need to maintain a relationship with a partner.

Managing time effectively was identified by two respondents. One was concerned that the client should make good use of time within an institutional setting while the other was involved with a client who needed to balance time between home and work responsibilities. 
Learning work skills was raised by one stage III student in a psychiatric rehabilitation setting. The final outcome of work skills, in this instance was not to get the client back into the work force, but was to do with learning specific "manual skills" (A/10).

Table 8.3 indicates that:

1. ADL was the most frequently referred to outcome by all the respondent groups with response rates of $0.43,0.61$ and 0.59 respectively.

2. There was little variation in the overall response rate between the three respondent groups $(0.79,0.97 \& 0.91)$.

\subsection{Locations of Respondents}

Table 8.4 is a summary of the two main categories of treatment outcomes that were generated by the respondents with respect to the location in which they were working at the time of the interview.

Table 8.4 indicates that:

1. Overall, the response rate varied between the three major settings (physical 1.37, psychiatric 1.50 and paediatric 2.33 ) but these differences are not statistically significant (chi-square $=2.81$, d.f. $=2$, n.s.). The distribution between the performance components and the occupational performance categories also differs. The results indicate that physical settings are more associated with occupational performance outcomes, while the balance is more even for both 
psychiatric and paediatric settings. However this is not a significant finding (chi-square $=2.7$, d.f. $=2$, n.s.).

Table 8.4

Summary of the Responses Given in Each Location

\begin{tabular}{|lcccccc|}
\hline \multicolumn{7}{c}{ LOCATIONS } \\
& \multicolumn{7}{c}{ PHYSICAL } & PSYCHIATRIC & PAEDIATRIC \\
& Acute & Rehab. & Com. & Acute & Rehab. & \\
OUTCOMES & $\mathrm{N}=8$ & $\mathrm{~N}=22$ & $\mathrm{~N}=5$ & $\mathrm{~N}=6$ & $\mathrm{~N}=20$ & $\mathrm{~N}=6$ \\
\hline PERFORMANCE & $5(0.63)$ & $9(0.41)$ & $1(.20)$ & $4(0.67)$ & $14(.70)$ & $7(1.17)$ \\
COMPONENTS & & & & & & \\
OCCUPATIONAL & $8(1.00)$ & $20(0.91)$ & $5(1.00)$ & $4(0.67)$ & $17(0.85)$ & $7(1.17)$ \\
PERFORMANCE & $13(1.63)$ & $29(1.32)$ & $6(1.20)$ & $8(1.34)$ & $31(1.55)$ & $14(2.33)$ \\
\hline SUBTOTALS & & & $48(1.37)$ & & $39(1.50)$ & $14(2.33)$ \\
TOTALS & & & & & & \\
\hline
\end{tabular}

2. If the 'locations' data is re-organised into long-term and short-term settings there is some difference between the response rates (long-term 1.54 and short term 1.42) however this is not statistically significant (chi-square $=0.20$, d.f. $=1$, n.s.). Also there is no real difference observable in the distribution of the performance component and occupational performance categories between these two settings (chisquare $=0.10$, d.f. $=1$, n.s. .

A more detailed analysis of the responses can be found in Tables B.1 and B.2.

These are located in Appendix B. 


\subsection{Discussion}

One second year student who was located in a psychiatric setting did not indicate an outcome even after prompting. This student focussed on what she was doing with the client rather than the outcome of his treatment. The impression given was that certain assessment procedures were being carried out and until this was completed, an outcome could not be contemplated.

In occupational therapy, the major concern is with the ability of the individual to carry out meaningful occupation within the limitations of his/her physical or psychological abilities. Generally, it would not be appropriate for improvement in performance components to be a final goal of treatment, rather the goals should be directed to functional performance ie. the occupational performance skills. As Kielhofner states:

"Role function provides the focal point for treatment, with medical problems as part of the necessary background information. Problems of motor control, sensory integration and intra psychic functions are approached in terms of their implications for occupational role dysfunctions. The significance of these problems is evaluated according to their impact on occupational role performance" (Kielhofner, 1983, p.108).

Many of the treatment outcomes were directed towards role functioning especially those related to the areas of carrying out life tasks, social skills, involvement in activity and employment. However, many outcomes were concerned with the improvement of performance components, in particular the sensory motor and interpersonal skills. As mentioned previously these were 
sometimes linked to role functioning but they retained importance as a primary goal.

Table 8.1 indicates that all three respondent groups put more emphasis on the occupational performance outcomes. However Table 8.4 indicates that the focus on the occupational performance outcomes is not consistent with all locations, ie. respondents in both acute psychiatry and in paediatrics put equal weighting on performance component and occupational performance outcomes.

The outcomes were in some cases stated in behavioural terms, for example:

"Use a tripod grip when writing" B/14

"Get shoes and stockings on independently" C/17

"Be competent in using a laundry" B/15

"Be able to recognise different money pieces" $\mathrm{A} / 31$

However, this type of outcome was not usual and was confined to the areas of motor improvement, competence in daily living tasks and work skills.

Generally, outcomes were expressed in an open-ended manner, for example:

"Have a wider circle of friends and acquaintances" A/15

"Make her own decisions" A/17

"Be involved with satisfying activity" C/13

"A greater sense of self worth" A/11

"Relax and enjoy herself in ordinary social situations" B/7

In Reitman's (1965) terms, outcomes that have no particular end point are 'poorly defined goal states' (see Chapter 4). The information processing approach states that the clearer the goals are, the more explicit the paths taken 
to achieve them will be. As indicated in the above discussion, the goals in occupational therapy are often open ended. The use of an information processing model would result in an assumption that there would be some difficulty in deciding on treatment methods that would be appropriate in relation to such goals.

\subsubsection{Comparisons Between the Problems Identified in Questions One and} Two and the Treatment Outcomes

The balance between the occupational performance and the performance component categories in each of the three questions has remained similar for the stage III student group in that they consistently identified less performance component skills compared to the occupational performance type (see Tables 6.1, A. 1 \& 8.1). However this was not the case for the stage II student and clinician groups. Both had a balance in favour of the performance component responses (compared to the occupational performance category) in the first two questions, but this trend was reversed in question three where a greater number of occupational performance outcomes were identified. It is possible that the focus by stage III students on occupational performance issues is a result of recent educational trends where a system model has been in vogue (Model of Human Occupation; Kielhofner 1985) compared to the medical model having influenced earlier occupational therapy education and therefore many of the clinician group. This explanation, however, does not clarify why stage II students were more focused on the performance component problems. It may be that this group has not had previous exposure to the performance component problems, so emphasise them because they are new to their experience. 
The stage II students consistently produced the lowest response rate over the three questions, stage III students identified more problems than the clinicians in responses to questions one and two, but less treatment outcomes than the clinicians. One of the observations made at the end of chapter seven was that one reason for the stage II students low response rate was their ability to focus on the critical issues and not give data that was peripheral in nature. If they had been more focussed then the ongoing response rates would have retained the initial level. However this has not happened ie. the response rate has decreased, so it would seem that the stage II students simply do not take as many cues into account as those with more experience.

It appears that one location in particular has a very focussed approach ie. the community area. There has been a consistently high response rate to the occupational performance issues and a very low rate for the performance component ones. Within the occupational performance category, the only subcategory that was identified was ADL. Seemingly this is the only aspect of intervention that was considered, suggesting that there is less diversity in the nature of the work compared to the other settings.

\subsection{Summary}

There has been no statistically significant difference noted in relation to either the respondent groups or the locations in which they worked. However, there is a tendency for the response rate to increase with experience and for the occupational performance treatment outcomes (ADL in particular) to be favoured in comparison to the performance components. 


\section{CHAPTER NINE}

\section{QUESTION 4: BENEFIT TO THE CLIENT}

\subsection{Introduction}

The response to the fourth question will be explored in this section, ie. "What are the main benefits to the client/patient? What will he/she get out of your intervention?"

The responses to this question were ultimately divided into five categories - skill acquisition, self-confidence, control of life, enjoyment and helpful relationships. Of these, self-confidence, control of life and enjoyment seemed to reflect an understanding of the inner needs/feelings of the client, while the skill acquisition and helpful relationships was more to do with the therapist's goal for the client. Some respondents' replies contained elements from more than one category.

\subsection{Data Analysis}

Table 9.1 is a summary of the responses given in respect of the benefit of treatment to the client. These are listed in order of frequency of response.

The highest response rates were for skill acquisition as the main benefit to the client. A wide range of issues were mentioned, many of which were similar to the ADL category used in the previous data chapters. Some respondents referred to specific skills that would be learned such as establishing routines, eating 
independently, getting up from the floor, while others were concerned that these skills would enable someone to live independently, go home, or be safe. The primary focus was on the learning of skills in order that the individual might carry out their usual roles more adequately.

Table 9.1

Summary of the Benefits to the Client

\begin{tabular}{|lcccc|}
\hline & \multicolumn{3}{c}{ RESPONDENTS } \\
BENEFIT: & $\begin{array}{c}\text { STAGE II } \\
\text { N=14 }\end{array}$ & $\begin{array}{c}\text { STAGE III } \\
\text { N=31 }\end{array}$ & $\begin{array}{c}\text { CLINICIANS } \\
\text { N=22 }\end{array}$ & $\begin{array}{c}\text { TOTAL } \\
\text { N=67 }\end{array}$ \\
\hline SKILL ACQUISITION & $9(.64 / 53)$ & $21(.68 / 53)$ & $11(.50 / 35)$ & $41(.61 / 47)$ \\
SELF CONFIDENCE & $4(.29 / 24)$ & $10(.32 / 25)$ & $6(.27 / 19)$ & $20(.30 / 25)$ \\
CONTROL OF LIFE & $4(.29 / 24)$ & $5(.16 / 13)$ & $5(.23 / 16)$ & $14(.20 / 16)$ \\
ENJOYMENT & - & $2(.06 / 5)$ & $4(.18 / 13)$ & $6(.09 / 7)$ \\
$\begin{array}{l}\text { HELPFUL } \\
\text { RELATIONSHIP }\end{array}$ & - & $1(.03 / 3)$ & $3(.14 / 10)$ & $4(.06 / 5)$ \\
OTHER & - & $1(.03 / 3)$ & $2(.09 / 6)$ & $3(.04 / 3)$ \\
\hline $\begin{array}{l}\text { TOTAL RESPONSES } \\
\text { *NUMBER OF } \\
\text { RESPONDENTS: }\end{array}$ & $14(1.21)$ & $40(1.29)$ & $31(1.38)$ & $88(1.31)$ \\
\hline
\end{tabular}

* Note: This figure refers to the number of subjects who identified benefits to the client. A subject may have given responses that were recorded in more than one category.

Of the total group of interviewees, $25 \%$ referred to their client's ability to feel more confident in themselves. In this category the respondents described the way in which an individual would feel better about him/herself, this was related to such things as the client's ability to manage tasks without assistance or be kept usefully occupied. Words such as self-esteem, confidence, self-worth, belief in self, and feelings of well-being were used to convey this concept. 
Another benefit that was mentioned by all three groups, was the ability of the client to gain some control over his/her life. A number of respondents made reference to the individual being able to control their own behaviour. Some were concerned that the individual should be able to set goals and make decisions that influenced his/her life, while for others the issue was one of not being dependent on others.

Only the stage III and the clinician groups made reference to enjoyment as being the major benefit. For some respondents, quality of life was related to enjoyment eg. the client will gain a "better quality of life; more enjoyable and interesting one" (A/22). Some respondents indicated that enjoyment should be gained from therapy sessions, eg. one clinician felt that the occupational therapy programme offered the client "something she can look foreword to" $(\mathrm{C} / 3)$, while others referred to life in general beyond involvement in an occupational therapy programme (eg. see $\mathrm{A} / 22$ above).

Four considered that the client's relationship with the therapist was a major benefit. One stage III student said that the value of this was that the client simply received attention, while two clinicians said the benefit was in having "someone to trust" (C/11) and "someone to treat him more as an equal" (C/7). The final respondent was a clinician working in paediatrics who said that in contrast to other agencies dealing with the child, the occupational therapist made a point of working with the parents to establish a programme. This partnership would help to ensure that the programme was implemented.

The remaining group labelled as other, were difficult to categorise in any way. Two of the respondents focussed on what the therapist could offer. In one 
instance this was "information about other agencies" (C/14) and the other clinician stated that "I hone in on things that are important to her" $(\mathrm{C} / 21)$. Finally, one student referred to the potential of the occupational therapy programme in offering the client "something to do" (A/24) but the value of this to the client was never stated.

Table 9.1 indicates that:

1. The response rate increases with experience $(1.21<1.29<1.38)$.

However the result is not statistically significant (chi-square $=0.20$, d.f. $=2$, n.s.).

2. Skill acquisition had the highest response rate by all groups $(0.64,0.68$ $\& 0.50$ respectively).

3. Enjoyment and helpful relationships were not identified as benefits by the stage II students.

4. If the data is re-organised to differentiate between the pragmatic concerns of skill acquisition / helpful relationship and the personal considerations of self-confidence / control of life /enjoyment, there is an almost equal balance in the response rates of the clinician group (0.64 $\mathrm{cf} 0.68)$. Both the stage II and III groups, however, gave more emphasis to the pragmatic concerns $(0.64 \mathrm{cf}$. $0.29 ; 0.71 \mathrm{cf} .0 .55$ respectively). These differences are not significant (chi-square $=1.62$, d.f. $=2$, n.s. $)$. 


\subsection{Location of Respondents}

Table 9.2

Location of the Respondents and the Perceived Benefits to the Client.

\begin{tabular}{|c|c|c|c|c|c|c|}
\hline \multirow[b]{3}{*}{ BENEFITS } & \multicolumn{5}{|c|}{ LOCATIONS } & \multirow{3}{*}{$\begin{array}{c}\text { PAEDIATRIC } \\
\qquad \mathrm{N}=6\end{array}$} \\
\hline & \multicolumn{3}{|c|}{ PHYSICAL } & \multicolumn{2}{|c|}{ PSYCHIATRIC } & \\
\hline & $\begin{array}{l}\text { Acute } \\
\mathrm{N}=8\end{array}$ & $\begin{array}{l}\text { Rehab. } \\
\mathrm{N}=22\end{array}$ & $\begin{array}{l}\text { Com. } \\
\mathrm{N}=5\end{array}$ & $\begin{array}{l}\text { Acute } \\
\mathrm{N}=6\end{array}$ & $\begin{array}{l}\text { Rehab. } \\
\mathrm{N}=20\end{array}$ & \\
\hline $\begin{array}{l}\text { SKILL } \\
\text { ACQUISITION }\end{array}$ & $5(.63 / 50)$ & $13(.59 / 48)$ & $5(1.71)$ & $3(.50 / 30)$ & $11(.55 / 42)$ & $4(.67 / 50)$ \\
\hline SELF-CONFIDENCE & $5(.63 / 50)$ & $3(.14 / 11)$ & $2(.40 / 29)$ & $5(.83 / 50)$ & $4(.20 / 15)$ & $1(.17 / 13)$ \\
\hline CONTROL OF LIFE & - & $5(.23 / 19)$ & - & $2(.33 / 20)$ & $6(.30 / 23)$ & $1(.17 / 13)$ \\
\hline ENJOYMENT & - & $4(.18 / 15)$ & - & - & $2(.10 / 8)$ & - \\
\hline $\begin{array}{l}\text { HELPFUL } \\
\text { RELATIONSHIP }\end{array}$ & - & $1(.05 / 4)$ & - & - & $2(.10 / 8)$ & $1(.17 / 13)$ \\
\hline OTHER & - & $1(.05 / 4)$ & - & - & $1(.05 / 4)$ & $1(.17 / 13)$ \\
\hline SUB TOTAL & $10(1.25)$ & $27(1.23)$ & $7(1.40)$ & $10(1.67)$ & $26(1.30)$ & $8(1.33)$ \\
\hline $\begin{array}{l}\text { *NUMBER OF } \\
\text { RESPONDENTS }\end{array}$ & $8(100 \%)$ & $22(100 \%)$ & $5(100 \%)$ & $6(100 \%)$ & $20(100 \%)$ & $6(100 \%)$ \\
\hline TOTALS & $44(1.26)$ & & & $36(1.38)$ & & $8(1.33)$ \\
\hline
\end{tabular}

* Note: This figure refers to the number of subjects who identified benefits to the client. A subject may have given responses that were recorded in more than one category.

Table 9.2 suggests that:

1. The response rate for the three broad categories of location (physical, psychiatric and paediatric) are much the same $-1.26,1.38 \& 1.33$ respectively. When location is divided into the short and long-term settings, a difference in response rate is observed but this is not significant (short-term 1.42 and long-term 1.27; chi-square $=0.20$, d.f. $=1$, n.s.). 
2. Skill acquisition and self-confidence are relevant in all locations and contexts (acute, rehabilitation, community and paediatrics).

3. The three long term settings (physical and psychiatric rehabilitation and paediatrics) identified the greatest range of sub-categories.

4. There is a high degree of agreement as to the major benefits for the client in the community setting. All respondents identified the category, 'skill acquisition'.

\subsection{Discussion}

Quite clearly the pragmatic consideration of skill acquisition was seen as being the major benefit with personal feelings of greater self-confidence being the second choice.

The patterns of responses indicates that the respondent groups viewed the benefits to the clients in a similar fashion, ie. skill acquisition mentioned most frequently, then self-confidence and control of life. Notably, neither enjoyment nor helpful relationships were mentioned by stage II students, possibly indicating this type of understanding develops at a later stage of experience.

The ability to take the client's perspective requires an understanding of his/her 'life world'. This term is used by Crepeau (1991) to refer to an individual's 
physical and social reality. She reports that fully understanding the life-world of another person is a difficult process because each individual interprets their observations of others' behaviour from his or her own perspective. So to enter another's life world, a reflective stance is needed from which conscious interpretations can be made to extract meaning from the interactions.

Crepeau (1991) says that there are a variety of barriers to taking the client's perspective one of which is the dominance of the medical model which tends to separate the illness from the client's experience. Such a separation can lead to the tendency for the health care professionals to focus on technical problems rather than everyday experiences and needs. The data which has arisen from question four may be an example of this dichotomy where the focus on skill acquisition is a technical concern whereas the focus on feelings arises from involvement with the client's life-world.

It is perhaps surprising that the clinicians did not show a balance in favour of identifying the client's feelings as this type of understanding should develop with experience as explained by Dreyfus and Dreyfus's (1986) Model of Skill Acquisition. The model identifies novices as focussing on 'context free' elements whereas in the next level, the advanced beginner is able to consider elements that relate to the patient as an individual, ie. the concern moves to 'situational' elements. The qualitative data analysis provides another perspective on this aspect of problem representation and will be discussed in chapter 12 . 


\subsection{Summary}

Statistical significance has not been established for any of the issues in this question. However, the general trend for clinicians to have a higher response rate when compared to students has been evident.

One of the themes that has emerged is that the technical side of the occupational therapist's work is more likely to be made explicit than the understandings that are gained from involvement with the concerns of the individual client. 


\section{CHAPTER TEN}

\section{QUESTION 5: DISCHARGE CRITERIA}

\subsection{Introduction}

This section is an analysis of question 5: "What criteria do you think should be met before he/she is discharged ?"

In the development phase of the interview, this particular question was not included for four of the second year students which reduces the total number of possible responses for this group to 10 . For some respondents the question was not relevant because their chosen client was not likely to ever be discharged from therapy. This was true of one of the stage II students, two of the stage III students and six clinicians. This therefore reduced the total numbers in each group to:

9 Stage II students; 30 Stage III students; 16 Clinicians.

Question five was included with the intention of obtaining another view of the treatment outcomes, ie. a long-term view as compared to the short-term view of question three. The summary of the responses was again divided into performance components and occupational performance outcomes. 


\subsection{Comparisons Between the Groups}

Table 10.1 is a summary of the types of problems (performance component and occupational performance) that were identified by each of the respondent groups.

Table 10.1

Summary of the Responses Given by the Three Respondent Groups

\begin{tabular}{|c|c|c|c|c|}
\hline \multirow[b]{3}{*}{$\begin{array}{l}\text { DISCHARGE } \\
\text { CRITERIA: }\end{array}$} & \multicolumn{3}{|c|}{ RESPONDENTS } & \multirow[b]{2}{*}{ TOTAL } \\
\hline & \multicolumn{2}{|c|}{$\begin{array}{l}\text { STUDENTS } \\
\text { STAGE II } \quad \text { STAGE III }\end{array}$} & CLINICIANS & \\
\hline & $\mathrm{N}=9$ & $\mathrm{~N}=30$ & $N=16$ & $\mathrm{~N}=55$ \\
\hline $\begin{array}{l}\text { PERFORMANCE } \\
\text { COMPONENTS }\end{array}$ & $5(0.55)$ & $5(0.17)$ & $4(0.25)$ & $14(0.25)$ \\
\hline $\begin{array}{l}\text { OCCUPATIONAL } \\
\text { PERFORMANCE }\end{array}$ & $9(1.00)$ & $31(1.03)$ & $21(1.32)$ & $61(1.12)$ \\
\hline TOTALS & $14(1.55)$ & $36(1.20)$ & $25(1.57)$ & $75(1.36)$ \\
\hline
\end{tabular}

Table 10.1 indicates that:

1. The stage III students had a lower response rate compared to the stage II students and clinicians ( $1.20 \mathrm{cf} .1 .55 \& 1.57)$, however the result is not statistically significant (chi-square $=1.10$, d.f. $=2$, n.s.).

2. All respondent groups put much greater emphasis on the occupational performance criteria compared to the performance components; in particular the stage III students and clinicians.

Tables 10.2 and 10.3 provide a more detailed analysis of the above responses these summaries are listed in order of frequency. 
Table 10.2

Summary of Performance Component Discharge Criteria

\begin{tabular}{|lcccc|}
\hline \multicolumn{5}{c}{ RESPONDENTS } \\
& \multicolumn{2}{c}{ STUDENTS } & CLINICIANS & TOTAL \\
DISCHARGE & STAGE II & STAGE III & N $=16$ & $\mathrm{~N}=55$ \\
\hline CRITERIA: & $\mathrm{N}=9$ & $\mathrm{~N}=30$ & $\mathrm{~N}$ & \\
\hline & & & & \\
SENSORY MOTOR & $2(.22 / 40)$ & $2(.07 / 40)$ & $2(.13 / 50)$ & $5(.11 / 43)$ \\
SELF RESPONSIBILITY & $2(.22 / 40)$ & $2(.07 / 40)$ & $1(.06 / 25)$ & $2(.04 / 14)$ \\
MENTAL STATE & $1(.11 / 20)$ & - & $1(.06 / 25)$ & $1(.02 / 7)$ \\
COGNITION & - & $1(.03 / 20)$ & - & $14(.25)$ \\
\hline $\begin{array}{l}\text { TOTAL RESPONSES } \\
\text { *NUMBER OF } \\
\text { RESPONDENTS }\end{array}$ & $5(.55)$ & $5(.17)$ & $4(.25)$ & $12(22 \%)$ \\
\hline
\end{tabular}

*Note: This figure refers to the number of subjects who identified the performance component discharge criteria. A subject may have given responses that were recorded in more than one category.

\subsubsection{The Performance Componentt Skills}

The sensory motor outcomes were expressed as either related to improvement in general activity tolerance level or in specific movements. The responses were relevant to clients in a range of settings.

The self responsibility sub-category referred to the ability of an individual to be realistic about what they were able to achieve, to recognise when assistance might be required and to ensure that he or she was not a risk to themselves or to other 
people. All respondents who mentioned this were working in the psychiatric field.

Two respondents, both in psychiatric rehabilitation areas, referred to the client's mental state needing to be stabilised prior to discharge, ie. his/her "mood is not fluctuating a lot" (B/2).

Only one respondent referred to any discharge criteria that might be considered in the cognition, sub-category and this was for the client to have an "improved concentration span" (A/14).

Table 10.2 indicates that:

1. The number of performance component discharge criteria categories identified per respondent, is greater for the stage II group than the stage III and clinician groups $(0.55,0.17 \& 0.25$ respectively). However, numbers involved are too small to warrant a statistical analysis.

\subsubsection{The Occupational Performance Skills}

Table 10.3 summarises the occupational performance discharge criteria.

$\underline{\mathrm{ADL}}$ related mainly to concerns regarding self care skills such as dressing and bathing. Budgeting ability was mentioned in two instances with cooking and general mobility in the home mentioned by several respondents. The need for assistive devices (ie. non-human support such as bath seats and kitchen aids) and support networks (ie. human supports such as district nursing, meals on wheels, and community occupational therapy services) was raised. There was concern that any home alterations and support networks should be in place prior to the client being discharged. Only one respondent stated the need for a care-giver to be given 
advice regarding the best way to assist a disabled family member. Safety was also a theme that was evident in regards to clients' independence. As can be seen in the Table 10.3, ADL was given the most support by the three respondent groups as a discharge criteria.

Table 10.3

Summary of the Occupational Performance Discharge Criteria

\begin{tabular}{|lcccc|}
\hline & \multicolumn{3}{c}{ RESPONDENTS } & \\
& \multicolumn{2}{c}{ STUDENTS } & CLINICIANS & TOTAL \\
DISCHARGE & STAGE II & STAGE III & & N $=55$ \\
\hline CRITERIA: & $\mathrm{N}=9$ & $\mathrm{~N}=30$ & $\mathrm{~N}=16$ & $36(.67 / 59)$ \\
\hline ADL & $6(.67 / 67)$ & $18(.60 / 58)$ & $12(.75 / 57)$ & $10(.19 / 16)$ \\
SOCIAL & $1(.11 / 11)$ & $6(.20 / 19)$ & $3(.19 / 14)$ & $7(.13 / 11)$ \\
ACTIVITY & $1(.11 / 11)$ & $3(.10 / 10)$ & $3(.19 / 14)$ & $5(.09 / 8)$ \\
EMPLOYMENT & - & $2(.07 / 6)$ & $3(.19 / 14)$ & $3(.06 / 5)$ \\
EDUCATION & $1(.11 / 11)$ & $2(.07 / 6)$ & - & $61(1.13)$ \\
\hline TOTAL RESPONSES & $9(1.00)$ & $31(1.03)$ & $21(1.32)$ & $51(93 \%)$ \\
*NUMBER OF & $8(89 \%)$ & $28(93 \%)$ & $15(94 \%)$ & \\
RESPONDENTS & & & & \\
\hline
\end{tabular}

*Note: This figure refers to the number of subjects who identified the occupational performance discharge criteria. A subject may have given responses that were recorded in more than one category.

With one exception, social competence was voiced only by respondents who were in psychiatric settings. Issues raised were those of clients needing to monitor their speech content in order to interact appropriately, to feel confident in doing this, to manage anger so that uncontrolled outbursts did not impair social relationships, and, in one instance to learn English as a second language. Thus social ability is 
being viewed in an integrated way where social skills are not the only issues but aspects such as self-confidence and ability to monitor behaviour are included as ingredients essential to social competence.

Involvement in activity was mentioned by all respondent groups. Some were concerned that individuals were able to carry out meaningful activities within their home environment, others were concerned that interest in an activity took the person out of the home environment in order that he/she had social contact.

Both the employment and education skills issues were related to specific settings where individuals were attending for the purpose of developing these skills, for example, in a school or an industrial therapy unit.

Table 10.3 indicates that:

1. The ADL criteria was of major concern to all respondent groups (average response rate of 0.67 ).

2. A high percentage of respondents referred to discharge criteria in the occupational performance categories (average of 93\%).

3. The response rate for clinicians is higher than the student groups (1.32 cf $1.00 \& 1.03$ ) however the result is not statistically significant (chisquare $=0.70$, d.f. $=2$, n.s.). 


\subsection{Location of Respondents}

Table 10.4 provides a summary of the two major categories of problems that were generated by the respondents with respect to the locations in which they were working at the time of the interview.

Table 10.4

Location of the Respondents and the Summary of Responses

\begin{tabular}{|c|c|c|c|c|c|c|}
\hline \multirow[b]{3}{*}{$\begin{array}{l}\text { DISCHARGE } \\
\text { CRITERIA }\end{array}$} & \multicolumn{5}{|c|}{ LOCATIONS } & \multirow{3}{*}{$\begin{array}{c}\text { PAEDIATRIC } \\
\text { N=5 }\end{array}$} \\
\hline & \multicolumn{3}{|c|}{ PHYSICAL } & \multicolumn{2}{|c|}{ PSYCHIATRIC } & \\
\hline & $\begin{array}{l}\text { Acute } \\
\mathrm{N}=7\end{array}$ & $\begin{array}{l}\text { Rehab. } \\
N=17\end{array}$ & $\begin{array}{l}\text { Com. } \\
\mathrm{N}=4\end{array}$ & $\begin{array}{l}\text { Acute } \\
\mathrm{N}=5\end{array}$ & $\begin{array}{l}\text { Rehab. } \\
N=17\end{array}$ & \\
\hline $\begin{array}{l}\text { PERFORMANCE } \\
\text { COMPONENT }\end{array}$ & $1(0.17)$ & $2(0.11)$ & - & $1(0.20)$ & $9(0.54)$ & $1(0.25)$ \\
\hline $\begin{array}{l}\text { OCCUPATIONAL } \\
\text { PERFORMANCE }\end{array}$ & $7(1.00)$ & $18(1.06)$ & $4(1.00)$ & $5(1.00)$ & $21(1.24)$ & $6(1.50)$ \\
\hline SUB-TOTAL & $8(1.14)$ & $20(1.18)$ & $4(1.00)$ & $6(1.20)$ & $30(1.78)$ & $7(1.40)$ \\
\hline TOTALS & $32(1.14)$ & & & $36(1.64)$ & & $7(1.40)$ \\
\hline
\end{tabular}

Table 10.4 indicates that:

1. The response rates varied between locations - physical 1.14; psychiatric 1.64 ; paediatric 1.40 . This variation is not statistically significant (chi-square $=3.05$, d.f. $=2$, n.s.).

2. In all settings, the response rates for the occupational performance criteria were much higher than those for the performance components. 
3. If the locations data is re-organised into long-term (rehabilitation and paediatric) and shorter-term (acute and community) settings, a difference in the response rate is observed but this is not statistically significant (long-term 1.46 and short-term 1.13; chi-square $=1.0$, d.f. $=1, \mathrm{n} . \mathrm{s}$.). No real difference is observable in the distribution of these settings in respect of the performance components and occupational performance $($ chi-square $=0.90$, d.f. $=1$, n.s. $)$.

4. No respondents in the community settings identified performance component discharge criteria.

A more detailed analysis of the responses can be found in Tables C.1 and C.2. These are located in Appendix C.

\subsection{Discussion}

A comparison of the two major categories of discharge criteria indicates that the majority of respondents identified criteria in the occupational performance category $(93 \%)$, by contrast relatively few mentioned the performance component category $(22 \%)$. Of the twelve respondents who did identify performance components, eight also identified occupational performance criteria. The remaining four were in rehabilitation settings - three were working in psychiatric rehabilitation and of those, two were in industrial therapy units and the other one in a rehabilitation programme; the final respondent was working in the specialised area of hand therapy. 
The identification of discharge criteria in the occupational performance category is consistent with Kielhofner's statement quoted in chapter eight, that role functioning is ultimately the important issue for occupational therapists. However, the fact that some respondents identified improvement in performance components as the final outcome raises the issue of whether or not these are also valid discharge criteria.

Some of the earlier categories listed under treatment outcomes are now missing, ie. interpersonal and intrapersonal. Such issues now seem to be related to occupational performance outcomes. For example, one respondent said ...

"he should be able to communicate on a level where ..... he can take some sort of control in his abilities to ..... socially interact with people" (A/11).

In this example, interpersonal skills are being combined with intrapersonal skills to ensure that the individual will be able to cope with forming and maintaining relationships.

This question has focussed on the long-term views of treatment outcomes. In a recent article Flemming (1991b) suggests in relation to a client that...

"the ability to imagine new ways that this person could function in the future may be essential to Occupational Therapy practice." (p. 994)

This is in comparison to medical clinical reasoning where making a definitive diagnosis based on an accurate history is vital. Flemming suggests that a different kind of reasoning is indicated for occupational therapists. She refers to this as 
'conditional' reasoning ie. thinking strategies that enable therapists to place clients in the context of the past as well as the current and future. Some respondents quite clearly had this temporal view and were thinking into the future when the client's situation might be different eg.

"It's a continuing care setting... keeping her occupied took the greater priority... she had been through rehabilitation... I decided to make sure that she didn't go backwards... she was mentally alert and desperately wanting to be kept occupied... we are already having to change the activities for her... she is becoming slightly less able..." $\quad \mathrm{C} / 13$

Such reasoning puts the focus on the uniqueness of the individual. Experience enables the therapist to both anticipate long-term goals and also to understand that specific outcomes might be different for each individual.

\subsubsection{Comparisons Between the Treatment Outcomes (Q.3) and the Discharge Criteria (Q.5)}

These two questions both identify treatment outcomes, but the discharge criteria give a longer term view of the outcomes. A comparison of Tables 8.1 and 10.1 indicate trends from short-term to long-term outcomes. A logical progression would be that there should be less long-term outcomes overall and a decreasing number of performance component outcomes considered at the final stages of treatment.

The overall response rate did decrease for both stage III and clinician groups but increased for the stage II group. The stage III and clinician groups were also 
consistent with the prediction that the response rates for the performance component categories would decrease. The one aspect that was not expected was that stage II students had a higher response rate for the performance component long-term outcomes when compared to the short-term outcomes. A comparison of the three groups' responses to questions three and five indicates that the difference in response rates between the stage III students and clinician groups was strongly in the direction of favouring less performance components as outcomes, but this was in reverse for the stage II student group (see Table C.3 in Appendix C). The numbers are too small to test for significance.

As already speculated in chapter eight, it may be that for stage II students, the identification of performance component problems is a new experience and provides a focus because of their novelty value. Once the implication of this type of problem is integrated into the larger picture of treatment planning, the focus is lessened and the more functional outcomes achieve dominance as was true for the stage III group.

A comparison of the location tables (8.4 and 10.4) indicates that the physical and paediatric settings both conform to the above expectation of a decrease in the longterm outcomes, while for the psychiatric setting the opposite is true ie. the response rate increases for the long-term outcomes. The main contributing factor to this unexpected trend is the relatively high response rate for the performance components in the psychiatric rehabilitation area. 


\subsection{Summary}

Statistical significance has not been established for the differences between respondent groups and locations. However, the trend for ADL to be a major subcategory is evident. The response rate for the occupational performance categories for discharge criteria is higher than that for the performance component categories for all groups and in all settings. 


\section{CHAPTER ELEVEN}

\section{QUESTION 6: EFFECTIVENESS OF TREATMENT}

\subsection{Introduction}

The following is an analysis of question 6: "How effective do you think the treatment procedures are with this client? In an ideal world is there anything you would like to change ?"

In the development phase of this interview, this particular question was not included for eight of the second year students which reduces the total number of respondents in this group, from fifteen to six. The number of respondents were as follows: Stage II, N=6; Stage III, N=31; Clinicians, N=22.

The focus of the question was the identification of factors that limited treatment. While the majority of respondents gave responses which indicated that they viewed treatment as being less than ideal, some viewed treatment as being entirely satisfactory. A further group indicated why treatment was satisfactory yet also described some of the limitations.

Table 11.1 is a summary of the responses given by the three respondent groups. This has been divided into the two major categories of 'dissatisfied with treatment' and 'satisfied with treatment'. 
Table 11.1

Summary of Reasons the Responses Given by the Three Respondent Groups.

\begin{tabular}{|lcccc|}
\hline \multicolumn{4}{c|}{ RESPONDENTS } & \\
REASONS: & STAGE II & STAGE III & CLINICIANS & TOTALS \\
\hline & $\mathrm{N}=6$ & $\mathrm{~N}=31$ & $\mathrm{~N}=22$ & $\mathrm{~N}=59$ \\
\hline $\begin{array}{l}\text { WISSATISFIED } \\
\text { WITH TREATMENT }\end{array}$ & $7(1.16)$ & $29(0.94)$ & $25(1.16)$ & $61(1.03)$ \\
$\begin{array}{l}\text { SATISFIED } \\
\text { WITH TREATMENT }\end{array}$ & $1(0.17)$ & $10(0.32)$ & $10(0.48)$ & $21(0.36)$ \\
\hline & $8(1.33)$ & $39(1.26)$ & $35(1.64)$ & $82(1.39)$ \\
\hline
\end{tabular}

Table 11.1 indicates that:

1. The clinicians generated a greater number of responses compared to the students ( $1.64 \mathrm{cf}$. to $1.26 \& 1.33$ ). However the result is not significant (chi-square $=1.2$, d.f. $=2$, n.s.).

2. The response rate for the two major categories indicates that all three groups put more emphasis on reasons for dissatisfaction with treatment compared with satisfaction.

A more detailed analysis of the above results has been summarised in Tables 11.2 and 11.3 . 


\subsection{Dissatisfaction with Treatment}

Table 11.2 is a summary of the issues raised in respect of why there was dissatisfaction with treatment procedures. These are recorded in sequence of frequency of response.

The aspect most frequently raised was the need for more time to be spent with individual clients. The advantages of more time spent with the client were wide ranging for example,bringing about changes (in behaviour) more quickly, consolidating new learning for the client, and providing more information for the therapist on which to make informed decisions.

Lack of co-operation between members of the treatment team was another major reason for limitations on treatment. Some comments were made regarding the need for all team members to understand the contribution of each other to the overall management of the client. Others suggested that referrals for occupational therapy services should be earlier; by implication, for this to happen, doctors and other team members should know what the service provides.

The reality of treatment programmes was raised by stage III students and clinicians. There were a number of issues around this topic. Some felt that the settings they were working in did not adequately simulate real situations, especially in relation to self-care, work and social skills. Others felt that their client lacked the opportunity to practice skills in the real world and one respondent indicated that it was not helpful for the client to be surrounded by people who were ill and not managing their lives effectively. 
Table 11.2

Summary of Reasons for Dissatisfaction With Treatment

\begin{tabular}{|lcccc|}
\hline & \multicolumn{3}{c}{ RESPONDENTS } \\
REASONS: & STAGE II & STAGE III & CLINICIANS & TOTAL \\
\hline & $\mathrm{N}=6$ & $\mathrm{~N}=31$ & $\mathrm{~N}=22$ & $\mathrm{~N}=59$ \\
\hline TIME WITH CLIENT & $2(.33 / 29)$ & $6(.23 / 21)$ & $9(.41 / 36)$ & $17(.31 / 29)$ \\
TEAM WORK & - & $5(.16 / 17)$ & $5(.23 / 20)$ & $10(.17 / 16)$ \\
$\begin{array}{l}\text { REALITY OF } \\
\text { TREATMENT }\end{array}$ & - & $5(.16 / 17)$ & $2(.09 / 8)$ & $7(.12 / 11)$ \\
$\begin{array}{l}\text { HOSPITAL } \\
\text { ENVIRONMENT }\end{array}$ & $2(.33 / 29)$ & $4(.13 / 14)$ & $1(.05 / 4)$ & $7(.12 / 11)$ \\
$\begin{array}{l}\text { COMMUNITY } \\
\text { RESOURCES } \\
\text { PATIENT } \\
\text { MOTIVATION }\end{array}$ & - & $3(.10 / 10)$ & $4(.18 / 16)$ & $7(.12 / 11)$ \\
EQUIPMENT DELAY & - & $3(.10 / 10)$ & - & $5(.08 / 8)$ \\
INCONCLUSIVE & - & $2(.06 / 7)$ & $1(.05 / 4)$ & $3(.05 / 5)$ \\
HOME ENVIRONMENT & - & - & $2(.09 / 8)$ & $2(.03 / 3)$ \\
OWN ABILITIES & $1(.17 / 14)$ & - & $1(.05 / 4)$ & $2(.03 / 3)$ \\
\hline $\begin{array}{l}\text { TOTAL RESPONSES } \\
\text { *NUMBER OF } \\
\text { SUBJECTS }\end{array}$ & $7(1.16)$ & $29(.94)$ & $25(1.16)$ & $1(.02 / 2)$ \\
\hline
\end{tabular}

*Note: This figure refers to the number of subjects who identified a reason for being dissatisfied with treatment. A subject may have given responses that were recorded in more than one category.

The constraints imposed by the hospital environment varied from views on the actual occupational therapy resources, such as inadequate kitchen facilities for training patients in kitchen tasks, to the size and location of rooms. For example, a clinician who was working with the elderly said that ... 
"being situated on a ground floor would be ideal so that people could get out on public transport and use community facilities " (C/13).

The constraints of the hospital environment was also considered to affect the motivation of clients. One respondent (a student) related this to the treatment activity a client had been assigned; in this instance it was hard to know if the constraint was due to lack of resources or lack of imagination on the part of the occupational therapist.

Discharge from a hospital without adequate community resources was considered by some respondents as being likely to lead to a deterioration of the client's condition and/or their being restricted to their own home. Mention was made of follow-up services, community facilities for clients to attend and support groups.

Another aspect identified only by students was the frustration of clients' lacking in motivation or insight and therefore not taking advantage of the programme being offered. As one student said: "If people had insight all the time, that would be really good ....." (A/14).

The time taken for the supply of aids and home alterations was a concern for those working in community settings. For some clients, by the time funding was arranged, their condition had deteriorated with the result that it was too late for the adaptation to their home to be helpful.

Only clinicians working in rehabilitation settings raised the issue of treatment programmes being inconclusive. As one interviewee said.. 
"It's difficult to know if treatment affects improvement in cognitive function, or if spontaneous recovery accounts for it " (C/5).

The other respondent was more concerned about deterioration in a patient's condition, ie. whether or not he was ultimately going to be blind. This uncertainty made it difficult for the clinician to decide on treatment priorities.

Two different perspective's on the home situation were raised - one respondent referred to putting families under stress if patients were discharged too early, and the other mentioned a client who ideally should not live alone.

The other issue was on a noticeably different theme. A student who had been working in a specialised paediatric setting stated that treatment procedures...

"could improve their effectiveness with my further training, my further understanding and my greater experience" (B/14).

This is an interesting perspective on the treatment restrictions as it is the only instance when a respondent has indicated that they themselves might influence treatment. In her development of a model for clinical reasoning in physiotherapy, Higgs (1990) considers that both cognitive and metacognitive reasoning skills are the driving forces behind clinical decision making.

Table 11.2 indicates that:

1. Some differences exist within the categories between groups eg. team work and reality of treatment were not issues of concern to stage II students whereas patient motivation was not an issue for clinicians; however the fact that the effectiveness of treatment was sometimes 
inconclusive, was a concern for clinicians. However the numbers in the various 'cells' of the table are too small to justify a more detailed statistical analysis.

2. There was a difference in the response rates with the stage III group being the lowest ( $0.94 \mathrm{cf} .1 .16 \& 1.16)$. However this difference is not statistically significant (chi-square $=0.60$, d.f. $=2$, n.s.).

\subsection{Satisfaction with Treatment}

The views of those who regarded treatment as being effective are summarised in Table 11.3.

Each respondent only gave one reason for success. This is in contrast to the reasons for dissatisfaction with treatment which often raised more than one issue for each respondent. The following is a summary of the issues:

Treatment procedures have enabled an individual to be independent and return to their home environment. The four who mentioned this made very similar statements. For example one clinician said that ..

"OT treatment is really effective 'cos it allows the person to go home " (C/9). 
Table 11.3

Summary of Reasons for Satisfaction With Treatment

\begin{tabular}{|c|c|c|c|c|}
\hline \multirow[b]{2}{*}{ REASONS: } & \multicolumn{3}{|c|}{ RESPONDENTS } & \multirow[b]{2}{*}{$\begin{array}{c}\text { TOTAL } \\
\mathrm{N}=59\end{array}$} \\
\hline & $\begin{array}{c}\text { STAGE II } \\
\quad \mathrm{N}=6\end{array}$ & $\begin{array}{c}\text { STAGE III } \\
\quad \mathrm{N}=31\end{array}$ & $\begin{array}{c}\text { CLINICIANS } \\
\quad \mathrm{N}=22\end{array}$ & \\
\hline INDEPENDENCE & - & $1(.03 / 3)$ & $3(.14 / 14)$ & $4(.07 / 6)$ \\
\hline PROVISION OF AIDS & - & $3(.10 / 10)$ & $1(.05 / 5)$ & $4(.07 / 7)$ \\
\hline MEET CLIENTS GOALS & $1(.17 / 17)$ & - & $2(.09 / 9)$ & $3(.05 / 5)$ \\
\hline $\begin{array}{l}\text { WITHIN CLIENTS } \\
\text { ABILITY }\end{array}$ & - & $2(.06 / 6)$ & $1(.05 / 5)$ & $3(.05 / 5)$ \\
\hline CLIENT SATISFACTION & - & $1(.03 / 3)$ & $1(.05 / 5)$ & $2(.03 / 3)$ \\
\hline GOOD TEAM WORK & - & - & $1(.05 / 5)$ & $1(.02 / 2)$ \\
\hline IMPROVEMENT SEEN & - & - & $1(.05 / 5)$ & $1(.02 / 2)$ \\
\hline OTHER & - & $3(.10 / 10)$ & - & $3(.05 / 5)$ \\
\hline TOTAL RESPONSES & $1(.17)$ & $10(.32)$ & $10(.48)$ & $21(.36)$ \\
\hline $\begin{array}{l}\text { NUMBER OF } \\
\text { RESPONDENTS }\end{array}$ & $1(17 \%)$ & $10(32 \%)$ & $10(48 \%)$ & $21(36 \%)$ \\
\hline
\end{tabular}

Problems can be solved by the provisions of aids, equipment and other resources and ensuring the individual can use these. Resources may include home-help, district nurse, district occupational therapist and social worker. This was related to the first category where the issue is enabling people to return to their own homes, however, in this instance as stated by one student the individual...

"doesn't have to be totally independent if she's utilising the resources that are made available to her, like home-help or rails, then that is satisfactory " (A/8). 
The client gains satisfaction from being involved in activities and knowing that a problem that was causing concern has been solved. For instance one student referred to a patient being...

"happier going home -- at night because she knows that the next day she can go out and see some friends rather than staying at home and getting lonely " $(\mathrm{A} / 15)$.

The clients goals are met through the treatment sessions. For instance one clinician said that treatment... "will enable him to live how he wants to live" (C/19) and another felt it was important to "suit the customer" (C/7).

In some instances treatment that was ongoing was considered successful because it was within the limitations of the client's ability. Progress might be very slow but no more could be expected considering the client's limitations.

One clinician described good working relationships with physiotherapy as a critical issue in ensuring treatment was effective and said it was "a split between the disciplines and that works fairly well" $(\mathrm{C} / 8)$.

Another clinician stated that treatment had been effective... "because I was able to see improvement by comparing initial written records with the current ones" (C/6). In this instance the issue was to do with improvement being evident when comparing the current situation with baseline data.

Of the group recorded as 'other', the respondents gave vague responses. Two did not give any particular reason as to why treatment was effective. One student 
referred to a client being satisfactory because he was both mobile and aware of safety issues.

Table 11.3 indicates that:

1. The response rate for satisfaction with treatment increases with experience $(0.17<0.32<0.48)$, however, this difference is not significant (chi-square $=1.5$, d.f. $=2$, n.s.).

2. There is a wide range of responses compared to the number of respondents. This has resulted in low response rates.

\subsection{Location of Respondents}

Table 11.4 provides a summary by respondent location, of the two major categories of responses to the issue of treatment effectiveness.

Table 11.4 indicates that:

1. The response rate varies across the three major settings (physical, psychiatric and paediatric) $1.55,1.25$ and 1.00 respectively, however, the result is not statistically significant (chi-square $=1.4$, d.f. $=2$, n.s.). Similarly, the variation in their distribution between dissatisfaction and satisfaction with treatment is not significant (chi-square $=1.0$, d.f. $=1$, n.s.; paediatrics has not been included because of the low cell numbers). 
Table 11.4

Location of the Respondents and the Summary of Responses

\begin{tabular}{|c|c|c|c|c|c|c|}
\hline \multirow[b]{3}{*}{$\begin{array}{l}\text { DISCHARGE } \\
\text { CRITERIA }\end{array}$} & \multicolumn{5}{|c|}{ LOCATIONS } & \multirow{3}{*}{ PAEDIATRIC } \\
\hline & \multicolumn{3}{|c|}{ PHYSICAL } & \multicolumn{2}{|c|}{ PSYCHIATRIC } & \\
\hline & $\begin{array}{l}\text { Acute } \\
\mathrm{N}=7\end{array}$ & $\begin{array}{l}\text { Rehab. } \\
\mathrm{N}=21\end{array}$ & $\begin{array}{l}\text { Com. } \\
N=5\end{array}$ & $\begin{array}{l}\text { Acute } \\
\mathrm{N}=4\end{array}$ & $\begin{array}{l}\text { Rehab. } \\
N=16\end{array}$ & \\
\hline $\begin{array}{l}\text { DISSATISFACTION } \\
\text { WITH TREATMENT }\end{array}$ & $9(1.29)$ & $22(1.05)$ & $4(0.80)$ & $6(1.50)$ & $14(0.86)$ & $6(1.00)$ \\
\hline $\begin{array}{l}\text { SATISFACTION WITH } \\
\text { TREATMENT }\end{array}$ & $3(0.43)$ & $11(0.52)$ & $2(0.40)$ & $1(0.17)$ & $4(0.20)$ & - \\
\hline SUB-TOTALS & $12(2.00)$ & $33(1.50)$ & $6(1.20)$ & $7(1.67)$ & $18(1.13)$ & $6(1.00)$ \\
\hline TOTALS & & & $51(1.55)$ & & $25(1.25)$ & $6(1.00)$ \\
\hline
\end{tabular}

2. When the location data is re-organised into long and short-term settings, a small difference (not significant) in response rates can be observed (long-term 1.33 and short-term 1.56; chi-square $=0.6$, d.f. $=$ 1, n.s.). The distribution of the satisfaction and dissatisfaction categories between the long and short-term settings shows little difference (chi-square $=0.005$, d.f. $=1$, n.s. $)$.

3. None of the respondents in paediatric settings expressed reasons for satisfaction with treatment.

A more detailed analysis of the above responses has been summarised in tables D. 1 and D.2 See Appendix D.

Table D.1 indicates that the two highest response rates for any one category of dissatisfaction with treatment came from the community and acute psychiatric 
areas, ie. equipment delay in the community setting (0.60) and insufficient time with clients in the psychiatric acute setting $(0.50)$.

Issues that were evident in most of the settings were time with the client, team work and reality of treatment. One exception to this was community settings where 'reality of treatment' and 'inadequate time' were not included. The former of these is understandably not an issue as the service is being provided in the client's own home. The other exception was in the acute psychiatric setting where poor 'co-ordination of team work' was not mentioned as a concern.

\subsection{Discussion}

This particular interview question has raised the issue of the 'restrictions on the operators' in information processing terminology. Many of the restrictions were related to hierarchical systems where early discharge and inadequate staffing can result in limited time spent with a client. Poor communication between staff can also be a major block to providing the most effective treatment. It is interesting to note that the majority of respondents did have some reservations about the effectiveness of treatment. This included both human and non-human resources.

Differences between the clinician and students groups were most notable in the area of patient motivation. Clinicians did not view this as a problem with respect to treatment effectiveness - presumably they did not ignore this aspect of the client but viewed it as a symptom to be dealt with rather than an aspect that thwarted their treatment plans. Students, on the other hand, were more concerned about their plans being frustrated by unco-operative clients. The majority of respondents were in physical rehabilitation settings which is perhaps surprising as poor 
motivation is most commonly associated with mental illness. Possibly this difficulty has more of an impact in locations where it is not expected.

Another area of difference in response rate was in respect of the constraints imposed by the hospital environment which was mentioned less frequently by the clinician group. This may be because they have been working in this setting for a longer period of time and so have become accustomed to working within the constraints whereas the students are viewing the situation with newer eyes and are more sensitive to such restrictions. Logically, no respondents from either community or paediatric services mentioned this aspect.

Inconclusive outcomes of treatment was only raised by the clinicians - possibly students are unable to consider this type of uncertainty at this stage and need to feel more in control.

Overall, the majority of stage II students concerns were those dealing with direct client contact $(71 \%)$ ie. time with client, patient motivation and own abilities. On the other hand, stage III student and clinicians put less focus on these areas (31\% $\& 36 \%$ respectively) and more on broader issues relating to resources, team-work and the reality of treatment.

Only a few respondents indicated that there was no more room for improvement in treatment procedures. This included one stage II student (17\%), eight stage III students $(26 \%)$ and five of the clinician group (23\%).

Because most of the constraints seemed to be related to hierarchical systems one might speculate that those who were not working within such environments would be the most satisfied. This was true for some respondents. eg. three out of 
the four who were located in a Hospice and five of the six who were working in rehabilitation settings located in the community (such as a day centre for disabled people), indicated only satisfaction with treatment. These settings do not have strict hierarchical systems so the therapist is able to be relatively autonomous in her/his work.

The remaining six respondents were in a variety of hospital based locations three in physical rehabilitation, two in psychiatric rehabilitation and only one in an acute medical/surgical ward. In contrast to those mentioned in the above paragraph, these settings are constrained by hospital hierarchical systems. This suggests that it is possible to be entirely satisfied with treatment procedures within hospital settings.

Some respondents indicated that treatment had both satisfactory and unsatisfactory features. For instance, one clinician (C/9) said that although treatment was satisfactory because it enabled the client to return home with some skills accomplished, further ADL skills could have been achieved if more time had been available. Another respondent (A/15) said that the client in question was much more satisfied with her life-style but ideally it would be better for her to live with someone else than by herself. 


\subsection{Summary}

Although, the clinician group had a higher response rate than the student groups, there was no statistical significance in the data in respect of the differences between groups and locations. There was a trend for least experienced group (ie. stage II students) to be more focused on issues that were related to client contact while the other two groups were concerned about broader issues. 


\section{CHAPTER TWELVE}

\section{“HORIZONTAL” DATA ANALYSIS}

\subsection{Introduction}

To date, the analysis of the data had been approached as a 'vertical' exercise where all responses to each of the questions have been considered in turn, themes extracted and differences between respondent groups and locations identified. The major differences to date as shown by statistical analysis has been with respect to the location of respondents rather than the degree of expertise.

In the course of conducting the interviews, it was noticeable that there were possible patterns in the way in which students and clinicians responded to the questions, taken collectively. These differences have not been evident in the question by question analysis, so to capture the 'qualitative' elements, each of the interviews was reviewed in a 'horizontal' manner. During this review it became apparent that there were a number of issues that differentiated the interviewees so these became the basis for a further analysis of the data.

The issues that arose were:

1. The logic between the problems, outcomes and beliefs, ie. the extent to which there was a clear line of reasoning evident throughout the interview. There were two major types of inconsistencies in the reasoning processes - one related to the problems and the other related to the outcomes:

i) Some respondents did not identify all of the problems in response to question one ie. other problems arose in the course of the interview. 
ii) Some identified treatment outcomes and/or discharge criteria that were not apparently related to the initial problems.

Despite some discrepancies between problem and outcomes occurring, there was usually a logical flow of thought that could be identified in the interview. The following analysis differentiates between those whose flow of thought was consistent with the problems and/or with the outcomes.

2. Elaboration of information, ie. the extent to which justification was given for claims made and a rationale provided to explain the answers to questions.

3. The human dimension, ie. the extent to which the respondent gave a clear sense of the personal identity of the client being discussed as apposed to a general description that could have applied to a number of individuals.

The interviews were taken in tum and rated on the following criteria:

\section{Focus on the problem:}

3 Problems identified in questions one and two are complete, clearly stated and related to outcomes.

2 Some problems are stated but are not complete as more information is given later.

1 No problems identified in response to question one but are identified later in the interview.

$0 \quad$ Problems never identified. 


\section{Focus on the Outcomes:}

3 Clearly focussed, logical progression from problems to outcomes and the beliefs are consistent with this progression.

2 Outcomes are stated but are not all related to the initial problems.

1 Outcomes appear unrelated to the initial problems.

$0 \quad$ No outcomes mentioned.

\section{Elaboration:}

3 Provides justification for claims, descriptive responses to questions.

2 Attempts some justification for claims, may need to be prompted to do this.

1 Does not attempt any justification, answers questions in a matter-offact way without explanations.

$0 \quad$ Not applicable.

\section{Human Dimension:}

3 Provides a clear sense of the personal identity of the client as an individual

2 Gives some sense of the individual as apposed to a general description.

1 Very general. Could have applied to any individual with the given problem.

$0 \quad$ Not applicable.

The results were then subjected to a t-test analysis for the purpose of making comparisons between the three respondent groups. 


\subsection{Comparisons Between Groups}

Tables 12.1 and 12.2 provide a summary of the analysis that was carried out using the above criteria.

Table 12.1

Means and Standard Deviations for Focus (Problems and Outcomes), Elaboration and Human Dimension - Comparison Between Groups

\begin{tabular}{|llll|}
\hline & $\begin{array}{c}\text { Stage II } \\
\mathrm{N}=14\end{array}$ & $\begin{array}{c}\text { Stage III } \\
\mathrm{N}=31\end{array}$ & $\begin{array}{c}\text { Clinicians } \\
\mathrm{N}=22\end{array}$ \\
\hline FOCUS PROBLEM & $2.14( \pm 0.95)$ & $2.68( \pm 0.54)$ & $2.55( \pm 0.67)$ \\
FOCUS OUTCOMES & $2.07( \pm 0.65)$ & $2.60( \pm 0.52)$ & $2.71( \pm 0.55)$ \\
ELABORATION & $1.57( \pm 0.60)$ & $1.77( \pm 0.75)$ & $2.27( \pm 0.67)$ \\
HUMAN DIMENSION & $1.46( \pm 0.60)$ & $1.44( \pm 0.62)$ & $2.25( \pm 0.88)$ \\
\hline
\end{tabular}

Table 12.2 indicates that:

1. There are no significant differences between the three groups in their focus on problems, but the difference between stage II \& III is close to significance $(\mathrm{t}=1.99, p=0.06)$.

2. There is a strong difference between both clinicians and stage III students in comparison with stage II in their focus on outcomes; no difference exists between stage III and clinicians. 
Table 12.2

Results of t-tests Between Groups for Scores on Focus (Problems and Outcomes), Elaboration and Human Dimension

\begin{tabular}{|c|c|c|c|c|}
\hline VARIABLE & COMPARISON & t-VALUE & PROBABILITY & SIGNIFICANCE \\
\hline FOCUS PROBLEM & Stage II \& III & 1.99 & 0.06 & No \\
\hline FOCUS PROBLEM & Stage II \& clinicians & 1.52 & - & No \\
\hline FOCUS PROBLEM & Stage III \& Clinicians & 0.78 & - & No \\
\hline FOCUS OUTCOME & Stage II \& III & 2.93 & $<0.01$ & $* *$ \\
\hline FOCUS OUTCOME & Stage II \& clinicians & 3.17 & $<0.01$ & $* *$ \\
\hline FOCUS OUTCOME & Stage III \& Clinicians & 0.74 & - & No \\
\hline ELABORATION & Stage II \& III & 0.83 & - & No \\
\hline ELABORATION & Stage II \& clinicians & 2.95 & $<0.01$ & $* *$ \\
\hline ELABORATION & Stage III \& Clinicians & 2.50 & $<0.05$ & $*$ \\
\hline $\begin{array}{l}\text { HUMAN } \\
\text { DIMENSION }\end{array}$ & Stage II \& III & 0.10 & - & No \\
\hline $\begin{array}{l}\text { HUMAN } \\
\text { DIMENSION }\end{array}$ & Stage II \& clinicians & 2.95 & $<0.01$ & $* *$ \\
\hline $\begin{array}{l}\text { HUMAN } \\
\text { DIMENSION }\end{array}$ & Stage III \& Clinicians & 3.93 & $<0.001$ & $* * *$ \\
\hline
\end{tabular}

* Significance has been represented by: ${ }^{*} \mathrm{p} \leq 0.05 ;{ }^{* *} \mathrm{p} \leq 0.01 ;{ }^{* * *} \mathrm{p} \leq 0.001$. Probabilities are shown only if $p \leq 0.10$.

3. In relation to elaboration, no difference was found between stage II and stage III, but clinicians obtained a significantly higher score than both these groups.

4. There is no difference between stage II and stage III students in their scores on the human dimension, but clinicians obtained a significantly higher score than both these groups. 
In all, six of the twelve comparisons were significant at 0.05 level (or higher); by chance, only one pairing would be expected to be significant. This indicates that an important variation between the groups has been revealed.

\subsubsection{Focus and Logical Progression}

It was expected that there should be considerable familiarity with the problems and the intended treatment goals as the interviewer asked respondents to discuss a client they had been working with for a period of time. Table 12.2 indicates that this was particularly true for stage III and clinician groups. Stage II students were less able to convey this consistency and their line of reasoning was more in tune with the problems rather than the outcomes. It is apparent that stage III students are able to link together the various elements of problem representation in much the same way as the clinicians.

The greatest difficulty in providing a clearly focused account arose with stage II students in psychiatric settings. For instance, one student $(B / 2)$ identified communication within a group as being the priority problem, then stated that the outcome should be that the client investigate her use of time and finally that the discharge criteria was for the client to recognise when she was getting sick and be able to deal with that. There is no clear pattern of reasoning evident nor enough extra information given to make sense of the line of thought.

Another second year student (B/3) also did not give a clear indication as to how treatment was proceeding. The overriding theme was that the client was suffering from delusions and that ongoing assessment was required in order that the client's ability could be determined once her mood had stabilised. However, during the course of the interview various aspects emerged which could easily have been 
translated into the problems and outcomes asked for. It would appear that the respondent was totally distracted by the delusional state of the client.

However, lack of clear focus was not confined to students. One clinician $(\mathrm{C} / 5)$ in a psychiatric setting also showed inconsistencies between the problems and outcomes. For instance confusion and low mood state were identified as major problems yet outcomes were to do with the client using his initiative to join in a group activity. In this instance, the respondent considered that more assessments needed to be carried out before treatment outcomes could be determined.

For two students the outcome was confined to participating in groups that were treatment sessions rather than considering why this might be a useful treatment activity in relation to the life of the client. One student (B/1) made reference to the client being involved in a self-awareness group and the other student (B/4) felt that participation in a group would assist in dealing with behaviour problems and poor concentration.

In contrast to this narrow focus on participation in treatment sessions being the ultimate goal of treatment, two students identified outcomes that were far beyond the reach of the client. For instance, one $(B / 12)$ stated that the client would be able to sew independently and join in sewing classes in the community, however, the student was not taking into account the mental ability of the client and the fact that currently she was unable to sew a straight line without supervision. A second student (A/21) referred to her client (a child) being able to do something that he felt was of benefit to the community, however, at this stage in his life he was not even able to indicate 'yes' or 'no' in response to a question because of the extent of his physical disability. 
Both these students had difficulty in projecting into the future in a realistic way. Flemming (1991a) comments that this kind of thinking process..."is essentially imagination tempered by clinical experience and expertise " (p 1012). Students of course, lack both experience and expertise so it is not surprising that they also have difficulty with long term planning.

This study was not designed to comment on the reality of the treatment goals but it is an issue that is evident in the data and could be addressed in a future study. The above observations are able to be drawn from some interviews because of the nature of the information that was provided. Although it can be determined that they are unrealistic, they are however consistent with the problems identified by the respondents earlier in the interview which is the issue that this study was considering.

\subsubsection{Elaboration}

The ability to justify decisions and elaborate on issues develops with experience (see table 12.1) although this is also lacking in some clinicians' responses. For instance one clinician $(\mathrm{C} / 20)$ who was working in an orthopaedic ward gave very stilted responses with very little explanation unless prompted to do so. The following quotes from a stage III student $(\mathrm{A} / 15)$ is an example of a poorly elaborated response for question six.

Q6: HOW EFFECTIVE DO YOU THINK THE TREATMENT PROCEDURES ARE WITH THIS CLIENT? IN AN IDEAL WORLD IS THERE ANYTHING YOU WOULD LIKE TO CHANGE ?

"At the moment they appear to be quite effective, she's getting a lot out of what's happening, she's finding benefits from things that are happening." 


\section{IN WHAT KIND OF WAY? WHAT BENEFITS DO YOU MEAN ?}

"She's happier going home to her flat on her own at night because she knows that the next day she can go out and see some friends and do things rather than stay at home getting lonely."

\section{SO THINGS ARE OK?}

"Ideally she could have people or maybe even have a boarder or something like that, but that would be in the ideal world but she hasn't got a big enough house for all that, so she can't."

It can be noted that for the student to elaborate at all on the response, there needed to be further question added to facilitate this process. By contrast another student (A/10), also in a psychiatric setting, said in response to the same question:

"Yes, I think he needs more one to one, it's a big group that he's working with....it would be 20 plus patients in the environment that he's in ..... it's too easy for him to wander out ..... he needs more one to one attention to focus on his problems, I mean the craft groups aren't suited to him really ... if we're looking at getting him out into the community into a work environment ...he's not going to get out into the community on the skills that he's learning here, he's not going to be able to use them. It's all right the communication, interaction skills that he's getting, but as far as putting him in a working situation he's not going to be employed to make paper maché picture frames and things like that."

This student was able to identify the needs of the client in relation to current treatment procedures and probable outcomes and explain why these procedures were, or were not, suitable. 
Coles (1989) referred to students' ability to develop relationships between information as "elaboration" ( $\mathrm{p} 43$ ). He viewed this as a product of students having experienced the context in which previously learned knowledge could be applied. Experience has provided clinicians with a context that enables them to draw on previous knowledge and gain greater understandings of their current situation. On the other hand, students in the early stages of their training, have not had enough time in a particular location to enable them to successfully draw on previous knowledge and describe the links between various elements of the data.

\subsubsection{Human Dimension}

There was a notable difference in the ability of students and clinicians to identify the human dimension. Many of the clinicians were able to provide responses that almost made the interviewer feel as if the client was known to her personally; this was in contrast to other respondents who did not describe the client's perspective at all. An example of providing the human dimension can be observed in one clinician's (C/17) response to question two. This respondent was working in a physical community setting.

Q2: WHICH PROBLEM AREA TOOK PRIORITY ON YOUR PLANNING? WHY?

"Dressing and undressing her feet. ....... She's a .... 'lady'; very, very nice but a lady-like person and it was crucial to her that she had'stockings on and that she had nice shoes on, and it wasn't appropriate to sit around, even if she was at home all day, ..... in slippers... " 
An example of a respondent giving very little of the human dimension was a student $(A / 2)$ who was also working in the community. In response to the same question she said:

"I don't know, they (getting out of his bed and chair) ..... were both just as important as each other.

WHY DO YOU SAY THEY ARE BOTH AS IMPORTANT AS ONE ANOTHER?

"Well ..... I suppose he was just as concerned with them equally .... so I was going to deal with both of them, there was no priority really, I suppose 'cause it was ADL tasks overall."

Often, those whose responses lacked a human dimension gave responses that focussed on techniques rather than the client, or generalised to include all clients in that particular category. Examples to illustrate these features have been taken from the clinician group. In response to question three one clinician who was working in the field of hand trauma $(\mathrm{C} / 8)$ said:

Q3: IN YOUR EVALUATION, WHAT WOULD BE A SATISFACTORY TREATMENT OUTCOME?

"A satisfactory treatment outcome would be a return of hand function to as normal as possible in terms of if you're looking at just the tendon aspect of it, that this person has full tendon excursion; in other words that they're able to fully extend their fingers and make a fist that reaches the palm and the same applies to the thumb as well ...." 
Another example in response to the same question comes from a respondent $(\mathrm{C} / 20)$ working in an orthopaedic ward.

\begin{abstract}
"That the person could safely transfer on and off the toilet, in and out of bed, and on and off the chair is the first priority so that there was minimal chance of them dislocating ..... and shower themselves being aware of all the precautions of total hip replacement."
\end{abstract}

In both these examples, there is a sense of the treatment outcomes being appropriate for any client ie, these were general principles, based on established treatment procedures rather then explanations that were related to a specific client. By contrast, a clinician $(\mathrm{C} / 7)$ who was working in a physical rehabilitation setting said:

"For him to dress himself as much by himself, even if it took a long time, because that would be very important to his pride and self image...."

Flemming (1991b) suggests that to work effectively with a client, the therapist must be able to "tailor" treatment to meet the need and values of each client. In a study of clinical reasoning, as discussed by Flemming, novice students reported that they did not have the confidence to interact with patients as individuals and so felt compelled to use a procedural approach until they were confident in using their skills. In the quotes presented above, one clinician $(\mathrm{C} / 20)$ had only two years experience while the other who was also technique orientated $(\mathrm{C} / 8)$ was very much an expert, ie. had 10 years of experience, four of these being in the current area of work. The final clinician quoted above $(\mathrm{C} / 7)$, had been working as an occupational therapist for 11 years, two of these being in the current location. It would seem that years of experience do not necessarily result in an approach that modifies treatment to meet the individual's values and needs. 
This lack of human dimension by some clinicians has been noted in the discussions pertaining to the question "What are the main benefits to the client?". The responses to this question favoured technical concerns rather than those gained from an involvement with the individual client's own concerns. The idea that occupational therapists work with both the physical and emotional characteristics of a person is not a new one (Fidler \& Fidler, 1963; cited by Flemming, 1991). If emotional aspects were considered equally with the physical ones in the respondents minds, one would expect that intrapersonal elements would be cited more frequently as part of the treatment outcomes than has been apparent (see Tables $8.2 \& 10.2)$.

Overall, this analysis has provided valuable information on problem representation by providing an integrated perspective of the interview. This particular chapter has provided evidence of differences between students and clinicians that was not apparent in the analysis of the individual questions. The analysis indicates that stage III students and clinicians are able to sort the client data and relate this to treatment outcomes, whereas the stage II students have difficulty identifying treatment outcomes that are consistent with their thinking about the client's situation. The clinicians, however, are able to consider the data in a qualitatively different way than either student group by describing and elaborating on the elements of the problem representation. Part of this elaboration process is the ability to convey a clear sense of the client as an individual. 


\subsection{Summary}

Clinicians are more able to give an elaborated response which justify decisions made about treatment and are also more likely to focus on the individual human dimension than the student groups. The stage II group demonstrated discrepancies in identifying outcomes that were consistent with the problems when compared to the stage II and clinician groups. 


\section{CHAPTER THIRTEEN}

\section{INTEGRATION AND ANALYSIS OF HYPOTHESES}

There were a number of hypotheses considered at the outset of this study. The following discussion will consider each of them in turn. Finally a model which summarises the main findings of the study will be presented.

\subsection{Hypothesis One}

That the longer term settings will generate more data about the client compared to the short-term settings.

This study has identified that the settings that are long-term in nature with the period of time for treatment measured over months or even years (ie. the rehabilitation and paediatric locations) do result in the generation of a greater number of problems compared to the short-term settings (see Table 6.4).

\subsection{Hypothesis Two}

That the environmental context will influence the nature of the problems and treatment outcomes considered. 
An examination of the problems identified by the respondents in the physical psychiatric and paediatric settings identified that there was a difference in the distribution of the response rates between the performance component and occupational performance categories. This was a trend in response to the first question but the differences became significant when identifying the priority problems in question two (see Table A.4). The physical settings were associated with occupational performance outcomes, paediatric with performance components with the balance being more even for the psychiatric settings.

When the location data was organised into long and short term settings, a difference was also observed in the distribution of the performance component and occupational performance categories with the long-term settings generating a greater number of performance component problems $(\mathrm{p}<.01)$.

The generation of performance component problems provides a more complex array of treatment options, ie. the alternative of treating performance component deficits is available, rather than focusing only on the resulting occupational performance difficulty.

It is noticeable that the difference between long and short-term settings is not so evident in respect of the treatment outcomes (see Table 8.4). The focus moves to the occupational performance category for both settings and the response rates are more comparable, suggesting that the greater range of problems generated in longterm settings has been sorted to develop a manageable number of outcomes.

Thus the evidence supports this hypothesis in relation to the problems that were identified, but not in respect of the treatment outcomes. 


\subsection{Hypothesis Three}

That direct connections between hypotheses and treatment outcomes will be more evident in the clinicians' thinking than in the students (ie. clinicians will have a clearer problem representation).

The qualitative analysis of the interviews indicates that links between hypothesis and treatment outcomes are evident to the same extent in the clinician and stage III groups, but are less evident in the stage II group (Table 12.2). Thus stage III students make these connections with the same frequency as clinicians whereas the least experienceD group (stage II) have more difficulty in linking the elements. Another aspect that has been demonstrated by this study is the clinicians' ability to provide justification for this linking and to elaborate on the ideas being conveyed.

Using Greeno's (1973) description of the stages of problem solving, the second year students would be at the first stage which is the development of a basic "cognitive tree". This is consistent with the initial observation that this group have difficulty in making direct connections between hypothesis and treatment outcomes.

Students with more experience (stage III) are able to make connections between the elements of the data with similar frequency as the clinicians, however, they are not able to clearly articulate the relationships between these elements. They are apparently able to construct a 'cognitive tree' which represents the problem. Their difficulty lies in the second stage of problem solving which is identifying the relationship between the problem state and the goal state. Clinicians demonstrate their ability to do this by justifying and elaborating. Students appear not to have yet 
developed a set of "transformational relations" (Greeno 1973) in their long term memory and so have difficulty making links between the problem elements.

This description of similarities between stage III and clinician groups is consistent with De Groot's (1966) observations that both novice and expert chess players tended to consider the same number of moves and look ahead about the same distance in assessing the effect of a move. In the same way, the stage III and clinician groups can both consider the same basic data and have a similar understanding of the outcomes.

Hypothesis three is therefore true for the stage II student group, but not for the stage III students.

\subsection{Hypothesis Four}

That compared to students, clinicians will be more likely to take a client centred focus.

The question that specifically requested information on how orientated the respondents were to the client's perspective (question four) did not provide evidence of any differences between students and clinicians in relation to taking the client's perspective.

However the qualitative analysis which integrated all the questions (see Table 12.2) did reveal that clinicians had more awareness of the human perspective when compared to students. This was manifested by the acknowledgment in the interview of the client as an individual with their own values and concerns. This 
same trend was also evident in response to the question dealing with why the respondents had chosen a particular priority for treatment (see Table A.2). Such a perspective is evidently an integral part of the clinicians thinking rather than something they focus on consciously when planning treatment.

This would seem to be part of a natural development process where once a novice learner is able to comfortably handle the technical skills and is familiar with the relevant knowledge, then he/she is able to consider the cues that arise from relationships with clients. This ability to relate to the client as an individual begins in the stage of the 'advanced beginner' in Dreyfus and Dreyfus's model of skill acquisition (1986, cited in Slater and Cohn 1991). Acknowledging this individuality is an initial step to being able to meet the needs of a particular client.

Crepeau (1991) has suggested that there are various reasons as to why there might be barriers to understanding the client's perspective, such as the dominance of the medical model (which tends to separate the illness from the patient's experience and results in the therapist focusing on technical skills) and the power of physicians with their focus on biomedical issues. As suggested by this study and supported by the model of skill acquisition, it is evident that one major barrier for students is their inability to deal with the client's perspective until they have first mastered the skills and knowledge relevant to the situation.

Hypothesis four has therefore been supported by the study. 


\subsection{Hypothesis Five}

That the beliefs of participants concerning occupational therapy treatment would be consistent with the assumptions identified by Mosey (1981).

Each of these assumptions which were previously outlined in chapter two will be considered in turn. Table 13.1 summarises the numbers of respondents who identified each of the assumptions.

i) Each individual has the right to a meaningful existence; to an existence that allows one to be productive, to experience pleasure and joy, to love and be loved and to live in safe, supportive and comfortable surroundings.

There are several themes in this assumption that will be explored:

The need to be productive has been referred to in various ways throughout the interviews. This theme was apparent when interviewees identified lack of involvement in leisure activities and employment as problems to be dealt with (Table 6.3), and involvement in these pursuits as an outcome of treatment (Tables $8.3 \& 10.3)$. 
Table 13.1

Summary of the Assumptions Identified by the Three Respondent Groups.

\begin{tabular}{|lllll|}
\hline & \multicolumn{4}{c}{ RESPONDENTS } \\
ASSUMPTIONS & $\begin{array}{c}\text { STAGE II } \\
\text { N=14 }\end{array}$ & $\begin{array}{c}\text { STAGE III } \\
\text { N=31 }\end{array}$ & $\begin{array}{c}\text { CLINICIANS } \\
\text { N=22 }\end{array}$ & $\begin{array}{c}\text { TOTAL } \\
\text { N=67 }\end{array}$ \\
\hline $\begin{array}{l}\text { ASSUMPTION 1: } \\
\text { (meaningful existance) }\end{array}$ & & & & \\
PRODUCTIVITY & $4(29 \%)$ & $15(48 \%)$ & $6(27 \%)$ & $25(37 \%)$ \\
PLEASURE & $0(0 \%)$ & $2(6 \%)$ & $4(18 \%)$ & $6(9 \%)$ \\
LOVE & $0(0 \%)$ & $0(0 \%)$ & $0(0 \%)$ & $0(0 \%)$ \\
SURROUNDINGS & $8(57 \%)$ & $19(61 \%)$ & $13(59 \%)$ & $40(60 \%)$ \\
\hline TOTAL * & $10(71 \%)$ & $27(87 \%)$ & $18(82 \%)$ & $55(82 \%)$ \\
\hline $\begin{array}{l}\text { ASSUMPTION 2: } \\
\text { (nature of the species) } \\
\text { COGNITIVE }\end{array}$ & $8(57 \%)$ & $12(39 \%)$ & $13(59 \%)$ & $33(49 \%)$ \\
SOCIAL & $6(43 \%)$ & $11(35 \%)$ & $10(45 \%)$ & $27(40 \%)$ \\
\hline TOTAL * & $8(57 \%)$ & $17(55 \%)$ & $17(77 \%)$ & $32(63 \%)$ \\
\hline $\begin{array}{l}\text { ASSUMPTION 3: } \\
\text { (personal choice) }\end{array}$ & $6(43 \%)$ & $13(42 \%)$ & $13(59 \%)$ & $32(48 \%)$ \\
\hline $\begin{array}{l}\text { ASSUMPTION 4: } \\
\text { (purposeful interaction) }\end{array}$ & $9(64 \%)$ & $17(55 \%)$ & $9(41 \%)$ & $0(0 \%)$ \\
\hline $\begin{array}{l}\text { ASSUMPTION 5: } \\
\text { (work/restplay balance) }\end{array}$ & $0(0 \%)$ & $0(0 \%)$ & $0(0 \%)$ & \\
\hline
\end{tabular}

* NB. This figure refers to the number of subjects who identified an assumption. A subject may have given responses that were recorded in more than one category.

The use of activity in treatment was one of the beliefs in chapter seven (see Table 7.3). In keeping with the above assumption, the nature of activity involvement was for psychological benefits such as improvement in self-esteem and to keep someone occupied and therefore happy. 
Overall, $27 \%$ of the clinicians, $48 \%$ of stage III students and $29 \%$ of stage II students conveyed the idea of productivity being a human need. Clearly the stage III students were more focused on this aspect compared to the other two groups.

Enjoyment for the client also arose in the question concerning the benefit of treatment to the client (Table 9.1). Again this was linked to being involved in an activity programme. Relatively few respondents identified this aspect (18\% of clinician group, $6 \%$ stage III and $0 \%$ stage II group) .

The next element of the assumption was not been mentioned by any respondents in this study, ie. the need for the individual to love and be loved.

Finally, the theme of people living in safe, supportive and comfortable surroundings was evident in various facets of the interview. Safety was commonly linked to the discharge of the individual from the shelter of a hospital environment to live in the community. Respondents who identified ADL problems and outcomes (Tables $8.3 \& 10.3$ ) frequently conveyed the idea that it is desirable to return people to their own homes where they can live in familiar / comfortable surroundings and many also spoke of the need for support to be available either from family or community services. This same theme was evident when respondents identified lack of community resources as a reason for dissatisfaction with treatment (Table 11.2). Finally the belief that people need to develop coping strategies (Table 7.3) was also related to the theme of the individual being safe and able to live in comfortable surroundings.

In summary, a relatively high number of respondents made obvious reference to the need for people to live in safe, supportive and comfortable surroundings (59\% clinicians, $61 \%$ stageIII and $57 \%$ stage II). These responses indicate that the idea of 
people having a meaningful existence is more closely related to the quality of their surroundings than the more emotional needs of experiencing pleasure and love. However, stage III students also had strong support for the need for productivity.

ii) Each individual is influenced by stage-specific maturation of the species, the social nature of the species, and the cognitive nature of the species.

It is difficult to test the present data for the first aspect of this assumption (stagespecific maturation) but it is of relevance that most participants indicated belief in the sequential nature of treatment (see Table 7.2) and as such should cater for individual needs at different stages of change in functional ability. The social environment of the individual was identified in this belief when, for instance, it was noted that being involved in leisure pursuits was one way of assisting someone to develop social networks. It was also raised under the subcategory "environment" (see Table 7.3). Attention was drawn to the fact that people do not live in a vacuum, they interact with and are influenced by other significant people eg. spouse, family, friends. The social needs of people was also identified in the problem and treatment outcome sections of the interview (see Tables 6.3, 8.3 \& 10.3).

Another aspect of the interviews that considered the human or social dimension of the environment was the issue of clients benefiting from occupational therapy intervention because they are able to form a trusting relationship with the occupational therapist (Table 9.1). The idea conveyed was that this was a first step in exploring an ability to interact before learning to trust other people.

The social environment was identified by the following percentages of respondent groups (clinicians $45 \%$, stage III $35 \%$ and stage II $43 \%$ ). 
The cognitive nature of individuals as identified in this assumption refers not only to the ability to think, reason and foreword plan, but also the effect of this on psychological well-being. Concern with these areas was evident in the problems and outcomes in the subcategories of 'cognition' and 'intrapersonal' (Tables 6.2 and 8.2). The impact of a sense of psychological well-being can also be seen in the belief that treatment is sequential in nature (Table A.2) where, for instance, low self-esteem was viewed as a cause for not carrying out daily tasks and selfconfidence was a result of being able to do these tasks. This cognitive view of people was identified by the following percentages of respondents (clinicians 59\%, stage III $39 \%$ and stage II $57 \%$ ).

iii) Each individual has the right to seek his or her potential through personal choice within the context of some social constraints.

The recognition of the client's right to determine how they wish to live their lives was identified in the belief section (see Table A.2), where some respondents stated that treatment should take into account concerns that were important to the client.

The desirability of enabling people to make choices in life was also apparent in response to the question regarding the benefits of occupational therapy to the client (question four). Some indicated that the major benefit of treatment was that the individual could take control of his/her own life (Table 9.1). This focus was also apparent in the problem and outcomes questions (see Tables 6.2, A.2, 8.2 \& 10.2) and in Table 11.2 where meeting clients goals was regarded as a reason for treatment being successful. The right of the client to have personal choice was identified by $59 \%$ of clinicians, $42 \%$ of stage III students and $43 \%$ of stage II students. 
iv) Each individual is able to reach his or her potential only through purposeful interaction with the human and non-human environment.

The ability to acquire skills in order that mastery of the non-human environment may be achieved was expressed in the belief section (see Table 7.3) and in the question dealing with the benefits to the client (see Table 9.1). Also in Table 9.1, the issue of developing self-confidence was in many instances linked to the idea of mastery of daily tasks. This is consistent with Mosey's (1981) idea that what is learnt about oneself through purposeful interaction with the non-human environment is an integral facet of occupational therapy intervention. Purposeful interaction with the non-human environment was identified by $41 \%$ of the clinicians, $55 \%$ of stage III students and $64 \%$ of stage II students.

Developing potential through social interaction (ie. the "human environment"), has already been considered under assumption two. In this study, the recognition of people needing other people as part of normal development is difficult to differentiate from the concept of people developing their own potential through this interaction.

v) Each individual has inherent needs for work, play and rest which must be satisfied in relatively equal balance.

This assumption had no obvious support from the respondents. However, one third year student did articulate the concept of balance in the life style of the individual by stating that... 


\subsubsection{Summary of Hypothesis Five}

Overall, most support was given for assumption one followed by assumptions two, four and three with no support for assumption five. There are variations in the level of support between the three groups for the components of the assumptions, When considering which of the assumptions and/or sub components yielded a response of $50 \%$ from each group, it can be noted that the need for people to live in safe, supportive and comfortable surroundings was identified by all three groups. The two student groups identified interaction with the non-human environment, both stage II and clinicians identified the cognitive nature of the species and only the clinicians identified seeking potential through personal choice. The stage III level of response for productivity was notably higher compared with the other two groups. No respondents identified the need to love and be loved and the idea of balance between work, play and rest.

In chapter two it was noted that there were some uncertainties concerning the basic core of occupational therapy. This study indicates that there is support for four out of five of the assumptions underlying the profession as described by Mosey (1981). Not every respondent mentioned all or any of the assumptions; however, when the interviews are looked at collectively, the major assumptions are present apart from the concept of balance between work, play and rest. As this is stated to be one of the oldest concepts in that it has been around since the inception of the profession, it is noteworthy that it is not apparent in this study. 


\subsection{Conclusions}

The environmental context affected problem representation in that it influenced both the amount of data to be considered at the outset and the nature of that data. Differences in students and clinicians understandings of the treatment planning process were related to qualitative differences (in their explanations of the process) rather than their basic understandings of the elements of the process. The beliefs that govern thinking about treatment demonstrate consistency with the literature (except for the concept of a balance between work, rest and play), and a consistency between the respondents regardless of location and/or experience.

Although an information processing approach has been used primarily in this study, such an approach used alone would not be sufficient to explain the strategies discovered in the interview. For some of the analysis it has been useful to draw on literature which takes a phenomenological approach.

At the outset of this study, it was stated that clinical knowledge is...

"the transformation of preconceived notions and expectations by encounter with actual practical situations" (Benner \& Wrubel, 1982, p11).

This study has noted that practical experience does change the internal representation of clinical problems. In chapter four, a model of problem solving in occupational therapy was presented; the problem representation component of this has now been developed to depict the differences between student and clinician in problem representation - ie. the understanding process (see Figures 13.1(a) and 13.1(b)). The model illustrates that both students and clinicians have access to the same information but that this is more clearly defined and organised in the clinician. 


\section{CLINICIANS}

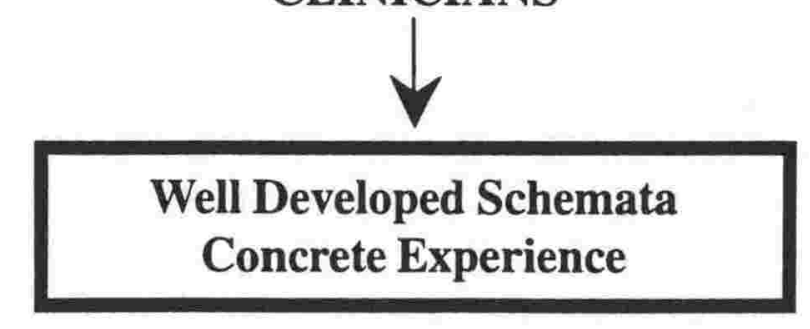

\section{PROBLEM REPRESENTATION}

\section{DOMAIN SPECIFIC KNOWLEDGE}

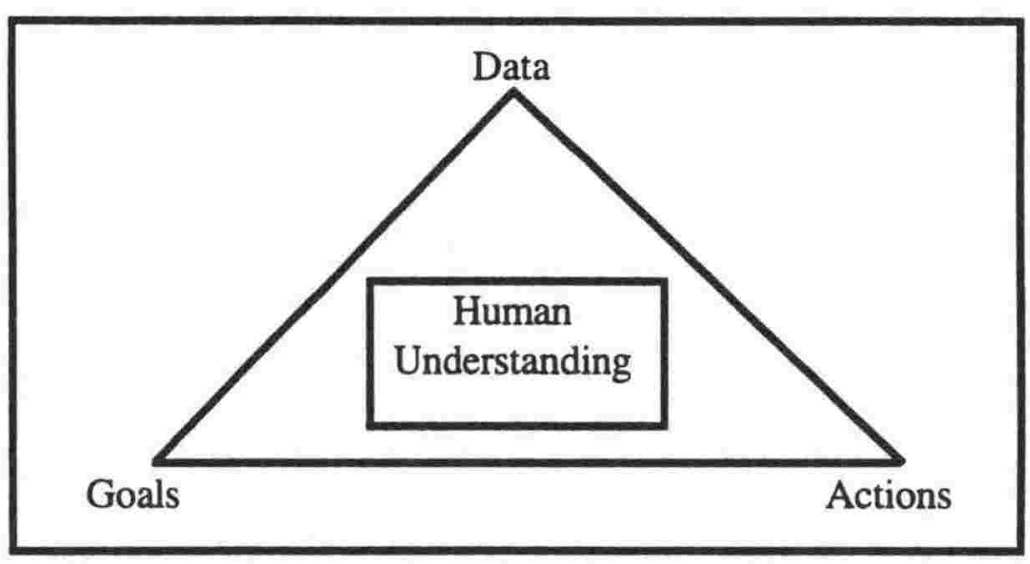

ENVIRONMENT AND RESTRICTIONS

Figure 13.1(a) Problem Representation in Occupational Therapy A Comparison Between Student \& Clinician. 


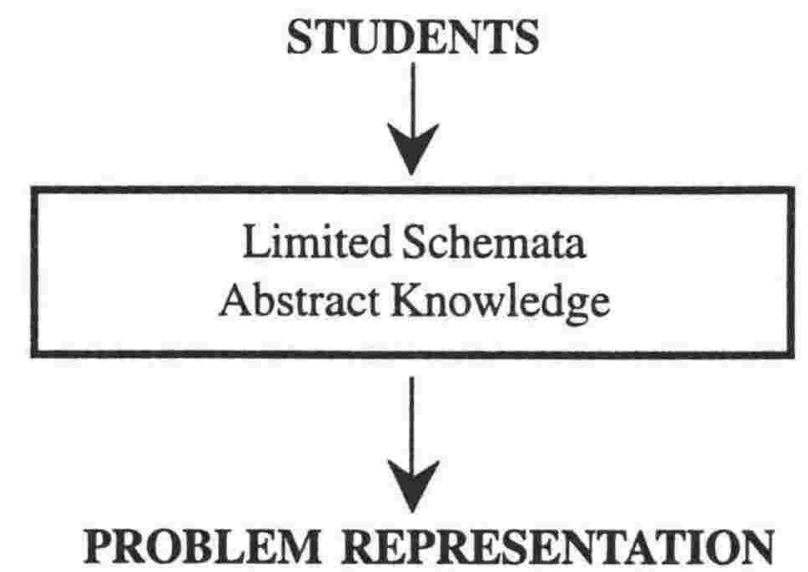

Environment

Restrictions

Domain specific knowledge

Goals

Actions

Data

Human Understanding

Figure 13.1(b) Problem Representation in Occupational Therapy A Comparison Between Student \& Clinician. 
Clinicians have well developed schema which enable a network of information to be drawn on and links with current information to be successfully made. The clinicians' view of the data, goals and operators are encapsulated in the knowledge and expertise that has been gained in a specific setting. Such information sets parameters and allows reasonable predictions to be made with confidence. Their intimate understanding of both the human and non-human elements of the environment will invariably familiarise them with the restrictions.

A relevant issue to raise at this stage is that although the data, goals and operators will vary to some extent from client to client, from the perspective of the clinician there will be past experiences that enable recall of patterns relevant to the current situation. This application of prior knowledge is arguably not a problem solving situation as the outcomes are fairly predictable and the actions that can be taken to reach the outcomes are routine. This is consistent with Gagné's view that problem solving is more than the application of a set of existing rules to achieve a goal. For Gagné, problem solving is a process whereby restructuring must take place with new learning occurring in order to form a higher order rule; this is then generalised to other new situations when problems of the same type are presented.

Students on the other hand, do not have well developed schema. They have some knowledge of the appropriate treatment procedures and some experience of clinical work but they have to adjust to the specifics of a new working environment before relational networks can be developed and schema formulated. Students have a tentative grasp on the various elements in problem representation and have not only to juggle with the data, the possible actions that can be taken and the goals, they also have to come to terms with the environment, ie. the particular treatments that are common within that setting and the restrictions that 
are peculiar to the setting. The problem space is less defined than that of the clinicians largely due to the lack of domain specific knowledge and a limited understanding of the work environment.

An aspect of problem representation that was not noted in the original model was the human dimension. The interaction with the client was a significant aspect of the problem representation with clinicians frequently weaving a human perspective into their understanding of the problem. This is depicted by the central box (human understanding) in Figure 13.1(a) and refers to the clinicians' understanding of their clients. Students, on the other hand, were able to note the client's concerns but this was similar to another piece of data rather than an indepth understanding of how disability impacts on the life of that individual. Figure 13.1(b) shows the students' representation of a problem - the various components or elements are present but they are not necessarily co-ordinated or clearly structured.

The model illustrates the transformation of knowledge by practical experience over a period of time. The abstract knowledge and factual data that is the focus of the beginner is transformed over time to the point where experience results in the availability of a rich supply of schema. Therefore compared to the students, who use theory as a guide, clinicians are able to use past concrete experiences as paradigms thereby refining theory through practice. 


\section{CHAPTER FOURTEEN}

\section{IMPLICATIONS FOR EDUCATION AND FURTHER RESEARCH}

This final chapter will first highlight the implications of this study for the education of occupational therapy students then suggest further research that could provide educators with a greater understanding of the learning needs of students.

\subsection{Implications for Education}

\subsubsection{Development of Schema and the Ability to Elaborate}

Educational strategies should develop students' abilities to make links between data and form relevant schema. Experience in one area of work and its resulting understandings of treatment planning processes for a particular client group is a pre-requisite for being able to link data and elaborate on the treatment planning issues.

1. At a simple level, one way of developing students' awareness of links between data is to provide these. This would be appropriate when dealing with case situations. Students could be given:

i) a summary of the initial situation data and links in this data eg. occupational therapy diagnoses.

ii) the goal state (ie. the treatment goals) related to the stated diagnoses. 
Skemp (1979) considers that a good understanding of these two facets is essential before appropriate action can be taken, ie. planning treatment. Such an approach should be used in both classroom and fieldwork settings for both level I and level II students. A useful approach would be to give the stage II students the treatment goals then expect them to plan the relevant treatment rather than requiring them to sort the data and develop the goals. This would eliminate much of the data that has to be processed and allow students to focus on one aspect only - ie. the treatment procedures (operators). Setting the parameters in this way would also limit the 'problem space', ie. the range of solution paths that the students would consider. As previously discussed in chapter four, the formulating of goals and objectives is critical in effective problem solving.

The links that are made for the student provide a pattern of thinking which will become familiar by later stages in their education programme when they will be expected to deal with the entire treatment planning process, ie. develop occupational therapy diagnoses, treatment goals as well as plan the treatment.

This approach is contrary to traditional methods which follows the occupational therapy process and requires students to sort the data, establish the problem and treatment goals and then plan treatment. The traditional approach makes complex cognitive demands on inexperienced students as they do not have the relevant schema to assist them in their reasoning processes.

2. Another approach to developing schemata is for students to develop expertise in specific areas. The implications for an education programme are as follows:

i) Long fieldwork placement would encourage students to consolidate knowledge and skills and be able to justify their treatment planning processes 
in specific fields of practice. How long such a placement would need to be and whether or not this is more valuable than providing a range of experiences via short fieldwork placements are debateable issues. However, from a cognitive perspective, the longer placements in one area would enable schema to be developed and deeper reasoning processes used.

ii) Analysis of problem solving that took place while on fieldwork placements is another method of developing a level of expertise in a particular area. In this instance, the expertise is not gained in skills and techniques but in the thinking and reasoning related to the skills and techniques that the student knows to be appropriate in particular settings. Thus schema could be developed based on a sound understanding of the context. This would provide the student with a solid base for reasoning and justifying the treatment procedures that were carried out. Students could be required to carry out this type of exercise following each fieldwork placement.

With this approach, the context has been established and understood. Coles (1989) says that this will then enable the student to draw on previous abstract knowledge which has been learnt out of context and develop a greater understanding of the 'concrete' situation. Elaboration, he says...

"does not happen proactively from abstract to concrete but retroactively from concrete to abstract". (p.45)

Thus it is the process of reflection on action that enables students to establish the links between elements of knowledge relevant for clinical settings. 
From a slightly different perspective, R Gagné (1985) says that using problem solving scenarios where students are able to elaborate on situations they have been involved in draws on the internal state of the individual, ie. not only their experience but also their motivation. Harnessing students' motivation can be a key factor in stimulating the use of deeper reasoning processes.

3. A third consideration is that requirements should be realistic in respect of students being able to elaborate and justify. This ability in respect of clinical problem solving should be expected in the latter period of the programme, once adequate experiential knowledge is gained in a range of fieldwork settings. Students will then be able to draw on knowledge and understandings gained in these settings to enable them to form relevant schema and justify decisions for problem solving scenarios which have been given as academic exercises.

The normal pattern of clinical experience is an inverted pyramid where there is little experience in the first year and extended experience in the final year. To tap the students' ability to reason critically in relation to treatment planning, then the pyramid should be reversed with much of the practical experience occurring in the initial stages of the course. This would enable the final year to draw on the understandings that students have gained from their practical experience. 


\subsubsection{Understanding the Client's Perspective}

Understanding the client's perspective is an integral part of the clinicians' thinking when planning treatment. Again, it is an aspect that students should not be expected to demonstrate until latter stages of their education programme. Realistically, this may be a facet of problem representation that does not occur naturally until the student has graduated and gained experience.

The use of assessment tools that specifically request client input may be of value to get students into the habit of asking questions that provide information on the client's concerns. However the evidence suggests that although this would enable appropriate information to be acquired, it is at the level of technical concerns such as knowing which skills the client wants to learn rather than an in-depth understanding of the individual.

The skills acquisition model (Dreyfus and Dreyfus, 1986) also suggests that having an awareness of the client beyond a technical concern does not develop until the student has passed from the 'novice' to the 'advanced beginner' stage. Based on the premise that students first have to master knowledge and technical skills, the best preparation for a new graduate would be to ensure that they have this basic mastery. This would enable them to quickly gain confidence in their skills in their chosen area of work and allow them to develop flexibility and, with this, an ability to respond to cues from the client. 


\subsubsection{Location Differences}

Some settings in which students gain experience of practice provide greater challenges than others. Long-term settings provide a more complex array of data, and for this reason, tools/methods that help students to sort data will be of particular value. Such tools should encourage students to sort data in a problem solving format. The previous suggestion of giving students both the occupational therapy diagnosis and treatment goals would have particular value in these settings, in that they would set limits on the problem space.

\subsubsection{Beliefs of Occupational Therapists}

It is evident that occupational therapists do have common understandings of their practice irrespective of the setting. Students should be aware of these and be able to articulate them with confidence.

\section{2 Implications for Further Research}

This study has identified that major differences between student and clinician lie in the qualitative aspects of the reasoning processes rather than the quantitative elements. This would indicate that further research should be more concerned with teasing out the qualitative issues. The following suggestions have been drawn from this study: 
1. Develop a greater understanding of the developmental process that occurs in students' ability to process information from fieldwork.

One suggested method would be an in depth analysis of interviews of students and their supervising therapists where both are asked to focus on the same client. The same students could be followed through their education programme and interviewed annually with their supervisors also interviewed on each occasion. This would allow differences to be identified between clinician and student as well as developments in the students' problem representation to be noted. One aspect that could be developed in such an approach would be the reality of the treatment outcomes. As previously indicated in this study, the reality of this particular aspect of problem representation was thought to be suspect in some of the students responses.

Factors to be taken into consideration in the selection of students:

Age - does life experience allow students to develop greater understandings of the human dimension or is it entirely related to experience as an occupational therapist?

Gender - what influence does this have on problem representation?

Another method would be the use of action learning and action research methods to clarify problem solving in occupational therapy. These procedures could be undertaken with clinicians and/or students while they are on fieldwork placement. To gain a developmental perspective, a group of students could be followed through the three years of their education programme. Such a study would enable participants to be... 
"actively and critically engaged in developing their own theories and meanings on the basis of group deliberation, experience and reflection" (Zuber-Skerritt, 1993 47).

2. Environmental factors could usefully be studied in greater depth rather than the global long and short-term settings. For example, the community setting has already been referred to as being notably less divergent in approach when compared to other settings such as rehabilitation. Two examples where clinicians did not take a humanistic perspective were in orthopaedic locations. To know if this were characteristic of the perspective of those working in this type of setting, a study which investigated more respondents in this location would need to be conducted.

Environments that have not been included in this study are community settings that are client driven and make use of a 'holistic' model (see Chapter 2) where therapist and client collaborate together to decide on behaviour change. These settings are particularly difficult for students because the planning process involves working with clients to reach a consensus, rather than making decisions on their behalf. To investigate how clinicians develop problem representations in these situations might be a first step in developing strategies that students could use. Locations where a client centred focus is used are more frequently becoming the work settings for occupational therapists so it is particularly important that these understandings are gained.

3. It was proposed in chapter four that an individual's understanding of his/her own strengths and weaknesses would be an element of problem representation. In this study only one respondent, a stage II student, alluded to this. From the 
students' perspective, their lack of knowledge would certainly be a restriction on treatment - yet this metacognitive view has not been evident in this study.

A proposal therefore, is that a study be undertaken where the focus is directed towards understanding an individual's perceptions of their strengths and weaknesses in relation to treatment planning ie. self-assessment by students and clinicians.

4. The length of the fieldwork placement has been described as a factor that influences students reasoning ability. A study that investigated the students' ability to think and reason throughout a placement could give valuable insights into the development of an internal problem representation (eg. after 2 weeks, 4 weeks, 6 weeks, 8 weeks).

5. Investigate the potential of an assessment tool that focuses on the client's contribution to treatment planning. Would such a tool enable students to take a more humanistic perspective in their problem representation? A similar proposal made by the recent American study of clinical reasoning in occupational therapy suggests that such a tool may "encourage patients to discuss their feelings about illness and disability" (Schwarts, 1991, p1035) and so assist students to develop an understanding of what disability means to the individual. However, my proposal is much more tentative, suggesting that while such tools may be of value a phenomenological perspective may ultimately be a product of experience.

6. An implication for teaching arising from this study is that concrete experience is a basis for understanding theory - partly because it defines the context. Thus the implementation and evaluation of a teaching method that encourages students 
to reflect on actual practical experience would be valuable in developing insights into effective ways of bridging the gap between theory and practice. Examples of teaching strategies are the use of diaries and journals during practice followed by tasks/assignments that involve students using the information they have recorded, and role play of actual situations in reflective sessions following fieldwork experience. Action learning and research methods could be employed with students being asked to participate in evaluation sessions of the teaching method under investigation.

\section{3 Conclusions}

Clinical reasoning is complex and influenced by the environment, experience and beliefs. With changing health systems and social values, basic philosophies of health care will inevitably change over time and with this some of the premises on which clinical reasoning in based. Experience, on the other hand, is a developmental phenomena that is not so prone to change. Understandings of how experience influences problem representation will always be useful and add to our basic understandings of the cognitive development of the student. 


\section{REFERENCES}

Atkin O. (1980). Models of Architectural Knowledge. London: Pion.

Azima, H., \& Azima, F. (1959). Outline of a dynamic theory of occupational therapy. American Journal of Occupational Therapy. 13 (5), 215 - 221.

Ayres, J. (1979). Sensory Integration and the Child. Los Angeles: Western Psychological Services.

Balla, J.I., Gibson, M., \& Chang, A. (Eds.) (1989). Learning in Medical School. A Model for the Clinical Professions. Hong Kong: University Press.

Barrows, H.S., \& Tamblyn, R.M. (1980). Problem Based Learning: An Approach to Medical Education. NY: Springer Publishing.

Bartlett, F.C. (1958). Thinking. London: Allen \& Unwin.

Benner, P., \& Wrubel, J. (1982). Clinical Knowledge Development: the value of perceptual awarness. Nurse Educator. 7(3), 11 - 17.

Blanton, L. (1954). Exercise to develop a range of movement of the forearm. American Journal of Occupational Therapy, 8(6), 263.

Bockoven, J.S. (1972). Moral Treatment in Community Mental Health. New York: Springer.

Boud, D. (1985). Problem Based Learning in Education for the Professions. HERDSA. (Higher Education Research and Development Society of Australasia), University of New South Wales. Sydney.

Broderick, M.E., \& Ammentorp, W. (1979). Information Structure: An analysis of nursing performance. Nursing Research. 28, $106-10$.

Bruner, J.S. (1968). Towards a Theory of Instruction. New York: Norton.

Chase, W.G., \& Simon, H.A. (1973). Perception in Chess. Cognitive Psychology, 4 , $55-81$

Christiansen, C. \& Baum, C. (1991). Occupational Therapy: Overcoming Human Performance Deficits. N.J.: Slack Inc.

Coles, C.R. (1989). The role of context in elaborated learning. In J. Balla, M. Gibson \& A. Chang (Eds.). Learning in Medical School. Hong Kong: University Press.

Corcoran, S.A. (1986). Task complexity and nursing expertise as factors in decision making. Nursing Research, 35(2), 107-12.

Corman, B.R. (1957). The effects of varying amounts and kinds of information as guidance in problem solving. Psychological Monographs. 71. Whole No 431. 
Crepeau, E. (1991). Achieving intersubjective understanding: examples from an occupational therapy treatment session. American Journal of Occupational Therapy, 45 (11), 1016-25.

De Beer, F. (1987). Major themes in occupational therapy: a content analysis of the Eleanor Clarke Slagle Lectures 1955-1985. American Journal of Occupational Therapy, 41(8), 527-31.

De Groot, A.D. (1966). Perception and memory versus thought: Some old ideas and recent findings. In B. Kleinmuntz (Ed). Problem Solving: Research, Method and Theory. New York: Wiley.

Dewey, J. (1933). How we think. New York: Heath.

Dreyfus, H.C., \& Dreyfus, S.E. (1986). Mind over machine. New York: Free Press.

Duncker, K. (1945). On Problem Solving. Psychological Monographs. 58:5, Whole No. 270.

Dunning, E. (1959). An Introduction to Remotivation Technique. American Journal of Occupational Therapy, XIII (5), 235 - 238.

Egan, D.E., \& Schwatz, B.J. (1979). Chunking in Recall of Symbolic Drawings. Memory and Cognition. 7, 149 - 158.

Elstein, A.S., Schulman, L.S., \& Sprafka, S.A. (1978). Medical Problem Solving. Cambridge Mass.: Harvard University Press.

Elstein, A.S., Schulman, L.S., \& Sprafka, S.A. (1990). Medical problem solving: A 10 year retrospective. Evaluation and the Health Professions 13(1), March, 5 36.

Ernst, G.W., \& Newell, A. (1969). GPS: A Case Study in Generality and Problem Solving. New York: Academic Press.

Fetlovich, P.J. (1981). Knowledge based components of expertise in medical diagnosis. (Tech Rep. No. PDS - 2) Pittsburgh, Pa. University of Pittsbugh Learning Research and Development Centre. Cited in Gagné E. (1985). The Cognitive Psychology of School Learning. Boston. Little Brown \& Co.

Fetlovich, P.J., \& Barrows, H.S. (1984). Issues of generality in medical problem solving. In H.G. Schmidt \& M.C. DeVolder (Eds.), Tutorials in Problem Based Learning (pp. 128-42). Holland: Van Goreum, Assen.

Fidler, G.S., \& Fidler, J.W. (1978). Doing and becoming: purposeful action and self actualization. American Journal of Occupational Therapy, 32 (5), 305-10.

Flemming, M.H. (1991a). The therapist with the three track mind. American Journal of Occupational Therapy, 45(11), 1007-14.

Flemming, M.H. (1991b). Clinical reasoning in medicine compared with clinical reasoning in occupational therapy. American Journal of Occupational Therapy. 44 (11), 988-96. 
Forbes, E. (1951). Two devices for use in treating Hemiplegics. American Journal of Occupational Therapy, 5(2), 49.

Frank, J. (1958). The therapeutic use of self. American Journal of Occupational Therapy, 12, 215.

Gagné, E.D. (1985). The Cognitive Psychology of School Learning. Boston: Little Brown \& Co.

Gagné, R.M. (1985). The Conditions of Learning and Theory of Instruction. (4th ed.). New York. Holt, Rinehart \& Winston Inc.

Gagné, R.M., Briggs, L.J., \& Wager, W.W. (1988). Principles of Instructional Design (3rd ed.). Holt, Rinehart \& Winston Inc. New York.

Glover, J.A., \& Bruning, R.H. (1987). Educational Psychology. Boston, Toronto: Little Brown \& Co.

Greeno, J.G. (1973). The structure of memory and the process of solving problems. In R.L. Solso (Ed.), Contemporary Issues in Cognitive Psychology: The Loyola Symposium (pp.103-34). Washington D.C: Winston.

Greeno, J.G. (1974). Hobbits and orcs: acquisition of a sequential concept. Cognitive Psychology, 6, 270-92.

Hayes, J.R. (1966). Memory, Goals and Problem Solving. In B. Kleinmuntz (Ed.), Problem Solving: Research, Method and Theory (pp.149-70). New York: Wiley.

Hayes, J.R. (1978). Cognitive Psychology. Thinking and Creating. Illinois: The Dorsey Press.

Hayes, J.R. (1989).The Complete Problem Solver. Lawrence Erbaum Associates: New Jersey.

Hayes, J.R, \& Simon, H.A. (1976). Psychological differences among problem isomorphs. Cognitive Theory. Vol II. In N. Castellon Jr., D. Pisoni \& G. Potts (Eds). Potomac, Marland: Lawrence Erlbaum.

Higgs, J. (1990). Fostering the aquisition of clinical reasoning skills. New Zealand Journal of Physiotherapy, Dec., 13 - 17.

Hilgard, E.R., Irvine, R.P., \& Whipple, J.E. (1953). Rote memorization, understanding and transfer: An extension of Katona's card trick experiments. Journal of Experimental Psychology, 46, 288-92.

Hopkins, H., \& Smith, H. (1983). Willard \& Spackmans Occupational Therapy (6th Ed.). Pensylvania: Lippincott.

Katz, N., \& Sachs, D. (1991). Meaning ascribed to major professional concepts: A comparision of occupational therapy students and practitioners in the United States and Israel. American Journal of Occupational Therapy. 45(2), 137-45.

Katona, G. (1940). Organizing and Memorizing. New York: Columbia University Press. 
Kielhofner, G. (1983). Health Through Occupation. Theory and Practice in Occupational Therapy. Philadelphia: F.A. Davis Co.

Kielhofner, G. (1992). Conceptual Foundations of Occupational Therapy. Philadelphia: F.A. Davis.

Kielhofner, G., \& Burke, J.P. (1983). The Evolution of knowledge and practice in occupational therapy: Past, present and future. In G. Kielhofner (Ed.), Health Through Occupation: Theory and Practice in Occupational Therapy. Philadelphia: F.A. Davis.

Kielhofner, G. (1985). A Model of Human Occupation. Baltimore. Williams \& Wilkins.

Kohler, A. (1925). The Mentality of Apes. New York: Harcourt Brace.

Laurillard, D. (1979). The process of learning. Higher Education, 8, 395-409.

Laurillard, D. (1984). Learning from problem solving. In F. Marton, D. Hounsell \& N. Entwistle (Eds.), The Experience of Learning. Edinburgh: Scottish Academic Press.

Licht, S. (1948). Occupational Therapy Source Book. Baltimore: Williams \& Wilkins.

Luger G.F (1975). Behavioural effects of problem structure in isomorphic problem solving situations. Research Report. 4, University of Edinburgh cited in Laurillard D. (1979). The process of learning. Higher Education, 8, 395-409.

Lyons, B.G. (1983). The issue is: purposeful versus human activity. American Journal of Occupational Therapy, 37(7), 493-95.

Luchins, A.S. (1942). Mechanization in Problem Solving. Psychological Monographs, 54(6), Whole No.248.

Magaro, P., Gripp, R., \& McDowell, D. (1978). The Mental Health Industry: A Cultural Phenomenon. John Wiley \& Sons.

Maier, N.R.F. (1930). Reasoning in Humans I: On direction. Journal of Comparative Psychology, 10, 115-43.

Maier, N.R.F. (1931). Reasoning in Humans II: The solution of a problem and its appearance in consciousness. Journal of Comparative Psychology, 12, 181-94.

Maier, N.R.F. (1933). An aspect of Human Reasoning. British Journal of Psychology, 14, 144-55.

Maier, N.R.F. (1937). Reasoning in rats and human beings. Psychological Review, 44, 365-78.

Maier, N.R.F. (1945). Reasoning in Humans III: The mechanisms of equivalent stimuli and of reasoning. Journal of Experimental Psychology, $35,349-60$. 
Maltzman, I. (1955). Thinking from a Behaviourist Point of View. Psychological Review, 62, 275-86.

Maltzman, I., \& Morrisett, L. (1953). The effect of task instruction on solution of different classes of anagrams. Journal of Experimental Psychology, 44, 24246.

Marton, F., \& Saljo, R. (1976a). On qualitative differences in learning I: Outcome and processes. British Journal of Educational Psychology, 46, 4-11.

Marton, F., \& Saljo, R. (1976b). On qualitative differences in learning II: Outcome as function of the learners conception of the task. British Journal of Educational Psychology, 46, 115-127.

Mattingly, C. (1991). The narative nature of clinical reasoning. American Journal of Occupational Therapy, 45(11), 988-1005.

Mattingly, C., \& Gillette, N. (1991). Anthropology, occupational therapy and action research. American Journal of Occupational Therapy, 45(11), 972-78.

Mayer, R.E. (1977). Thinking and Problem Solving: An Introduction to Human Cognition and Learning. USA: Scott, Foresman and Company.

Mayzner, M.S., \& Tresselt, M.E. (1958). Anagram Solution times: A function of letter order and word frequency. Journal of Experimental Psychology, 56, 35076.

Mayzner, M.S., \& Tresselt, M.E. (1962). Anagram solution times: A function of word position probabilities. Journal of Experimental Psychology. 63, 510-13.

Mayzner, M.S., \& Tresselt, M.E. (1963). Anagram Solution times: A function of word length and letter position variables. Journals of Psychology, 55, 469-75.

Mayzner, M.S., \& Tresselt, M.E. (1966). Anagram Solution times: A function of multiple solution anagrams. Journal of Experimental Psychology. 71, 66-73.

Meyer, A. (1922). The Philosophy of Occupational Therapy. Archives of Occupational Therapy. 1:1,1922. Cited by Kielfhofner G. (1992) Conceptual Foundations of Occupational Therapy. Philadelphia. F. Davis.

Miller, G.A. (1956). The Magical Number, 7 Plus or Minus 2. Psychological Review, 63, 81 - 97.

Mosey, A.C. (1981). Occupational Therapy: Configuration of a Profession. Raven Press: N.Y.

Mosey, A.C. (1985). Eleanor Clarke Slagle Lecture: A monistic or pleuralistic approach to professional identity. American Journal of Occupational Therapy. 39(8), $504-509$.

Neisser, V. (1984). Interpreting Harry Bahrick's Discovery: what confers immunity against forgetting? Journal of Experimental Psychologly: General, 113, 32 35 . 
Newell, A., \& Simon, H.A. (1972). Human Problem Solving. Englewood Cliffs, N.J.: Prentice Hall.

Norman ,G.R. (1988). Problem Solving Skills, Solving problems and problem based learning. Medical Education. 22(4), 279 - 286.

Occupational Therapy Newspaper (1979). Highlights of action taken by the representative assembly 6:1. cited in: Mosey, A.C. (1981). Occupational Therapy: Configuration of a Profession. New York. Raven Press.

Pedretti L.W., Smith R.O. \& McGuire M.J. (1992). Use of adjunctive modalities in occupational therapy. American Journal of Occupational Therapy 46(12), 1075-81.

Polya, G. (1957). How to Solve It (2nd ed.). Garden City, New York. Doubleday, Anchor Books.

Polya, G. (1965). Mathematical Discovery. New York: Wiley.

Ramsden, P. (1984). The context of learning. In F. Marton, et al. (Eds.), The Experience of Learning. Edinburgh: Scott Academic Press.

Reed, K.L. (1984). Models of Practice in Occupational Therapy. Baltimore: Williams \& Wilkins.

Reed, S.K., Ernest, G.W., \& Banerjerii, R. (1974). The Role of Analogy in Transfer Between Similiar Problem States. Cognitive Psychology, 6, 436 - 450.

Rees, H.J., \& Israel, H.E. (1953). An investigation of establishment and operation of mental sets. Psychological Monographs, 46, No. 210.

Reilly, M. (1962). Occupational therapy can be one of the great ideas of 20th century medicine. American Journal of Occupational Therapy, 16(1), 1 - 9.

Reitman W. (1965). Cognition and Thought. New York. Wiley.

Rogers, J., \& Holm, M. (1991). Occupational Therapy Diagnostic Reasoning: A Component of Clinical Reasoning. American Journal of Occupational Therapy. 45(11), 1045-53.

Saugstand, P., \& Raaheim, K. (1960). Problem Solving: experience and availability of function. British Journal of Psychology, 51, 97-104.

Schlade, J.K., \& Schultz, S. (1992). Occupational Adaptation: Towards a holistic approach for contemporary practice. Part I.American Journal of Occupational Therapy, 46(9), $829-837$.

Shalik, H. A. (1954). Versatile pollex device for use in occupational therapy. American Journal of Occupational Therapy. VIII(5), 208 - 13.

Shannon, P. (1977). The derailment of occupational therapy. American Journal of Occupational Therapy, 31(4), 229-34. 
Schwarts K.B. (1991). Clinical reasoning and new ides on intelligence: Implications for teaching and learning. American Journal of Occupational Therapy, 45(11), 1033-37.

Simon H.A. (1978). Information processing theory of human problem solving. In Estes W.K. (Ed.) Handbook of Learning and Cognitive Processes. Human Information Processing. Vol 15. Hillsdale, N.J. Lawrence Erlbaum Associates.

Simon, H.A., \& Chase, W.G. (1973). Skills in Chess. American Scientist, 61, 394 403.

Simon, H.A., \& Gilmarton, K. (1973). A simulation of memory for chess positions. Cognitive Psychology, 5, 29-46.

Skemp, R.R. (1979). Intelligence, Learning and Action. A Foundation for Theory and Practice in Education. John Wiley \& Sons.

Slagle, E.C. (1928). Handicrafts used as treatment. Handicrafter 1: $26-27$. Cited in Reed, K.L. (1984). Models of Practice in Occupational Therapy. Baltimore: Williams \& Wilkins.

Slater, D.Y., \& Cohn, E.S. (1991). Staff development through analysis of practice. American Journal of Occupational Therapy, 45(11), 1038-44.

Thomas, J.C. Jr. (1974). An analysis of behaviour in hobbits-orcs problem. Cognitive Psychology, 6, 257-69.

Thorndike, E.L. (1898). Animal Intelligence: An experimental study of the associative processes in animals. Psychological Monographs, 2 , No. 8.

Toulmin, S.E. (1958). The Use of Argument. London/New York: Cambridge University Press.

Trombly, C.A. (1989). Occupational Therapy for Physical Dysfunction (3rd ed.). Williams \& Wilkins.

Voss J.F. Tyler, S.W. \& Yengo L.A. (1983). Individual differences in the solving of social science problems. In Dillan R.F. \& Schmeck R.R.(Eds.) Individual Differences in Cognition. Vol 1. New York Academcic Press.

Wallas, G. (1926). The Art of Thinking. New York: Harcourt.

Wertheimer, M. (1959). Productive Thinking. New York: Harper and Row.

White, R. (1964). Sense of interpersonal competence. In R. White (Ed.), The Study of Lives. New York: Atherton Press. 


\section{APPENDIX A}

Supplementary data analysis for chapter seven.

Table A.1 is a summary of the types of problems (ie. performance component and occupational performance) that were identified by each of the respondent groups.

Table A.1

Summary of the Responses given by the Three Respondent Groups

\begin{tabular}{|lcccc|}
\hline \multicolumn{4}{c}{ RESPONDENTS } \\
& STAGE II & STAGE III & CLINICIANS & TOTAL \\
TYPE OF PRIORITY & $\mathrm{N}=14$ & $\mathrm{~N}=31$ & $\mathrm{~N}=22$ & $\mathrm{~N}=67$ \\
\hline PROBLEM: & $8(0.56)$ & $14(0.45)$ & $14(0.64)$ & $36(0.54)$ \\
\hline $\begin{array}{l}\text { PERFORMANCE } \\
\text { OCMPONENT } \\
\text { PERFORMATIONAL }\end{array}$ & $7(0.50)$ & $26(0.84)$ & $12(0.55)$ & $45(0.67)$ \\
\hline TOTALS & $15(1.06)$ & $40(1.29)$ & $26(1.18)$ & $81(1.21)$ \\
\hline
\end{tabular}

Table A.1 indicates that:

1. The number of problem categories identified as priorities was less for stage II students compared to the other 2 groups (1.06 cf. 1.18).

However this result is not statistically significant (chi-square $=0.50$, d.f. $=2$, n.s.).

2. The response rates for the two major categories were similar for both clinician $(0.64 \& 0.55)$ and stage II $(0.56 \& 0.50)$ groups, but the stage III students put an emphasis on the occupational performance category ( $0.84 \mathrm{cf} .0 .45$ ). However a chi-square analysis indicates that the 
variation between groups is not significant (chi-square $=2.90$, d.f. $=2$, n.s.).

A more detailed analysis of the above responses has been summarised in Tables 7.2 and 7.3. These tables reflect the same sequence of sub-categories used in chapter six so that comparisons can readily be made to Tables 6.2 and 6.3 where the problems identified in response to question one were summarised. Explanations of the sub-categories can be seen in Chapter 6.

However, one different subcategory now arises, that of self responsibility. The two respondents both refer to the clients needing to make their own decisions, rather than having other people control their lives. This relates directly to the subcategory of 'control' in Table 6.2.

Table A.2

Summary of the Performance Component Problems

\begin{tabular}{|lcccc|}
\hline & \multicolumn{3}{c|}{ RESPONDENTS } & \\
PRIORITY & STAGE II & STAGE III & CLINICIANS & TOTAL \\
\hline PROBLEMS & $\mathrm{N}=14$ & $\mathrm{~N}=31$ & $\mathrm{~N}=22$ & $\mathrm{~N}=67$ \\
\hline SENSORIMOTOR & $3(.21 / 38)$ & $5(.16 / 36)$ & $5(.23 / 36)$ & $13(.19 / 36)$ \\
INTRAPERSONAL & $3(.21 / 38)$ & $3(.10 / 21)$ & $2(.09 / 14)$ & $8(.12 / 22)$ \\
COGNITIVE & - & $4(.13 / 29)$ & $3(.09 / 14)$ & $7(.10 / 19)$ \\
INTERPERSONAL & $2(.14 / 25)$ & - & $4(.18 / 29)$ & $6(.09 / 17)$ \\
SELF RESPONSIBILITY & - & $2(.06 / 14)$ & - & $2(.03 / 17)$ \\
\hline TOTAL RESPONSES & $8(.56)$ & $14(.45)$ & $14(.64)$ & $36(.54)$ \\
*NUMBER OF & $8(57 \%)$ & $13(42 \%)$ & $12(55 \%)$ & $33(49 \%)$ \\
SUBJECTS: & & & & \\
\hline
\end{tabular}

*Note: This figure refers to the number of subjects who identified performance component problems. A subject may have given responses that were recorded in more than one category. 
Table A. 2 indicates that:

1. Some differences exist within the performance component categories between the three groups - intrapersonal (less emphasis given by clinicians), cognitive (most emphasis given by the stage III students but not rated at all by the stage II students) and interpersonal (not rated at all by the stage III students). The numbers in the cells are too small to warrant a statistical analysis.

2. The greatest consistency between groups was in respect of the percentage of replies given for the sensorimotor components $(0.38 \%$, $0.36 \% \& 0.36 \%)$.

3. The response rates do not indicate major differences between groups. This is confirmed by statistical analysis (chi-square $=0.90$, d.f. $=2$, n.s.)

Table A.3 indicates that:

1. All three groups gave the greatest weight to ADL (71\%, 54\% \& $67 \%$ respectively).

2. Differences exist within all the other occupational performance subcategories between the groups. The response rate on three of these (employment, time and education) is low even by those groups who did mention them so the differences are not considered to be useful distinctions. In the remaining two categories, 'leisure' was given the least emphasis by the clinicians and 'social' was not responded to at all by the stage II students. While differences appear to exist between the three groups, the numbers in each cell are too small to draw any conclusions.

3. The stage III group had a higher response rate in comparison to the stage II and clinician groups (.82 cf. $.50 \& .55)$. However this result is not statistically significant (chi-square $=2.2$, d.f. $=2$, n.s.).

4. Family concerns, which had been raised as a problem area in response to question one, were not raised as a priority issue. 
Table A.3

Summary of the Occupational Performance Problems

\begin{tabular}{|lcccc|}
\hline & \multicolumn{3}{c|}{ RESPONDENTS } & \\
& & & & \\
PRIORITY & STAGE II & STAGE III & CLINICIANS & TOTAL \\
\hline PROBLEMS: & $\mathrm{N}=14$ & $\mathrm{~N}=31$ & $\mathrm{~N}=22$ & $\mathrm{~N}=67$ \\
\hline A.D.L & $5(.36 / 71)$ & $14(.45 / 54)$ & $8(.36 / 67)$ & $27(.40 / 60)$ \\
LEISURE & $2(.14 / 29)$ & $6(.19 / 23)$ & $1(.05 / 8)$ & $9(.13 / 20)$ \\
SOCIAL & - & $2(.06 / 8)$ & $2(.09 / 17)$ & $4(.06 / 9)$ \\
FAMILY & - & - & - & - \\
EMPLOYMENT & - & $2(.06 / 8)$ & - & $2(.03 / 4)$ \\
TIME & - & $1(.03 / 4)$ & $1(.05 / 8)$ & $2(.03 / 4)$ \\
EDUCATION & - & $1(.03 / 4)$ & - & $1(.03 / 4)$ \\
\hline TOTAL RESPONSES & $7(.50)$ & $26(.82)$ & $12(.55)$ & $45(.67)$ \\
*NUMBER OF & $7(50 \%)$ & $24(77 \%)$ & $12(55 \%)$ & $43(64 \%)$ \\
\hline SUBJECTS: & & & & \\
\hline
\end{tabular}

*Note: This figure refers to the number of subjects who identified occupational performance problems. A subject may have given responses that were recorded in more than one category.

Table A.4 is a summary of the two main categories of problems that were generated by the respondents with respect to the location in which they were working at the time of the interview. 
Table A.4

Summary of the Responses Given in Each Location

\begin{tabular}{|lcccccc|}
\hline \multicolumn{7}{c}{ LOCATIONS } \\
& \multicolumn{7}{c}{ PHYSICAL } & PSYCHIATRIC & PAEDIATRIC \\
& Acute & Rehab. & Com. & Acute & Rehab. & \\
$\frac{\text { PRIORITY }}{\text { PROBLEMS }}$ & $\mathrm{N}=8$ & $\mathrm{~N}=22$ & $\mathrm{~N}=5$ & $\mathrm{~N}=6$ & $\mathrm{~N}=20$ & $\mathrm{~N}=6$ \\
\hline $\begin{array}{l}\text { PERFORMANCE } \\
\text { COMPONENTS }\end{array}$ & $2(0.25)$ & $11(0.50)$ & - & $2(0.33)$ & $15(0.75)$ & $6(1.00)$ \\
$\begin{array}{l}\text { OCCUPATIONAL } \\
\text { PERFORMANCE }\end{array}$ & $6(0.75)$ & $16(0.73)$ & $5(1.00)$ & $5(0.84)$ & $11(0.55)$ & $2(0.33)$ \\
\hline SUB TOTAL & $8(1.00)$ & $27(1.23)$ & $5(1.00)$ & $7(1.17)$ & $26(1.30)$ & $8(1.33)$ \\
TOTALS: & & $40(1.14)$ & & $33(1.27)$ & & $8(1.33)$ \\
\hline
\end{tabular}

Table A.4 indicates that :

1. The response rate for the three broad categories of location (physical, psychiatric and paediatric) are much the same $(1.14,1.27 \& 1.33$ respectively). However they do differ significantly in respect of their distribution between performance components and occupational performance (chi-square $=6.0$, d.f. $=2, p<0.5$ ). The results indicate that physical locations are more associated with occupational performance problems, paediatric with performance components (but the numbers are too few to be confident of this) while the balance is more even for psychiatric.

2. If the 'location' data is re-organised into long term (rehabilitation and paediatrics and shorter term (acute and community) settings, the response rates differ, but not significantly (chi-square $=0.50$, d.f. $=1$, n.s.). However, a significant difference is observable in the distribution of the performance components and the occupational performance categories (chi-square $=6.43$, d.f. $=1, p<0.01$ ). The 
results indicate that short term settings are associated with occupational performance problems while the balance is more even in the long term settings.

A more detailed analysis of the responses can be found in Tables A.5 and A.6. The responses have been listed in the same sequence as Tables A.2 and A.3.

Table A.5

Location of the Respondents and the Performance Component Priority Problems

\begin{tabular}{|c|c|c|c|c|c|c|}
\hline \multirow[b]{4}{*}{$\begin{array}{l}\text { PRIORITY } \\
\text { PROBLEMS }\end{array}$} & \multicolumn{5}{|c|}{$\underline{\text { LOCATIONS }}$} & \multirow{4}{*}{ PAEDIATRIC } \\
\hline & \multicolumn{3}{|c|}{ PHYSICAL } & \multicolumn{2}{|c|}{ PSYCHIATRIC } & \\
\hline & Acute & Rehab. & Com. & Acute & Rehab. & \\
\hline & $N=8$ & $\mathrm{~N}=22$ & $\mathrm{~N}=5$ & $\mathrm{~N}=6$ & $\mathrm{~N}=20$ & \\
\hline SENSORIMOTOR & $2(.25 / 100)$ & $6(.27 / 55)$ & - & - & $1(.05 / 7)$ & $4(.67 / 67)$ \\
\hline INTRAPERSONAL & - & - & - & $2(.33 / 100)$ & $6(.30 / 40)$ & - \\
\hline COGNITIVE & - & $3(.14 / 27)$ & - & - & $3(.15 / 20)$ & $1(.17 / 17)$ \\
\hline INTERPERSONAL & - & $1(.05 / 9)$ & - & - & $5(.25 / 36)$ & - \\
\hline $\begin{array}{l}\text { SELF } \\
\text { RESPONSIBILITY }\end{array}$ & - & $1(.05 / 9)$ & - & - & - & $1(.17 / 17)$ \\
\hline TOTAL RESPONSES & $2(.25)$ & $11(.50)$ & - & $2(.33 / 100)$ & $15(.75)$ & $6(1.00)$ \\
\hline $\begin{array}{l}\text { *NUMBER OF } \\
\text { SUBJECTS: }\end{array}$ & $2(29 \%)$ & $10(43 \%)$ & - & $2(33 \%)$ & $12(60 \%)$ & $6(100 \%)$ \\
\hline
\end{tabular}

*Note: This figure refers to the number of subjects who identified a performance component problems. A subject may have given responses that were recorded in more than one category.

Table A.5 indicates that:

1. The response rate for the three broad categories of location (physical, psychiatric and paediatric) differ $-0.37,0.65 \& 1.00$ respectively. However this is not statistically significant (chi-square $=5.54$, d.f. $=2$, n.s.). Sensorimotor problems were most evident in the physical and 
paediatric settings; intrapersonal and interpersonal problems were given the highest response rates in psychiatric settings however the numbers in the cells are too small to warrant a statistical analysis.

2. If the 'location' data is re-organised into long term (rehabilitation and paediatric) and short-term (acute and community) settings, a significant difference in response rate can be noted (long-term 0.67 and short-term 0.21 ; chi-square $=4.98$, d.f. $=1, p<0.01$ ).

3. No community respondents identified performance component elements as treatment priorities. 
Table A.6

Location of the Respondents and the Occupational Performance Priority Problems

\begin{tabular}{|c|c|c|c|c|c|c|}
\hline \multirow[b]{4}{*}{$\frac{\text { PRIORITY }}{\text { PROBLEMS }}$} & \multicolumn{5}{|c|}{ LOCATIONS } & \multirow{3}{*}{ PAEDIATRIC } \\
\hline & \multicolumn{3}{|c|}{ PHYSICAL } & \multicolumn{2}{|c|}{ PSYCHIATRIC } & \\
\hline & Acute & Rehab. & Com. & Acute & Rehab. & \\
\hline & $\mathrm{N}=8$ & $\mathrm{~N}=22$ & $N=5$ & $\mathrm{~N}=6$ & $\mathrm{~N}=20$ & $N=6$ \\
\hline A.D.L. & $6(.75 / 100)$ & $9(.41 / 56)$ & $5(1.0 / 100)$ & $4(.67 / 80)$ & $2(.10 / 18)$ & $1(.17 / 50)$ \\
\hline LEISURE & - & $4(.18 / 25)$ & - & $1(.17 / 20)$ & $4(.20 / 36)$ & - \\
\hline SOCIAL & - & $2(.09 / 13)$ & - & - & $2(.10 / 18)$ & - \\
\hline FAMILY & - & - & - & - & - & - \\
\hline EMPLOYMENT & - & - & - & - & $2(.10 / 17)$ & - \\
\hline TIME & - & $1(.05 / 6)$ & - & - & $1(.05 / 9)$ & - \\
\hline EDUCATION & - & - & - & - & - & $1(.17 / 50)$ \\
\hline TOTAL RESPONSES & $6(.75)$ & $16(.73)$ & $5(1.00)$ & $5(.84)$ & $11(.55)$ & $2(.33)$ \\
\hline $\begin{array}{l}\text { *NUMBER OF } \\
\text { SUBJECTS }\end{array}$ & $6(75 \%)$ & $15(68 \%)$ & $5(100 \%)$ & $5(83 \%)$ & $10(50 \%)$ & $2(33 \%)$ \\
\hline
\end{tabular}

*Note: This figure refers to the number of subjects who identified occupational performance problems. A subject may have given responses that were recorded in more than one category.

In Table A.6:

1. The ADL problems as priority issues occur in all locations and contexts (acute, rehabilitation and community). They were mentioned with greatest frequency by those in the three physical settings and also in acute psychiatry. ADL accounts for all the problems in the 'acute' and 'community' contexts of the physical locations.

2. The response rates for the three broad areas of location (physical, psychiatric and paediatric) show some variation $(0.77,0.62$ and 0.33 respectively) however this is not statistically significant (chi-square $=$ 1.60 , d.f. $=2$, n.s.). 
3. The two rehabilitation settings provided the greatest variation of responses. The physical rehabilitation area had an emphasis on 'ADL', however the psychiatric rehabilitation area had a more even distribution of responses between the sub-categories.

4. The community area had the greatest consistency $(100 \%)$ in respect of a priority problem area, ie. ADL, which was the only one mentioned.

5. Paediatric area had a low response rate (0.33).

6. The reorganisation of the data by long-term and short-term settings, indicates that the response rate is higher in the short-term settings $(0.84$ for short-term and 0.60 for long-term). This observation is not statistically significant (chi-square $=0.97$, d.f. $=1$, n.s.). 
Table A.7

Location of the Respondents and the Beliefs Concerning the Delivery of Treatment Programmes

\begin{tabular}{|c|c|c|c|c|c|c|}
\hline \multirow[b]{4}{*}{$\begin{array}{l}\text { PROCESS } \\
\text { BELIEFS: }\end{array}$} & \multicolumn{5}{|c|}{ LOCATIONS } & \multirow{4}{*}{ PAEDIATRIC } \\
\hline & \multicolumn{3}{|c|}{ PHYSICAL } & \multicolumn{2}{|c|}{ PSYCHIATRIC } & \\
\hline & Acute & Rehab. & Com. & Acute & Rehab. & \\
\hline & $N=8$ & $\mathrm{~N}=22$ & $\mathrm{~N}=5$ & $\mathrm{~N}=6$ & $\mathrm{~N}=20$ & \\
\hline SEQUENTIAL & $1(.13 / 25)$ & $8(.36 / 57)$ & $1(.20 / 17)$ & $3(.50 / 75)$ & $10(.50 / 67)$ & $3(.50 / 75)$ \\
\hline $\begin{array}{l}\text { IMPORTANT TO } \\
\text { CLIENT. }\end{array}$ & $1(.13 / 25)$ & $3(.14 / 21)$ & $3(.60 / 50)$ & - & $4(.20 / 27)$ & $1(.17 / 25)$ \\
\hline SAFE & $1(.13 / 25)$ & $3(.14 / 21)$ & $1(.20 / 17)$ & $1(.17 / 25)$ & - & - \\
\hline SUCCESSFUL & $1(.13 / 25)$ & - & $1(.20 / 17)$ & - & $1(.05 / 7)$ & - \\
\hline TOTAL RESPONSES & $4(.50)$ & $14(.64)$ & $6(1.20)$ & $4(.67)$ & $15(.75)$ & $4(.67)$ \\
\hline $\begin{array}{l}\text { *NUMBER OF } \\
\text { SUBJECTS }\end{array}$ & $4(50 \%)$ & $14(64 \%)$ & $5(100 \%)$ & $3(50 \%)$ & $14(70 \%)$ & $4(67 \%)$ \\
\hline
\end{tabular}

*Note: This figure refers to the number of subjects who identified process beliefs. A subject may have given responses that were recorded in more than one category.

1. Treatment being important to the client was particularly important for those in community settings $(0.60)$, while treatment being sequential was an importat belief for those in psychiatric and paediatric settings (response rate of 0.50 in all settings).

2. The process issues overall had a particularly high response rate from those in the community settings (1.40) where all respóndents referred to the process issues.

3. The response rates for the three broad categories of location (physical, psychiatric and paediatric) are much the same; $0.77,0.77$ and 0.83 respectively. Likewise the response rates for the long and short-term settings does not differ significantly ( 0.75 for long-term and 0.84 for short-term). 
Table A.8

Location of the Respondents and the Beliefs Concerning the Nature of Treatment Programmes

\begin{tabular}{|c|c|c|c|c|c|c|}
\hline \multirow[b]{4}{*}{$\begin{array}{l}\text { CONTENT } \\
\text { BELIEFS: }\end{array}$} & \multicolumn{5}{|c|}{ LOCATIONS } & \multirow{4}{*}{ PAEDIATRIC } \\
\hline & \multicolumn{3}{|c|}{ PHYSICAL } & \multicolumn{2}{|c|}{ PSYCHIATRIC } & \\
\hline & Acute & Rehab. & Com. & Acute & Rehab. & \\
\hline & $\mathrm{N}=8$ & $\mathrm{~N}=22$ & $N=5$ & $\mathrm{~N}=6$ & $\mathrm{~N}=20$ & \\
\hline $\begin{array}{l}\text { COPING } \\
\text { STRATEGIES }\end{array}$ & $4(.50 / 50)$ & $7(.32 / 44)$ & $2(.40 / 50)$ & $3(.50 / 75)$ & $2(1.0 / 15)$ & $1(.17 / 20)$ \\
\hline ACTIVITY & - & $6(.27 / 38)$ & $1(.20 / 25)$ & - & $6(.30 / 46)$ & $1(.17 / 20)$ \\
\hline SKILLS & $3(.38 / 38)$ & $2(.09 / 13)$ & - & $1(.17 / 25)$ & $1(.05 / 8)$ & $3(.50 / 60)$ \\
\hline ENVIRONMENT & $1(.13 / 13)$ & $1(.05 / 6)$ & $1(.20 / 25)$ & - & $4(.20 / 30)$ & - \\
\hline TOTAL RESPONSES & $8(1.00)$ & $16(.73)$ & $4(.80)$ & $4(.67)$ & $13(.65)$ & $5(.83)$ \\
\hline $\begin{array}{l}\text { *NUMBER OF } \\
\text { SUBJECTS }\end{array}$ & $8(100 \%)$ & $15(68 \%)$ & $4(80 \%)$ & $3(50 \%)$ & $12(60 \%)$ & $4(67 \%)$ \\
\hline
\end{tabular}

*Note: This figure refers to the number of subjects who identified content beliefs. A subject may have given responses that were recorded in more than one category.

Table A. 8 indicates that:

1. There is a slightly lower response rate from those in psychiatric settings when campared to physical and paediatric locations ( $0.85 \mathrm{cf} .1 .00 \&$ 1.00). This finding is not significant (chi-square $=0.29$, d.f. $=2$, n.s.). It can be noted that developing skills is an important area for those in paediatrics (0.67).

2. If the data is re-organised into long-term and short-term settings, overall there is little difference in the response rates between these settings (long-term 0.92 and short-term 1.00). However when considering the 
sub-categories it can be observed that coping strategies are of most concern to those in the short-term settings, ie. acute $(0.50 \& 0.75)$ and community (0.40). Also, activity was only raised by those in long-term settings. 


\section{APPENDIX B}

Supplementary data analysis for chapter eight.

Table B.1

Location of Respondents and the Performance Component Outcomes

\begin{tabular}{|c|c|c|c|c|c|c|}
\hline \multirow[b]{3}{*}{$\begin{array}{l}\text { TREATMENT } \\
\text { OUTCOMES }\end{array}$} & \multicolumn{5}{|c|}{$\underline{\text { LOCATIONS }}$} & \multirow{3}{*}{$\begin{array}{c}\text { PAEDIATRIC } \\
\text { N }=6\end{array}$} \\
\hline & \multicolumn{3}{|c|}{ PHYSICAL } & \multicolumn{2}{|c|}{ PSYCHIATRIC } & \\
\hline & $\begin{array}{l}\text { Acute } \\
\mathrm{N}=8\end{array}$ & $\begin{array}{l}\text { Rehab. } \\
\mathrm{N}=22\end{array}$ & $\begin{array}{l}\text { Com. } \\
\mathrm{N}=5\end{array}$ & $\begin{array}{l}\text { Acute } \\
\mathrm{N}=6\end{array}$ & $\begin{array}{l}\text { Rehab. } \\
\mathrm{N}=20\end{array}$ & \\
\hline SENSORIMOTOR & $4(.50 / 80)$ & $5(.23 / 56)$ & - & - & - & $3(.50 / 43)$ \\
\hline INTERPERSONAL & - & $2(.09 / 22)$ & - & - & $8(.40 / 57)$ & - \\
\hline $\begin{array}{l}\text { SELF } \\
\text { RESPONSIBILITY }\end{array}$ & - & $1(.04 / 11)$ & - & $3(.50 / 75)$ & $1(.05 / 7)$ & $2(.33 / 29)$ \\
\hline COGNITION & - & $1(.04 / 11)$ & - & - & $2(.10 / 14)$ & $2(.33 / 29)$ \\
\hline INTRAPERSONAL & $1(.13 / 20)$ & - & $1(.20 / 100)$ & $1(.17 / 25)$ & $3(.15 / 21)$ & - \\
\hline $\begin{array}{l}\text { TOTAL } \\
\text { RESPONSES }\end{array}$ & $5(.63)$ & $9(.41)$ & $1(.20)$ & $4(.67)$ & $14(.70)$ & $7(1.17)$ \\
\hline $\begin{array}{l}\text { *NUMBER OF } \\
\text { RESPONDENTS }\end{array}$ & $4(50 \%)$ & $8(36 \%)$ & $1(20 \%)$ & $4(67 \%)$ & $10(50 \%)$ & $5(83 \%)$ \\
\hline
\end{tabular}

*Note: This figure refers to the number of subjects who identified performance component outcomes. A subject may have given responses that were recorded in more than one category.

Table B. 1 indicates that:

1. The physical and paediatric settings were the only ones to identify outcomes in the sensorimotor area. The interpersonal skills were only of concern to those who worked in rehabilitation settings, especially in psychiatry.

2. There was a large range of response rates varying from 0.20 in the community and 1.17 in paediatrics. On consideration of the three 
locations of physical, psychiatric and paediatrics differences in response rates can be noted $(0.43,0.69 \& 1.17$ respectively). This finding is not significant (chi-square $=4.21$, d.f. $=2$, n.s.). When the locations were re-organised into long and short-term settings a difference in response rates was again evident, but this was not significant (long-term 0.63 and short-term 0.53 ; chi-square $=0.10$, d.f. $=1$, n.s.).

Table B.2

Location of the Respondents and the Occupational Performance Outcomes

\begin{tabular}{|c|c|c|c|c|c|c|}
\hline \multirow[b]{4}{*}{ OUTCOME: } & \multicolumn{5}{|c|}{ LOCATIONS } & \multirow{4}{*}{ PAEDIATRIC } \\
\hline & \multicolumn{3}{|c|}{ PHYSICAL } & \multicolumn{2}{|c|}{ PSYCHIATRIC } & \\
\hline & Acute & Rehab. & Com. & Acute & Rehab. & \\
\hline & $\mathrm{N}=8$ & $\mathrm{~N}=22$ & $\mathrm{~N}=5$ & $\mathrm{~N}=6$ & $\mathrm{~N}=20$ & \\
\hline ADL & $8(1.0 / 100)$ & $14(.64 / 70)$ & $5(1.0 / 100)$ & $3(.50 / 75)$ & $6(.30 / 35)$ & $2(.33 / 29)$ \\
\hline ACTIVITY & - & $4(.18 / 20)$ & - & - & $6(.30 / 35)$ & $2(.33 / 29)$ \\
\hline SOCIAL & - & $1(.05 / 5)$ & - & $1(.17 / 25)$ & $2(.10 / 12)$ & - \\
\hline EMPLOYMENT & - & - & - & - & $1(.05 / 6)$ & - \\
\hline EDUCATION & - & - & - & - & - & $3(.50 / 43)$ \\
\hline TIME & - & - & - & - & $2(10 / 12)$ & - \\
\hline FAMILY & - & $1(.05 / 5)$ & - & - & $1(.05 / 6)$ & - \\
\hline $\begin{array}{l}\text { TOTAL } \\
\text { RESPONSES }\end{array}$ & $8(1.00)$ & $20(.91)$ & $5(1.00)$ & $4(.67)$ & $17(0.85)$ & $7(1.17)$ \\
\hline $\begin{array}{l}\text { *NUMBER OF } \\
\text { RESPONDENTS }\end{array}$ & $8(100 \%)$ & $20(91 \%)$ & $5(100 \%)$ & $4(100 \%)$ & $14(70 \%)$ & $5(83 \%)$ \\
\hline
\end{tabular}

*Note: This figure refers to the number of subjects who identified occupational performance outcomes. A subject may have given responses that were recorded in more than one category. 
Table B. 2 indicates that:

1. The activity of daily living (ADL) outcome was the only one identified by respondents in all locations. With one exception, (the social network sub-category), the outcomes other than ADL were evident only in the long-term settings, ie. physical and psychiatric rehabilitation and paediatrics.

2. The response rates in the major locations of physical, psychiatric and paediatric did show some variation $(0.94,0.81 \& 1.17$ respectively (chi-square $=0.57$, d.f. $=2$, n.s.). When the data was re-organised into long and short-term settings there was even less variation in the response rates (long-term 0.92 and short-term 0.89 ; chi-square $=4.21$, d.f. $=2, p=. n . s$.). 
Table C.2

Location of the Respondents and the Occupational Performance Discharge

Criteria

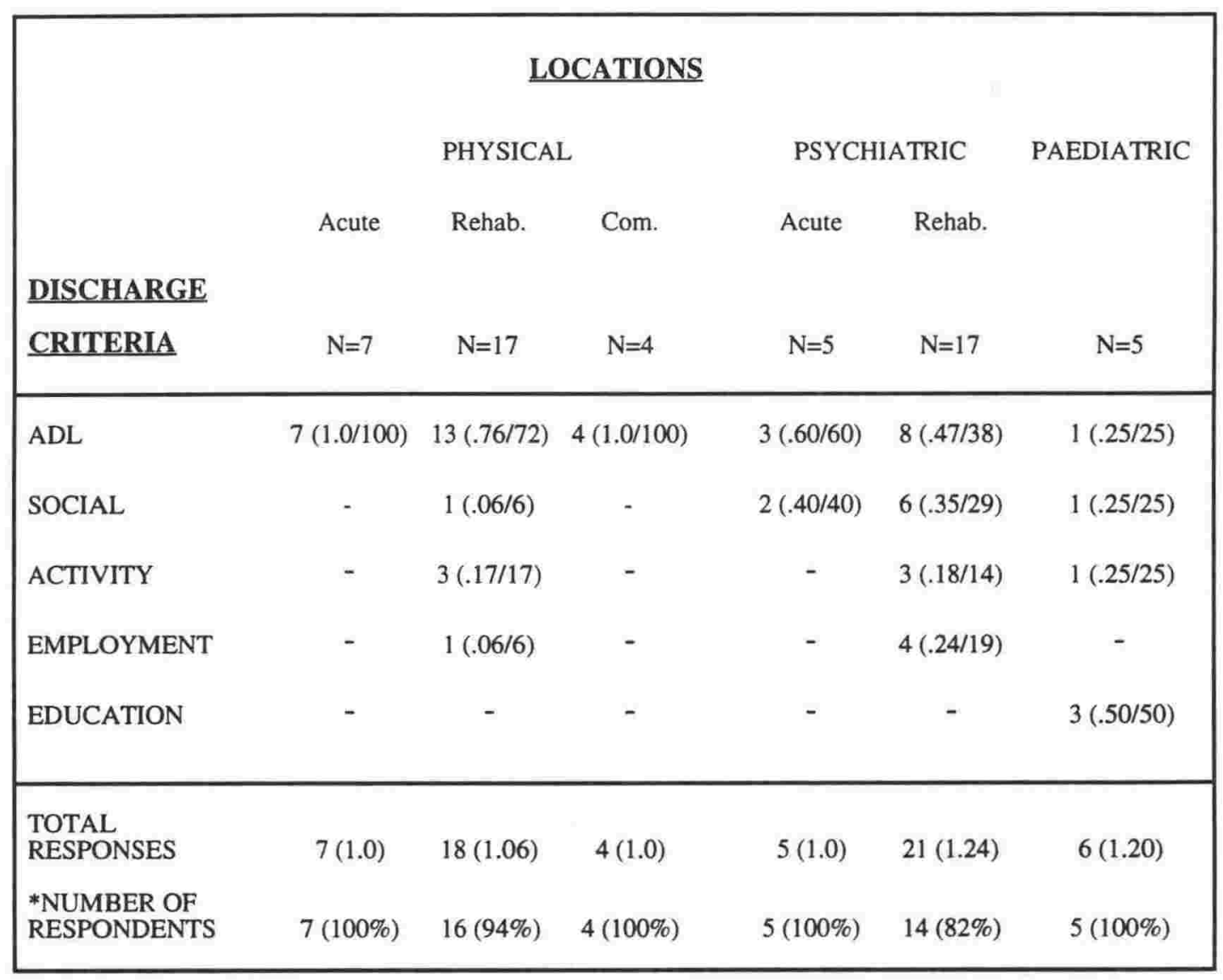

*Note: A subject may have given responses that were recorded in more than one category.

Table C. 2 indicates that:

1. The only respondents who did not refer to occupational performance discharge criteria were in rehabilitation settings $(6 \%$ physical rehabilitation and $18 \%$ psychiatric rehabilitation).

2. The response rates for the three broad categories of physical, psychiatric and paediatric showed little variation (1.04, 1.18 and 1.20 respectively). This variation is not significant (chi-square $=0.30$, d.f. $=$ $2, \mathrm{n} . \mathrm{s}$.). If the data is re-organised into long and short-term settings there is a slight variation is response rates, but again this is not 
significant (long-term 1.15 and short-term 1.00; chi-square $=0.32$, d.f. $=1$, n.s.).

3. The ADL outcome was relevant in all contexts and locations and had the highest response rates from those in the physical settings.

Table C.3

A comparison of thePerformance Component and Occupational Performance Outcomes given in Response to QuestionsThree and Five

\begin{tabular}{|llll|}
\hline & \multicolumn{2}{c|}{ RESPONDENTS } \\
& \multicolumn{2}{c|}{ STUDENTS } & CLINICANS \\
& STAGE II & STAGE III & \\
\hline PERFORMANCE & & & \\
\hline COMPONENTS: & & $18 / 31(0.58)$ & $16 / 22(0.73)$ \\
OUTCOMES (Q3) & $6 / 14(0.43)$ & $5 / 30(0.17)$ & $4 / 16(0.25)$ \\
DISCHARGE (Q5) & $5 / 9(0.55)$ & & \\
OCCUPATIONAL & & $30 / 31(0.97)$ & $20 / 22(0.91)$ \\
PERFOMANCE: & & $31 / 30(1.03)$ & $21 / 16(1.32)$ \\
\hline OUTCOMES (Q3) & $11 / 14(0.79)$ & $9 / 9(1.00)$ & \\
DISCHARGE (Q5) & $919)$ &
\end{tabular}

Note: The size of the groups varied, with less respondents providing information on discharge criteria in question five. For example there were 14 respondents in the stage II group for question three and only 9 for question five.

Table C. 3 indicates that:

1. Stage II students had a higher response rate for the discharge performance component category when compared to the stage III and clinician groups. 
2. Stage II students had a low response rate for the performance component outcomes when compared to the clinician group.

3. Stage III students had a higher response rate for the performance component discharge criteria when compared to the outcomes. This trend was reversed for the other two groups both being strongly biased in favour of less performance components.

4. There was a high response rate for the occupational performance outcomes for all groups and for both questions. The trend for all groups was for the response rate to increase for the discharge criteria.

Table C. 4

A Comparison of the Response Rrates for Treatment Outcomes given in Questions Three and Five

\begin{tabular}{|lccc|}
\hline & \multicolumn{2}{c|}{ LOCATIONS } & \\
& PHYSICAL & PSYCHIATRIC & PAEDIATRIC \\
\hline OUTCOMES (Q3) & $48 / 35(1.37)$ & $39 / 26(1.50)$ & $14 / 6(2.33)$ \\
DISCHARGE (Q5) & $23 / 28(1.14)$ & $36 / 22(1.64)$ & $7 / 5(1.40)$ \\
\hline
\end{tabular}

*Note: The sizes of each of the three groups varied, with less respondents providing information on discharge criteria in question five.

Table C. 4 suggests that:

1. The physical and paediatric locations have a decreased response rate for the discharge criteria, this trend is reversed in the psychiatric locations.

2. The difference between the response rates for questions three and five, is relatively high for the paediatric location when compared to physical and psychiatric locations. 


\section{APPENDIX D}

Supplementary data analysis for chapter eleven.

Table D.1

Location of the Respondents who Expressed Some Dissatisfaction With Treatment

\begin{tabular}{|c|c|c|c|c|c|c|}
\hline \multirow[b]{4}{*}{ RESPONSES: } & \multicolumn{5}{|c|}{ LOCATION } & \multirow{4}{*}{ PAEDIATRIC } \\
\hline & \multicolumn{3}{|c|}{ PHYSICAL } & \multicolumn{2}{|c|}{ PSYCHIATRIC } & \\
\hline & Acute & Rehab. & Com. & Acute & Rehab. & \\
\hline & $N=7$ & $\mathrm{~N}=21$ & $\mathrm{~N}=5$ & $\mathrm{~N}=4$ & $N=16$ & \\
\hline TIME WITH CLIENT & $3(.43 / 33)$ & $5(.24 / 23)$ & - & $2(.50 / 33)$ & $5(.38 / 36)$ & $2(.33 / 33)$ \\
\hline TEAM WORK & $3(.43 / 33)$ & $1(.05 / 5)$ & $1(.20 / 25)$ & - & $3(.19 / 21)$ & $2(.33 / 33)$ \\
\hline REALITY OF TREATMENT & $1(.14 / 11)$ & $3(.14 / 14)$ & - & $1(.25 / 16)$ & $1.0(6 / 7)$ & $1(.17 / 17)$ \\
\hline HOSPITAL ENVIRONMENT & $2(.29 / 22)$ & $3(.14 / 14)$ & - & $1(.25 / 16)$ & $1(.06 / 7)$ & - \\
\hline COMMUNITY RESOURCES & - & $4(.19 / 18)$ & - & - & $3(.19 / 21)$ & - \\
\hline PATIENT MOTIVATION & - & $4(.19 / 18)$ & - & $1(.25 / 16)$ & - & - \\
\hline EQUIPMENT DELAY & - & - & $3(.60 / 75)$ & - & - & - \\
\hline INCONCLUSIVE & - & $1(.05 / 5)$ & - & - & $1(.06 / 7)$ & - \\
\hline HOME ENVIRONMENT & - & $1(.05 / 5)$ & - & $1(.25 / 16)$ & - & - \\
\hline OWN ABILITIES & - & - & - & - & - & $1(.17 / 17)$ \\
\hline TOTAL RESPONSES & $9(1.29)$ & $22(1.05)$ & $4(.80)$ & $6(1.50)$ & $14(.86)$ & $6(1.00)$ \\
\hline $\begin{array}{l}\text { * NUMBER OF } \\
\text { RESPONDENTS }\end{array}$ & $5(71 \%)$ & $14(67 \%)$ & $4(80 \%)$ & $4(100 \%)$ & $11(69 \%)$ & $6(100 \%)$ \\
\hline
\end{tabular}

*Note: This figure refers to the number of subjects who identified reasons for dissatisfaction with treatment. A subject may have given responses that were recorded in more than one category. 
Table D. 1 indicates that:

1. The highest response rates are in the acute areas $(1.29 \& 1.50)$ while the other short term area (ie. community) has the lowest response rate $(0.80)$. As this finding suggests, there is little difference in response rates between the long and short-term areas (long-term 0.98 and shortterm 1.19).

2. When considering the three broad areas of location, again there is little difference in the response rates $(1.06,1.00$ and 1.00 respectively; chisquare $=0.10$, d.f. $=2$, n.s.).

Table D.2

Location of the Respondents Who Were Satisfied With Treatment

\begin{tabular}{|c|c|c|c|c|c|c|}
\hline \multirow[b]{4}{*}{ REASONS: } & \multicolumn{5}{|c|}{ LOCATION } & \multirow{3}{*}{ PAEDIATRIC } \\
\hline & \multicolumn{3}{|c|}{ PHYSICAL } & \multicolumn{2}{|c|}{ PSYCHIATRIC } & \\
\hline & Acute & Rehab. & Com. & Acute & Rehab. & \\
\hline & $\mathrm{N}=7$ & $\mathrm{~N}=21$ & $\mathrm{~N}=5$ & $\mathrm{~N}=6$ & $\mathrm{~N}=20$ & $N=6$ \\
\hline INDEPENDENCE & $3(.5 / 100)$ & - & $1(.20 / 50)$ & - & - & - \\
\hline PROVISION OF AIDS & - & $3(.14 / 27)$ & - & - & $1(.05 / 25)$ & - \\
\hline MEET CLIENTS GOALS & - & $3(.14 / 27)$ & - & - & - & - \\
\hline WITHIN CLIENTS ABILITY & - & $1(.05 / 9)$ & - & - & $2(.10 / 50)$ & - \\
\hline CLIENT SATISFACTION & - & $1(.05 / 9)$ & - & $1(.17 / 100)$ & - & - \\
\hline GOOD TEAM WORK & - & $1(.05 / 9)$ & - & - & - & - \\
\hline IMPROVEMENT SEEN & - & - & - & - & $1(.05 / 25)$ & - \\
\hline OTHER & - & $2(.09 / 18)$ & $1(.20 / 50)$ & - & - & - \\
\hline TOTAL RESPONSES & $3(.43)$ & $11(.52)$ & $2(.40)$ & $1(.17)$ & $4(.20)$ & - \\
\hline *NUMBER OF SUBJECTS & $3(43 \%)$ & $11(52 \%)$ & $2(40 \%)$ & $1(17 \%)$ & $4(20 \%)$ & - \\
\hline
\end{tabular}

*Note: This figure refers to the number of subjects who identified reasons for satisfaction with treatment. A subject may have given responses that were recorded in more than one category. 
Table D. 2 indicates that:

1. The response rate is highest in the physical settings with no respondents in paediatrics expressing satisfaction with treatment. The response rates for the three broad categories of locations are physical 0.48 , psychiatric 0.25 and paediatric 0.00 . The numbers in each of the cells are too small to warrant a statistical analysis.

2. When the data is re-organised into the long and short-term settings the response rate indicates little difference between the settings (short-term 0.38 and long-term 0.35 ). 